\title{
Posthuman Contours_New Museum Infrastructures
}

\author{
by \\ Aris Peci \\ Bachelor of Architectural Science, \\ Ryerson University, 2016 \\ A thesis \\ presented to Ryerson University \\ in partial fulfillment for the degree of \\ Master of Architecture \\ in the program of \\ Architecture \\ Toronto, Ontario, Canada 2018 \\ (C) Aris Peci, 2018
}




\section{Author's Declaration}

I hereby declare that I am the sole author of this thesis. This is a true copy of the thesis, including any required final revisions, as accepted by my examiners.

I authorize Ryerson University to lend this thesis to other institutions or individuals for the purpose of scholarly research.

I further authorize Ryerson to reproduce this thesis project by photocopying or by other means, in total or in part, at the request of other institutions or individuals for the purpose of scholarly research.

I understand that my thesis may be made electronically available to the public. 


\section{Posthuman Contours}

New Museum Infrastructures

Aris Peci

Master of Architecture, 2018

Architecture Program

Ryerson University

\begin{abstract}
Contemporary architectural discourse continues

to use humanist definitions of the user leading

to incompatible built interfaces. This thesis

speculates on what potential modalities arise

when we radically shift our understanding of the user from that of the Human to the Posthuman.

The museum is utilized as a typology to explore the conceptual framework of a Posthuman user for the development of an architectural system.

By approaching the museum as an infrastructural network rather than an insulated boundary condition we can begin to understand the emergent networks and autonomous processes that constitute contemporary built ecologies. Design systems that are developed through a Posthuman perspective begin to engender design ecologies that operate through autonomous states in collaboration with artifacts, actors, and interfaces.
\end{abstract}




\section{Acknowledgments}

Firstly, I would like to thank my thesis supervisor

Colin Ripley. This thesis is the culmination of a year long project in which Colin has played a critical role in my development as a designer and architectural researcher. His willingness to share his great wealth of knowledge and experience in the guiding of a thesis project were critical in producing this body of work. Most importantly, the discussions and critiques we had always provided deeply rich and interesting ideas to explore.

I also would like to express my gratitude to Jenn McArthur in her role as a second reader and for always keeping me grounded in the process of completing this project.

Paul Floerke was also instrumental in raising important and sensitive questions at every stage of the thesis.

To my colleagues and friends in architecture, thank you for weathering this storm with me and for your support, inspiration, and memories along the way.

Finally, I would like to thank Luan, Mimoza, and Ledja for their unwaivering support throughout the entirety of my architectural education. You have helped me through some of the greatest challenges this process has delivered, and it is to you I owe my greatest triumphs. 



\section{TABLE OF CONTENTS}

Author's Declaration

Abstract iii

Acknowledgements $\quad$ iv

Table of Contents vi

List of Figures viii

0 CULTURAL LANDSCAPES

0.1 Artifact Migrations

0.2 Where Bodies end and Prosthetics Begin

0.3 Working Methodologies

1 CONTEXT_POSTHUMAN CONTOURS

1.1 How we Became Posthuman

1.2 Critical Position_Point of Entry

2 TOWARDS A PROSTHETIC ARCHITECTURE

2.1 A Machine for Living

2.2 Systems Architecture

2.3 Museum Frameworks

2.4 Prosthetic Architecture

3 MUSEUM PARAMETERS

3.1 Digital Mediation of Space

3.2 Artifact

3.3 From Users to Actors 
4.1 Museum Infrastructures

4.2 Design Strategy

4.2.1 Identify the Network

4.2.2 Redistribute the Network

4.2.3 Combinatorial Systems

4.3 Infrastructure Systems

5.3.1 Tower

5.3.2 Barge

5.3.3 Bridge

4.4 Bridge Systems

5 THE POSTHUMAN MUSEUM

5.1 Context_Artifact

5.2 Artifact_Storage

5.3 Artifact_User

6 NEW TERRITORIES_A POSTHUMAN ARCHITECTURE

Appendix A: Museum Research

106

Appendix B: Model Photos

110

Appendix C: Project Drawings

118

Bibliography 


\section{FIGURE LIST}

Figure 1 Artifact Migrations, Dymaxion Map

Source: https://www.thingiverse.com/thing:1995457

Edited by Aris Peci

Figure 2 Michael Webb, Cushicle

Source: https://mondo-blogo.blogspot.com/2010/11/blow-me-inflatable-art-architectureand.html, accessed Feb. 12, 2018

Figure 3 Le Modulor, 1948

Source: Le Corbusier. Modulor: A Harmonious Measure to the Human Scale and the Universally Applicable to Architecture and Mechanics. (London, Faber \& Faber 1961) p. 28

Figure 4 Precedent Timeline

Source: $\quad$ Aris Peci, 2018

Figure 5 Unite Living Units Concept

Source: $\quad$ Aris Peci, 2018

Figure 6 Unite d'Habitation Section

Source: http://backgroundimgfer.pw/Le-Corbusier-diagram-demonstrating-the-quotFivePoints-of-a-New.html, accessed November 6, 2017

Figure 7 Engineers Aesthetic shown in Section of Cruise Ship

Source: https://www.wikiwand.com/en/MS_Kungsholm_(1928), accessed November 7, 2017

Figure 8 City as Fun Palace, Cedric Price

Source: $\quad$ Mathews, Stanley. From Agit-Prop to Free Space: The Architecture of Cedric Price (London, Black Dog Publishing 2007) p. 72

Figure 9 Fun Palace, Floor Plan

Source: $\quad$ Mathews, Stanley. From Agit-Prop to Free Space: The Architecture of Cedric Price (London, Black Dog Publishing 2007) p. 78

Figure 10 Plan as Programme, Cedric Price

Source: $\quad$ Mathews, Stanley. From Agit-Prop to Free Space: The Architecture of Cedric Price (London, Black Dog Publishing 2007) p. 80

Figure 11 Cedric Price, Map of Potteries Thinkbelt Infrastructure

Source: https://discoversociety.org/2014/07/01/the-thinkbelt-the-university-that-neverwas/, accessed November 14, 2017

Edited by Aris Peci 
Figure 12 Cedric Price, Potteries Thinkbelt

Source: $\quad$ Mathews, Stanley. From Agit-Prop to Free Space: The Architecture of Cedric Price (London, Black Dog Publishing 2007) p. 54

Figure 13 Centre Pompidou Elevation

Source: https:/www.inexhibit.com/wp-content/uploads/2013/12/Centre-Pompidou-Parisconceptual-elevation-Piano-Rogers-1.jpg, accessed October 12, 2017

Figure 14 Centre Pompidou Information Theme Park

Source: $\quad$ https://www.google.ca/url?sa=i\&rct=j\&q=\&esrc=s\&source=images\&cd=\& accessed October 12, 2017

Figure 15 TGB, Spatial Model

Source: Koolhaas, Rem and Bruce Mau. "Strategy of the Boid" in S, M, L, XL: Office for Metropolitan Architecture. (New York, The Monacelli Press 1998) p. 625

Figure 16 TGB, Spatial Model

Source: Koolhaas, Rem and Bruce Mau. "Strategy of the Boid" in S, M, L, XL: Office for Metropolitan Architecture. (New York, The Monacelli Press 1998) p. 626

Figure 17 Superimposition of Voids

Source: Koolhaas, Rem and Bruce Mau. "Strategy of the Boid" in S, M, L, XL: Office for Metropolitan Architecture. (New York, The Monacelli Press 1998) p. 627

Section Cover: $\quad$ River Thames Photograph

Source: Photograph taken by Kyle Prescod, taken May 20 2018

Figure 18 Site Context

Source Google Maps

Edited by Aris Peci

Figure 19 Museum Parameters

Source: $\quad$ Aris Peci, 2018

Figure 20 Excerpt from Space and the Machine, continuous integration of ICT technology Source: Parry, Ross and Andrew Sawyer. "Space and the Machine: Adaptive Museums, pervasive technology and the new gallery environment." In Reshaping Museum Space: Architecture, Design, Exhibitions. (New York, Routledge 2005) p.40

Edited by Aris Peci

Figure 21 Spatial Concept, Iteration One

Source: $\quad$ Aris Peci, 2017

Figure 22 Spatial Concept, Iteration Two

Source: $\quad$ Aris Peci, 2017 
Figure 23 Modeling the Wholesale Logistics Base

Source: Lecavalier, Jesse. The Rule of Logistics: Walmart and the Architecture of Fulfillment. (Minneapolis, University of Minnesota Press 2016) p. 120

Figure 24 User as Data within the Environment

Source: Lecavalier, Jesse. The Rule of Logistics: Walmart and the Architecture of Fulfillment. (Minneapolis, University of Minnesota Press 2016) p. 120

Edited by Aris Peci

Figure 25 Existing Museum Networks

Source: $\quad$ Aris Peci, 2018

Figure 26 Artifact Storage Data

Source: Keene, Suzanne, ed. Collections for people: Museums' stored collections as a public resource. (London, UCL Institute of Archaeology 2008) p.60

Edited By Aris Peci

Figure 27 Museum Classifications

Source: $\quad$ Aris Peci, 2018

Figure 28 The Redistributed Museum

Source: $\quad$ Aris Peci, 2018

Figure 29 Combinatoric Iteration 1

Source: $\quad$ Aris Peci, 2018

Figure 30 Combinatoric Iteration 2

Source: $\quad$ Aris Peci, 2018

Figure 31 Combinatoric Iteration 3

Source: $\quad$ Aris Peci, 2018

Figure 32 Infrastructure Explorations

Source: Aris Peci, 2018

Figure 33 Museum as Tower In the London Context

Source: $\quad$ Aris Peci, 2018

Figure 34 Museum as Tower in the London Context

Source: $\quad$ Aris Peci, 2018

Figure 35 Tower Combinatorics

Source: $\quad$ Aris Peci, 2018 
Figure 36 Museum Tower Frameworks

Source: $\quad$ Aris Peci, 2018

Figure 37 Museum as Barge

Source: $\quad$ Aris Peci, 2018

Figure 38 Barge Combinatorics

Source: $\quad$ Aris Peci, 2018

Figure 39 Museum Infrastructure Growth

Source: $\quad$ Aris Peci, 2018

Figure 40 Museum Bridge Frameworks

Source: $\quad$ Aris Peci, 2018

Figure 41 Museum as Bridge in the London Context

Source: $\quad$ Aris Peci, 2018

Figure 42 Bridge Combinatorics

Source: $\quad$ Aris Peci, 2018

Figure 43 Logistics Diagram - Infrastructure Logic

Source: $\quad$ Aris Peci, 2018

Figure 44 User and Artifact as Homogenous Data

Source: $\quad$ Aris Peci, 2018

Figure 45 User Circulation Process

Source: $\quad$ Aris Peci, 2018

Figure 46 Bridge Axonometric 1

Source: $\quad$ Aris Peci, 2018

Figure 47 Artifact Circulation Process

Source: $\quad$ Aris Peci, 2018

Figure 48 Bridge Axonometric 2

Source: $\quad$ Aris Peci, 2018

Figure 49 Thames River Circulation Process

Source: $\quad$ Aris Peci, 2018

Figure 50 Bridge Axonometric 3

Source: $\quad$ Aris Peci, 2018

Figure 51 Process Pavilions

Source: $\quad$ Aris Peci, 2018 
Figure 52 Bridge Axonometric 4

Source: $\quad$ Aris Peci, 2018

Figure 53 Posthuman Assemblage

Source: $\quad$ Aris Peci, 2018

Figure 54 Museum Relationships. Comparing the Normative Museum to the Posthuman Museum

Source: $\quad$ Aris Peci, 2018

Figure 55 Relationships between exhibited collections and collections in store.

Source: $\quad$ Aris Peci, 2018

Figure 56 Site Plan

Source: $\quad$ Aris Peci, 2018

Figure 57 Pedestrian Bridge Floor Plan

Source: $\quad$ Aris Peci, 2018

Figure 58 Pedestrian Bridge Floor Plan Level 2

Source: $\quad$ Aris Peci, 2018

Figure 59 Sorting Pavilion Level One

Source: $\quad$ Aris Peci, 2018

Figure 60 Exhibition Storage Level One

Source: Aris Peci, 2018

Figure 61 Sorting Pavilion Level One

Source: $\quad$ Aris Peci, 2018

Figure 62 Exhibition Storage (1) Level One

Source: Aris Peci, 2018

Figure 63 Exhibition Storage (2) Level One

Source: $\quad$ Aris Peci, 2018

Figure 64 Amazon Fulfillment Centre

Source: https://blogdegeografiadejuan.blogspot.com/2017/06/amazon-robotiza-sualmacen-en-espana.html accessed March 20, 2018

Figure 65 Amazon Fulfillment Centre 2

Source: https://robohub.org/while-amazon-doubles-its-number-of-warehouse-robots-to30k-competing-systems-emerge/ accessed March 20, 2018 
Figure 66 Amazon Warehousing Robotics

Source: $\quad$ https://www.sohu.com/a/231739273_175818 accessed March 20, 2018

Figure 67 Assemblage Possibility 1

Source: $\quad$ Aris Peci, 2018

Figure 68 Assemblage Possibility 2

Source: $\quad$ Aris Peci, 2018

Figure 69 Framing Storage Structures

Source: $\quad$ Aris Peci, 2018

Figure 70 Enabling the Conduit

Source: $\quad$ Aris Peci, 2018

Figure 71 Fluctuating Program Blocks

Source: $\quad$ Aris Peci, 2018

Figure 72 Façade Translation

Source: $\quad$ Aris Peci, 2018

Figure 73 Layered

Source: $\quad$ Aris Peci, 2018

Figure 74 West Elevation

Source: $\quad$ Aris Peci, 2018

Figure 75 Render Looking East

Source: $\quad$ Aris Peci, 2018

Figure 76 Longitudinal Section

Source: $\quad$ Aris Peci, 2018

Figure 77 Sorting Pavilion

Source: Aris Peci, 2018

Figure 78 Sorting Pavilion Elevation

Source: $\quad$ Aris Peci, 2018

Figure 79 Exhibition Storage 1

Source: Aris Peci, 2018

Figure 80 Pedestrian Walkway

Source: $\quad$ Aris Peci, 2018

Figure 81 Exhibition Storage 2

Source: $\quad$ Aris Peci, 2018 
Figure 82 Sculpture Garden

Source: $\quad$ Aris Peci, 2018

Figure 83 Condenser Pavilion

Source: $\quad$ Aris Peci, 2018

Figure 84 Interior Museum Render Render

Source: $\quad$ Aris Peci, 2018

Figure 85 Interior Museum Render

Source: $\quad$ Aris Peci, 2018

Figure 86 Render from South of Bridge

Source: $\quad$ Aris Peci, 2018

Figure 87 Museum Network

Source: $\quad$ Aris Peci, 2018

Figure 88 Museum Index

Source: $\quad$ Aris Peci, 2018

Figure 89 Museum with percentage of artifacts in storage

Source: $\quad$ Aris Peci, 2018

Figure 90 Off-site Storage

Source: $\quad$ Aris Peci, 2018

Figure 91 Averaging out collections in storage

Source: $\quad$ Aris Peci, 2018

Figure 92 Context Model 1:2000

Source: $\quad$ Aris Peci, 2018

Figure 93 Context Model 1:2000

Source: $\quad$ Aris Peci, 2018

Figure 94 Sectional Model 1:200

Source: $\quad$ Aris Peci, 2018

Figure 95 Sectional Model 1:200

Source: $\quad$ Aris Peci, 2018

Figure 96 Building Model 1:300

Source: $\quad$ Aris Peci, 2018

Figure 97 Building Model 1:300

Source: $\quad$ Aris Peci, 2018 
Figure 98 Building Model 1:300

Source: $\quad$ Aris Peci, 2018

Figure 99 West Elevation

Source: $\quad$ Aris Peci, 2018

Figure 100 East Elevation

Source: $\quad$ Aris Peci, 2018

Figure 101 Longitudinal Section

Source: $\quad$ Aris Peci, 2018

Figure 102 Level One

Source: $\quad$ Aris Peci, 2018

Figure 103 Level Two

Source: $\quad$ Aris Peci, 2018

Figure 104 Large Axonometric

Source: $\quad$ Aris Peci, 2018 


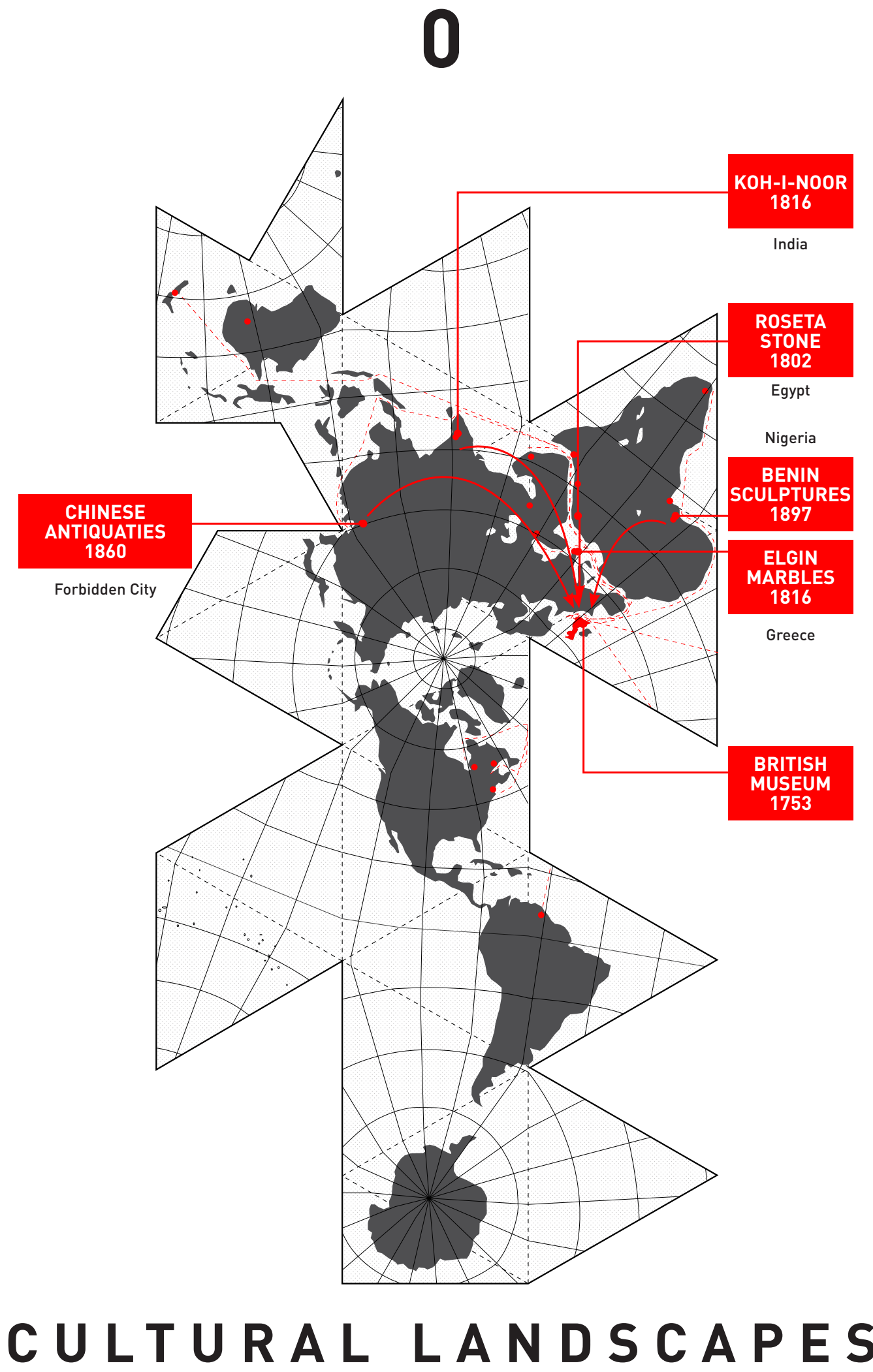




\subsection{ARTIFACT MIGRATIONS}

Consciously or subconsciously,

archeological interpretation and the

public presentation of archaeological

monuments are used to support the

prestige or power of modern nation-

states.

Neil Asher Silberman, 'Nationalism and

Archaeology' 1

From the ethnographic collections by Captain

Cook in the late $18^{\text {th }}$ century in the pacific

expeditions to the punitive raids of Benin city in modern day Nigeria, imperial power has been a major factor in the redistribution of artifacts around the globe. The British Museum is the purest representation of cultural imperialism with London being its epicentre and the River Thames its underlying infrastructure connecting the museum to vast colonies. In its primary conception the function of the British Museum was to bring into its domain a collection of the worlds artifacts, creating a British representation of the world in miniature in which Britain is the master. ${ }^{2}$ The $18^{\text {th }}$ century through to the $20^{\text {th }}$ century saw one of the largest artifact migrations along global shipping lanes throughout the British Empire, from the peripheries of the empire to London, symbolically enacting it as the colonial seat of power. Artifacts from the far reaches of the world (figure 1) find themselves on the ports of the River Thames.
The museum as an institution became a powerful symbol of British imperialism whose representations of the world reflected a colonial perspective. An object in the colonial museum is fundamentally altered in the context of its display. In London, museum collections were built after successful colonial ventures with displays of imperial conquest and the hope that such displays like the empire itself, would be a lasting achievement. ${ }^{3}$ As a result, this artifact migration evolved from an imperial war-chest to a global resource and institution. The British Museum evolved from the colonial epicentre to a world heritage centre where the whole world could meet in one building. In the contemporary network the geographic location of artifact is at the heart of global cultural landscapes. Sovereign states such as the Greek government are now negotiating the repatriation of cultural objects setting forth a larger global cultural dialogue. In response, the British Museum acting as a proxy for the current British ethos has largely 
rejected these demands for repatriation. It sees itself as a museum of the world, for the world. The River Thames is at the heart of the existing museum network in the contemporary London context. Museum building in Britain in the nineteenth century was a direct consequence of war, colonialism and missionary expeditions, which brought with it artifacts across the English Channel and up to the Port of London on the River Thames. The museum reflects the views and attitudes of dominant cultures, and the material evidence of the colonial achievements of the European cultures in which museums are rooted. ${ }^{4}$ 


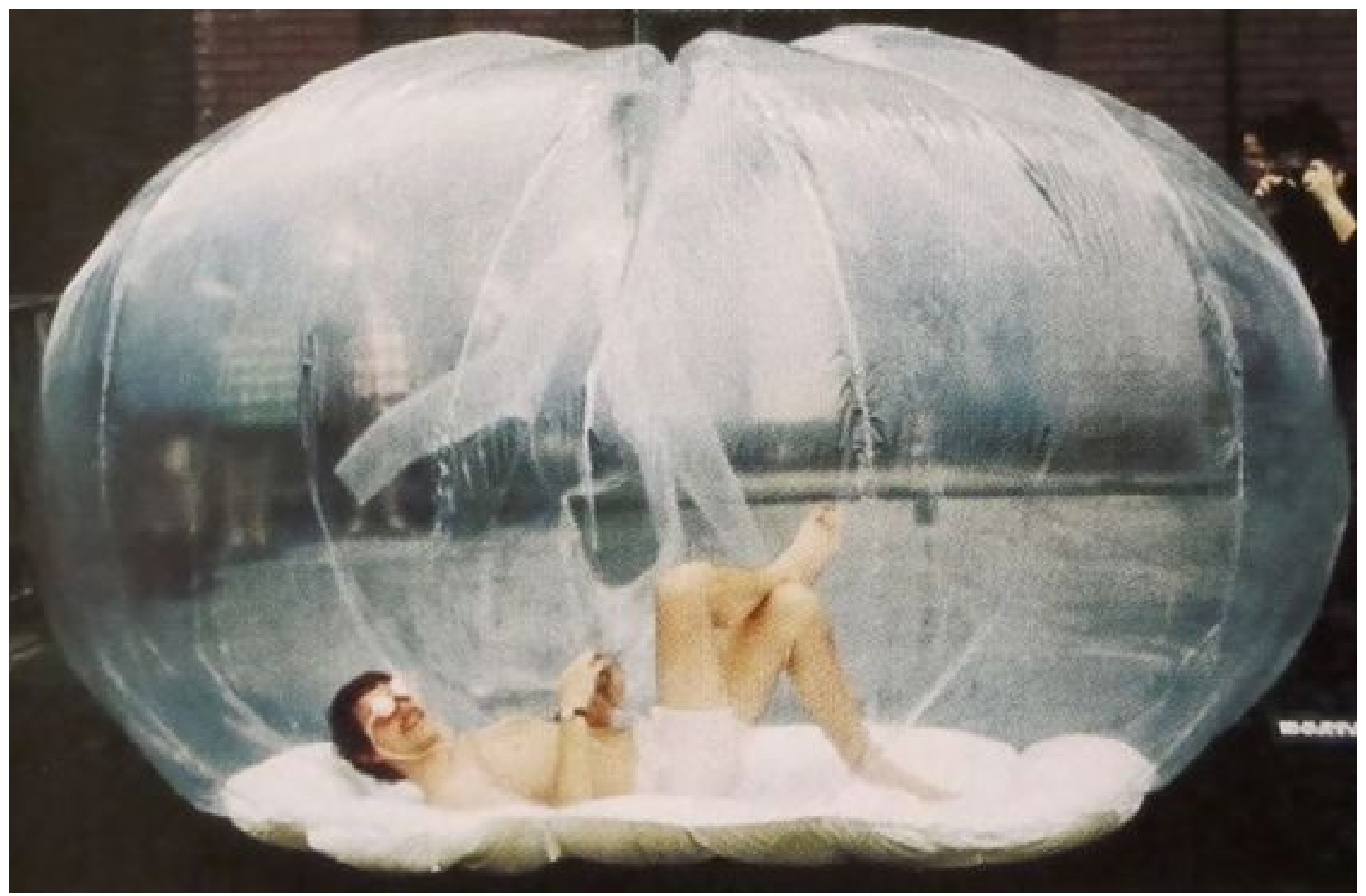

Figure 2. Michael Webb, Cushicle

\subsection{WHERE BODIES END AND PROSTHETICS}

\section{BEGIN}

The technology and information revolution has brought us to a critical question. What do we do with the human body? Do we cast it aside and change vehicles or do we continually modify and enhance it until we no longer recognize the final image? We are continually witnessing the evolution of a paradigm in which humans and machine intelligence co-develop in various degrees of interdependency. The departure from the body is a result of the development of a globally networked subjectivity found in the late twentieth century. ${ }^{5}$ This is a theme that is heavily explored and represented by postmodernity, for which architecture played a key role.

In this era of ubiquitous networks, we have come to shift our understanding and conceptualization of the body from what it does to the tools it uses. The body has always been a tool, a prosthesis of consciousness. ${ }^{6}$ The body extends itself through an ever-increasing set of protocols and prosthetics to adapt to a rapidly changing environment. Architecture, being one extension, has always been concerned with what to do with the human body and how to facilitate 
its functioning. From the primitive hut to the postmodern movement - architecture continually deals in the identification and development of material and informational protocols, in the aim of constructing an environment for human use, whether it be virtual or actual.

Technology has had a destabilizing effect on architecture. In contemporary architectural praxis, technology has done away with the rigid demarcations of architectural program in favor of more fluid and indeterminate explorations. ${ }^{7}$ We are beginning to see that same vector apply to the biological substrate of the human body. Technology is beginning to liberate the human body to take on a variety of forms and scales. As Ito precisely put it, the continuous extension of man through technological prosthetic will ultimately lead to networks of overlapping systems that in the end will probably envelope the entire globe as a single system. ${ }^{8}$ This concept can be found in normative practice today where we are constantly seeing the environment being decoded into a flexible digital matrix.

With the human body construct being more fluid than ever, how should architectural discourse progress forward? It has been evidently clear that contemporary architecture in the $21^{\text {st }}$ century operates on a global homogeneous territory, entangled in dense infrastructure and ecological networks. The human body, through prosthetic enhancement, has itself also embarked on an evolutionary movement towards increasingly autonomous prosthetics which take away our self-sufficiency. The human body itself then becomes an artifact for preservation and display. The body as artifact is the starting point for this thesis seeking to investigate how we frame such a diverse field of architectural modalities, how we humans situate ourselves within constantly evolving realities and finally what affect this has on architecture as a museum for this artifact.

\subsection{WORKING METHODOLOGIES}

The ideas of this thesis have been investigated in three areas: Contextualizing the Posthuman thesis within the discourse of architecture, understanding Posthuman parameters and exploring them through an architecture, and finally the design of a Posthuman museum as an experimentation of these concepts.

In Chapters One and Two, the evolving relationship between humans and the objects of everyday use and the ensuing networks that are developed are discussed. This discussion begins with the early development of Posthumanism as a theory and its similarities to concepts in architectural discourse. This is further examined in chapter two through the lens of specific precedent studies that begin to form a time-line of specific paradigms within architecture that ultimately lead us to a Posthuman paradigm. This analysis points to an increasing need for architecture to respond to contemporary 
networked topologies in the twenty-first century. Chapters Three and Four, identify London as the site for the thesis project and discuss the critical parameters within the territory of Posthuman and museum design. These parameters form the basis of the design research explorations in understanding and designing Posthuman spatial assemblages. Three strategies emerged as a result of these design research explorations that lay out a potential Posthuman network between these factors: architecture as a diffuse system, museum narratives, and hybrid integration of infrastructural systems. These strategies construct the spatial, artifact, and user systems that form a Posthuman architectural framework.

Finally, Chapters Five and Six utilize a Posthuman architectural framework to develop the concept of a museum infrastructure in an urban context. The process first began by identifying and extracting the existing museum network, followed by intensifying modes of interaction within that network. The architectural form that emerges is determined by these museum networks and materialized to become a node as part of a larger system. The result is a museum infrastructure that supports the growth of artifact and spatial networks within the city of London.

\section{NOTES}

1 Silberman, Neil A. Nationalism and Archaeology. (New York, H.Holt 1989) p.12

2 Barringer, Tim, and Tom Flynn, . Colonialism and the Object: Empire, Material Culture and the Museum. (London, Routledge 1998) p.11

3 Duthie, Emily. "The British Museum: An Imperial Museum in a Post-Imperial World". (Public History Review, 2011) p.12

4 Simpson. Making Representations: Museums in the Post-Colonial Era. (Psychology Press, 2001) p.246

5 Hayles, Katherine N. How We Became Posthuman: Virtual Bodies in Cybernetics, Literature, and Informatics . (Chicago, University of Chicago Press 1999) p.6 6 Wigley, Mark. "Prosthetic Theory: The Disciplining of Architecture." (Assemblage No. 15, 1991) p.9

7 Harrison, Ariane. "Charting Posthuman Territory" in Architectural Theories of the Environment: Posthuman Territory. (New York, Routledge 2013) p. 10 


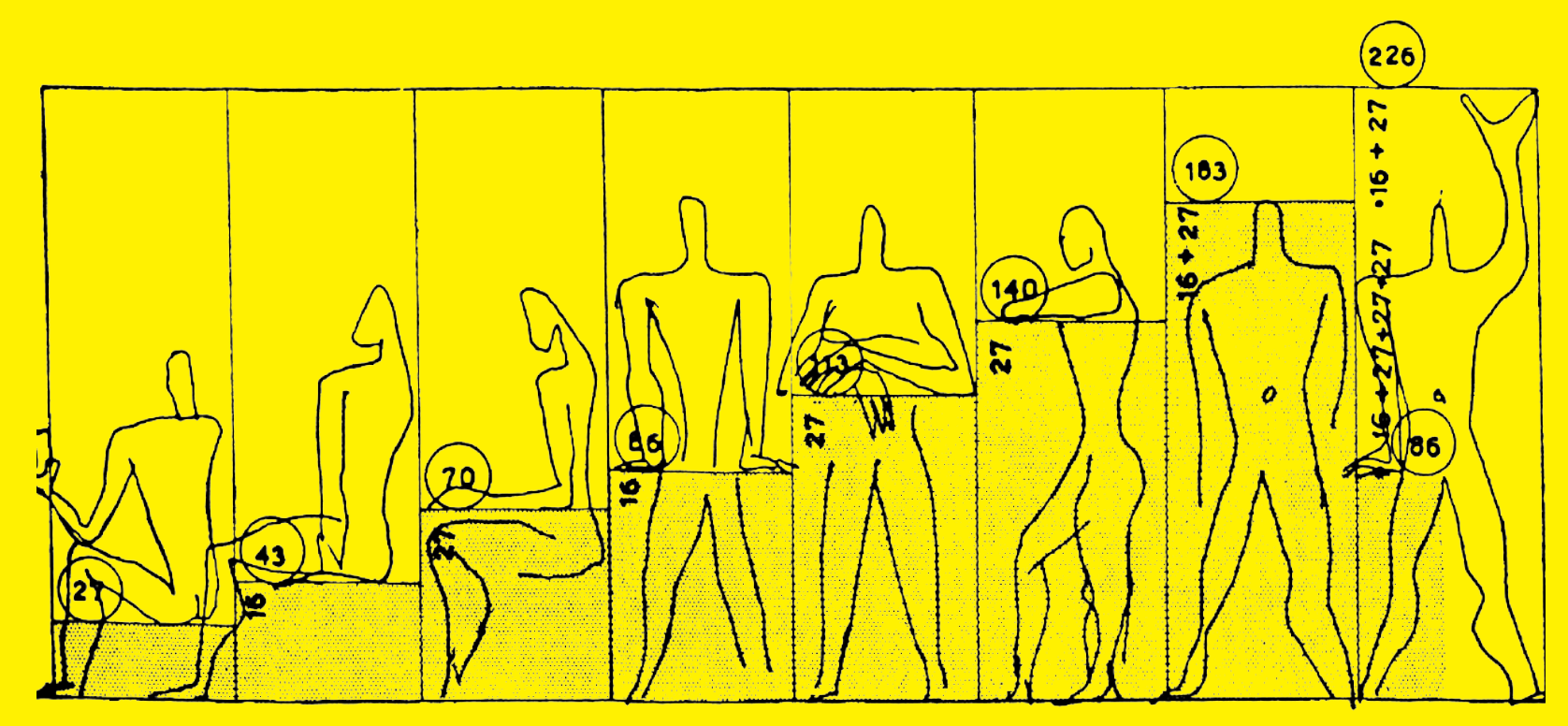

Figure 3. Le Modulor, 1948 


\subsection{HOW WE BECAME POSTHUMAN}

The thesis began with an exploration of the role of the user in contemporary architecture. Normative architectural modalities utilize the user primarily through an anthropocentric lens. There is no sense in continuing to define the anthropocentric body directly; to do that is to create a copy that is nothing more than the original model. This thesis instead aims to render the body sensitive to material assemblages that come into constant contact with it. By focusing on the body, we are instead directed to what the body has become sensitive of. ${ }^{9}$ Architecture, fundamentally, is a tool in which we can begin to articulate the contours of the human precisely because it is developed for the body. It is important to note that the human body is no longer embodied in the biological substrate but rather has become a collection of heterogeneous components, a materialinformational entity whose boundaries undergo continuous construction and reconstruction. ${ }^{10}$ For the purposes of this research we will refer to this heterogeneous entity as the Posthuman. Within the discourse of architecture, we are actively engaged in articulating the Posthuman because we are in the process of not only reengineering the physical environment, but that of the human whose qualities are being calibrated for seamless integration into a new society. ${ }^{11}$ This new paradigm explains why the specific biological construction called the Human is giving way to a different construction called the Posthuman. ${ }^{12}$

Central to the new understanding of the contemporary human condition has been a mounting awareness of the transgression of the biological by the technological. As technologies becomes more and more ubiquitous and more central to our identity, they inherently become extensions of body and posthuman agency. The act of acquiring a body is an ongoing process that produces a sensory medium and a sensitive world. ${ }^{13}$ The increasing application of network theory to the construction of the human body is a result of the endless number of prosthetic artifacts we have assembled to create the Posthuman. Network theory, and by 
extension infrastructural logistics is central to understanding the Posthuman assemblage because it does away with relationships based on distance and begins to formulate nodes based on agency. ${ }^{14}$

\subsection{CRITICAL POSITION POINT OF ENTRY}

How can we begin to utilize the Posthuman paradigm so that it begins to engender new architectural modalities? For architecture to start to reflect the co-evolution of the human body and of contemporary design ecologies, it must first come to terms with what it means to have Posthuman users. Normative architectural practice is constantly adapting to new paradigms in service of outdated conceptions of use and user. The problem is difficult to solve because, as stated above, to understand the space our Posthuman bodies inhabit, architecture must be utilized at a multiplicity of scales to render the Posthuman skin.

\section{“Conceptual fields evolve similarly to material culture, in part because concept and artifact engage each other in continuous feedback loops." 15}

Therefore, architecture presents an intriguing avenue in which to explore this question as contemporary design ecologies have evolved to include robotics, cybernetics, and informatic systems.
Posthuman theory is not a uniquely architectural concept; Katherine Hayles locates the origins of Posthumanism in cybernetics when theories of the technological began to model biological systems. Architectural theory has revolved around the proportional relationship between built form and the human body. Le Modulor, by Le Corbusier, being recently the most influential in a long line of proportional systems dating back to Vitruvius, and da Vinci's Vitruvian Man. Le Modulor is a critical point of departure for this thesis as it seeked to reconcile construction methodologies, design, and its overall relation to the human body. Based on the golden mean, found in the proportions of the human body, it resolves the mathematical proportions and one of architecture's earliest endeavours - to construct a shelter for the body of man. Le Corbusier intended to establish a series of proportional measurements for application to a wide range of design projects, whether the design problem is on the scale of a household object, or city master plans. By utilizing a proportional system that created a universality of dimension, particularly objects planned for prefabrication, it became a tool of uniformity. This became one of the key concepts of Modern architecture, and its dissemination for an architecture that is perfectly adapted to the normative body. While contemporary architecture as practiced today may not utilize the proportional system found in Le Modulor, we 
continue to see architectural discourse revolve around the concept of the normative body. Examples of this can be found in works such as the Architectural Graphic Standards. The normative body refuses the very idea of human evolution; thus, the body is forced to interact with an environment that remains the same. What is the Posthuman geometry? And how do we articulate its contours? The Posthuman does not require a proportioning system for design standards; rather what is required is to articulate a Posthuman network that in turn influences architectural networks so that they may operate in codependent feedback loops.

\section{NOTES}

9 Latour, Bruno. "How to Talk about the Body?

The normative Dimension of Science

Studies" in Body and Society Vol. 12, 2004. p.206

10 Hayles, Katherine N. How We Became

Posthuman: Virtual Bodies in

Cybernetics, Literature, and Informatics .

(Chicago, University of Chicago Press 1999) p.3

11 Kwintor, Sanford. "The computational Fallacy"

in Computational Design Thinking. (New York, Wiley \&

Sons 2011) p.213

12 Hayles, Katherine N. How We Became

Posthuman: Virtual Bodies in

Cybernetics, Literature, and Informatics .

(Chicago, University of Chicago Press 1999) p.2
13 Latour, Bruno. “How to Talk about the Body? The normative Dimension of Science Studies" in Body and Society Vol. 12, 2004. p.207

14 Hayles, Katherine N. How We Became Posthuman: Virtual Bodies in Cybernetics, Literature, and Informatics . (Chicago, University of Chicago Press 1999) p.24

15 Ibid. 17 


\section{2}
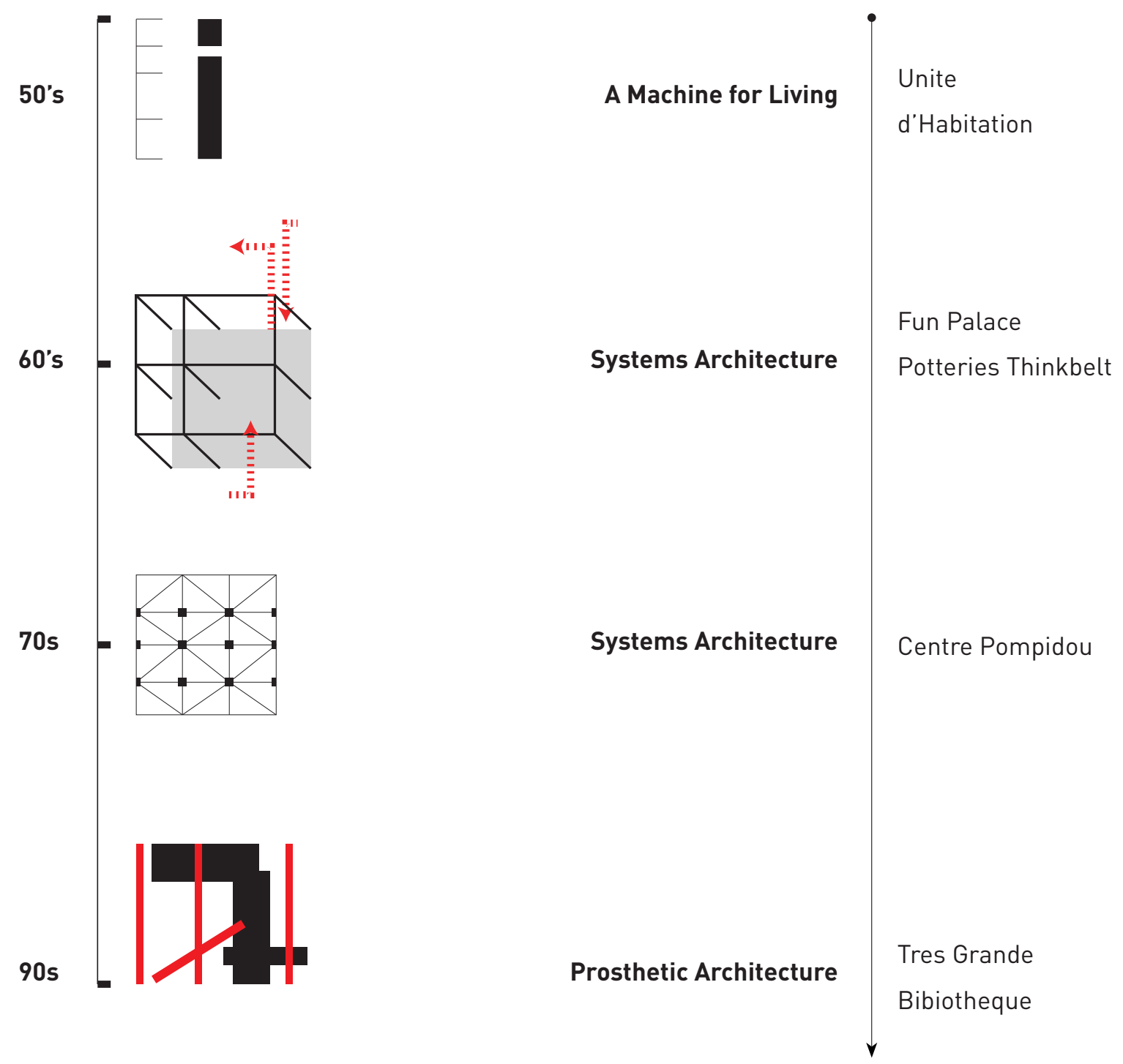

Figure 4. Precedent Timeline 
This precedent analysis highlights seminal projects that are important in the development of a Posthuman architectural theory. They come together as a body of work spanning 50 years from iconic architects such as Le Corbusier, Cedric Price, and Rem Koolhaas. From the onset of Modern architecture, we see a coupling between industrial production processes and architectural style. Le Corbusier was a champion of the engineered aesthetic and played a major role in the cross-disciplinary approach of Modern architecture. The incorporation of cybernetics and interactive systems theory continues well into the 60 s and 70 s with the work of Cedric Price and the infamous Fun Palace scheme, going on to have a significant influence on the Piano and Roger's Centre Pompidou. The advent of cybernetic thinking brought along with it a radical re-conceptualization of the body and its relationship with technology. Finally, in the Post-Modern era we see a culmination of this theory in the prosthetic architecture of the Tres Grande Bibliotheque competition proposal by Rem koolhaas and OMA. This project is one of the first schemes in which a Posthuman architectural framework is deployed.

\subsection{A MACHINE FOR LIVING}

With the creation of Le Modulor, Le Corbusier was responding to the increasing use of mass-production and standardization in many industries including architecture. The ubiquity

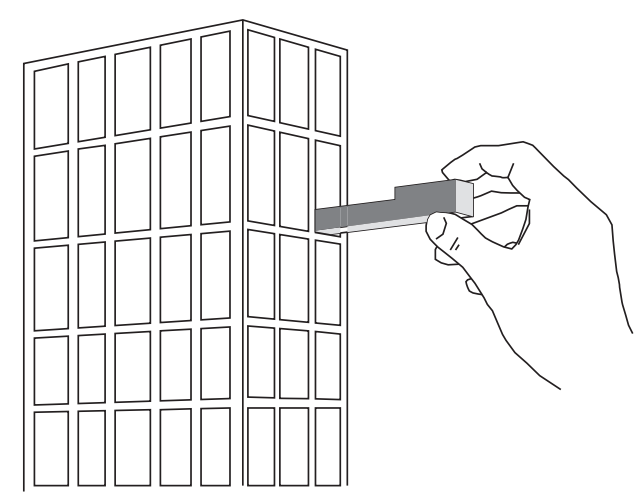

Figure 5. Unite Living Units Concept

of mass-production and the engineer's aesthetic created new problems, and with Le Modulor Corbusier believed that he had created a new tool capable of resolving them. He set out to address one of the ideas central to his body of work, the idea of the house as a machine for living. This concept draws inspiration from the engineer's aesthetic which Corbusier believed to be at full height in post-war Europe because there was a real need to utilize mass-produced housing to respond to the growing housing crisis. If Le Modulor is the antithesis to the Posthuman, then the Unite d'Habitation in Marseille represents the anti-precedent.

Unite d'habitation addressed the housing crisis in post-war Europe, but for Corbusier there was a larger concern at hand. How should the inhabitant live in the new modern world? Conceptually, Unite was intended to be a unit of living for the modern lifestyle. In its application, Unite was designing the Modern Man, with a 


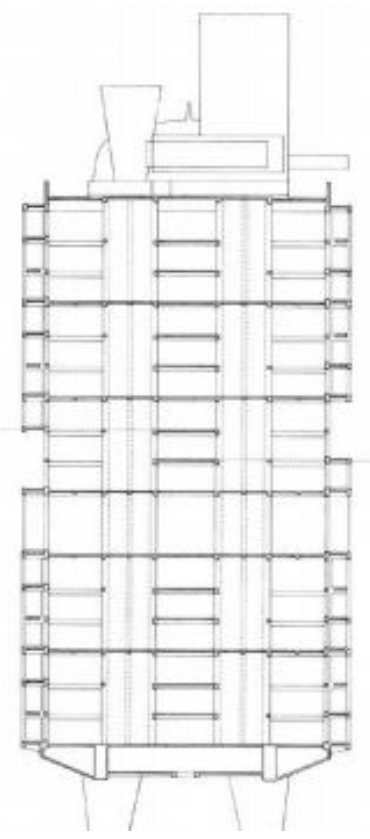

Figure 6. Unite D’Habitation Section

singular static boundary condition. Corbusier believed that "only the architect can strike the balance between man and his environment." 16 For humans to live in the age of mass-production they must first be reduced to variables that can be seamlessly integrated into the massproduction process. Le Modulor achieves that by dissecting the proportions of the human body and standardizing them for use in the larger manufacturing system. The design of Unite is governed by only fifteen measures, these measurements being of the 'Modulor'. ${ }^{17}$

The building was designed to operate as an isolated 'vertical garden city'. Within Unite, it was never entirely clear what group or type

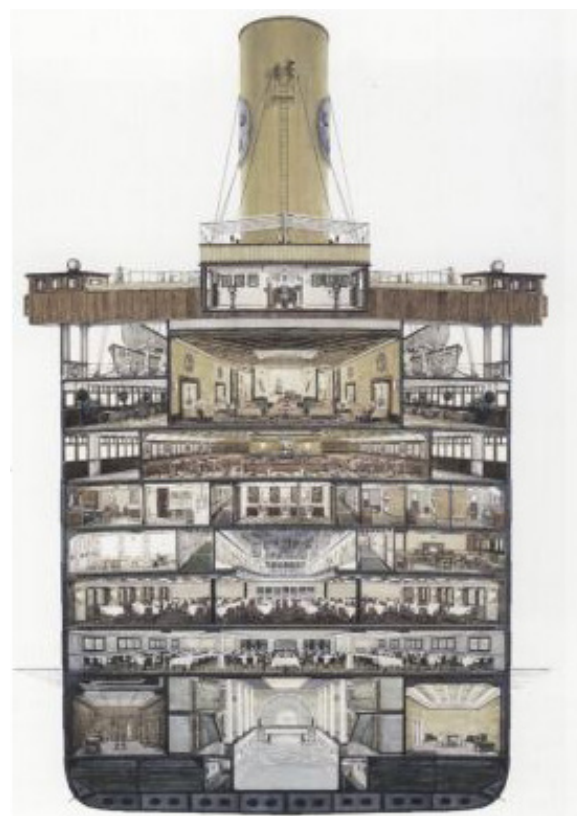

Figure 7. Engineers Aesthetic shown in section of cruise ship

of people were supposed to be housed; it was intended to be a prototype for an international housing model. Each building was conceived of in isolation, having an ostentatious relationship with an abstract nature. For Le Corbusier to achieve mass production and standardization, the principals behind Unite had to negate the city so that the schemes application could traverse multiple geographies. Through the pilotis, any reference to continuity and to a spatial proximity was removed. The Unite d'habitation is a conceptual framework, and as such the user becomes a parameter that is deconstructed to mere functionality calibrated as 1.13 or 2.26 metres. When this architectural project 
expanded its territory travelling from Marseille to Algiers, the concept of the standardized user was essential as both territories were deemed homogeneous. Therefore, the standardized user became essential because it was a common denominator to be used in architectural practice. What followed in Modernism was an architectural era that not only normalized the environment but also the user within that environment. With the ubiquity of mass-production, the user perception and experience of space became firmly rooted within their physical body. With the eventual rejection of Modernism in Post-Modernism the normative user as an architectural construct remained evident.

Figure 8. City As Fun Palace, Cedric Price

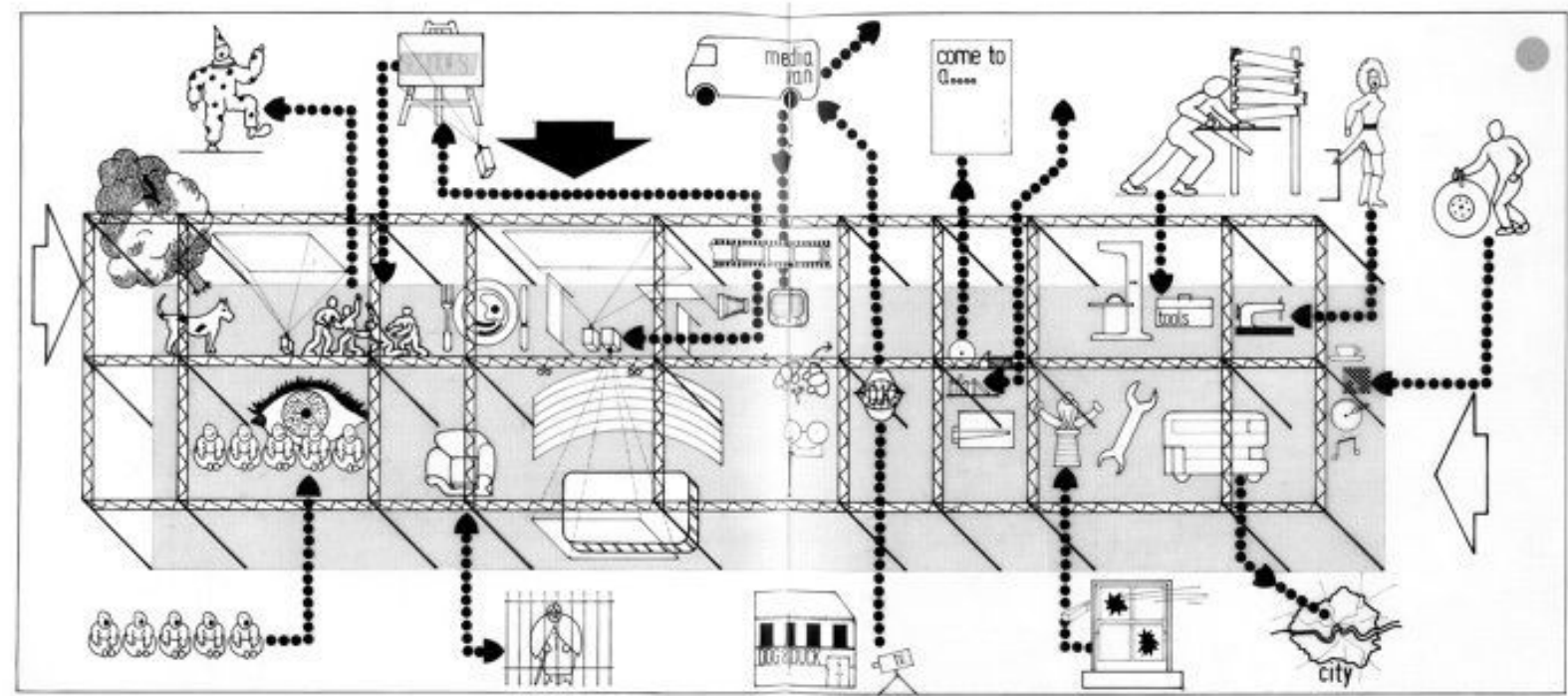

\subsection{SYSTEMS ARCHITECTURE}

In his Fun Palace and the Potteries

Thinkbelt projects, Price began to lay the ground work for an architectural discourse that revolved around cybernetics, systems technology, and information and communication infrastructures. These proposals were much less about buildings in the traditional sense but rather impermanent, improvisational and interactive systems. ${ }^{18}$ They were designed to be highly adaptable to the volatile territory conditions the post-industrial era promised to usher in. Developed in 1964, Fun Palace was intended to be an improvisational architecture always in the process of construction, reconstruction and reassembly. The Fun Palace was one of the first architectural projects that revolved around the concept of 


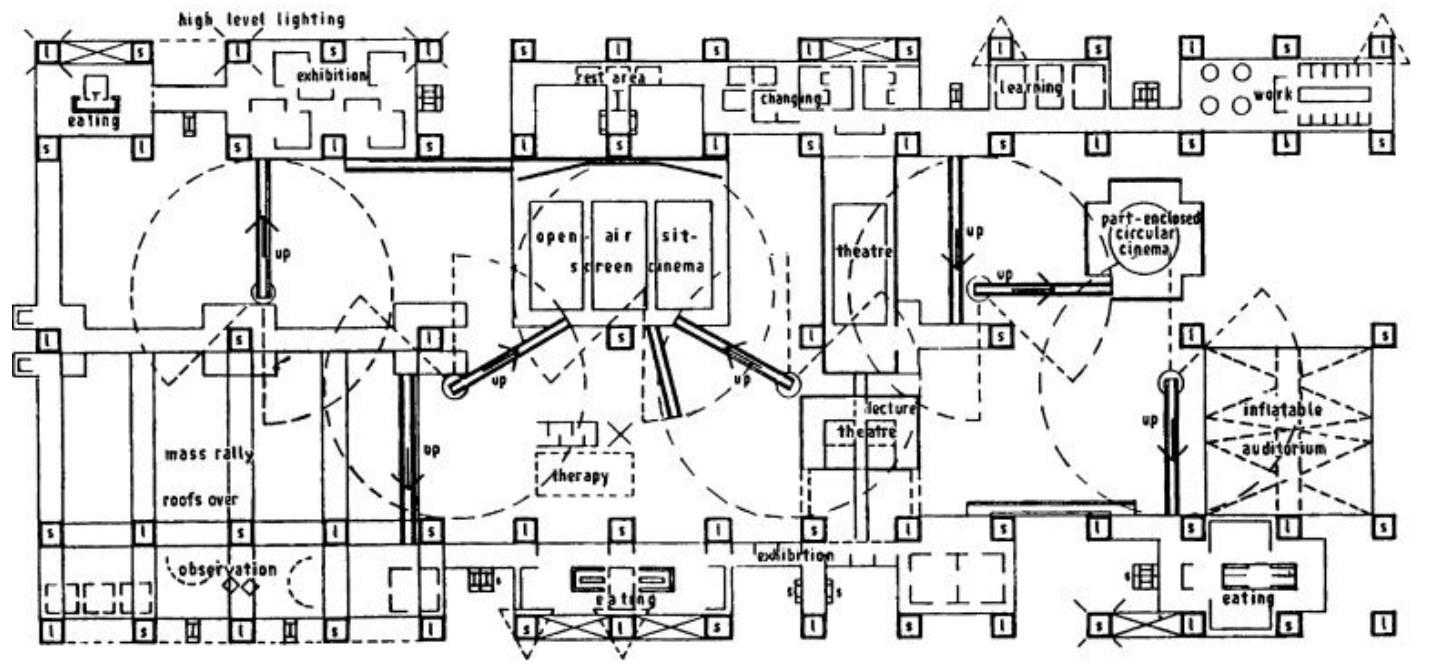

Figure 9. Fun Palace, Floor Plan

having the user as an active agent within the construction of its architectural framework rather than mere passengers. The possibility of having users 'design' a space as they 'used' it was at the very center of the Fun Palace as a system of architecture. ${ }^{19}$ In this vein, Price hoped to create an improvisational architectural feedback loop that would could anticipate and adapt to user patterns and programme. This concept found itself manifested in a skeletal framework within and around which activities might grow and develop thanks to an array of sensors and inputs that would create real-time feedbacks systems on use and occupancy. Cedric Price understood that cybernetics would play a key role in deploying the dynamic systems proposed in Fun Palace because it was ad hoc in nature, determined by users, unstable, indeterminate, and unknowable in advance..$^{20}$ The cybernetic movement is also positioned by Hayles as the beginning of the Posthuman paradigm and it is this period where we see the cross-section between Posthuman discourse and architectural discourse. The result was a nonsite specific architectural system that could be deployed as an infrastructure to emancipate and democratise theatre education. This is very much a Posthuman architectural approach as the user

Figure 10. Plan as Programme, Cedric Price

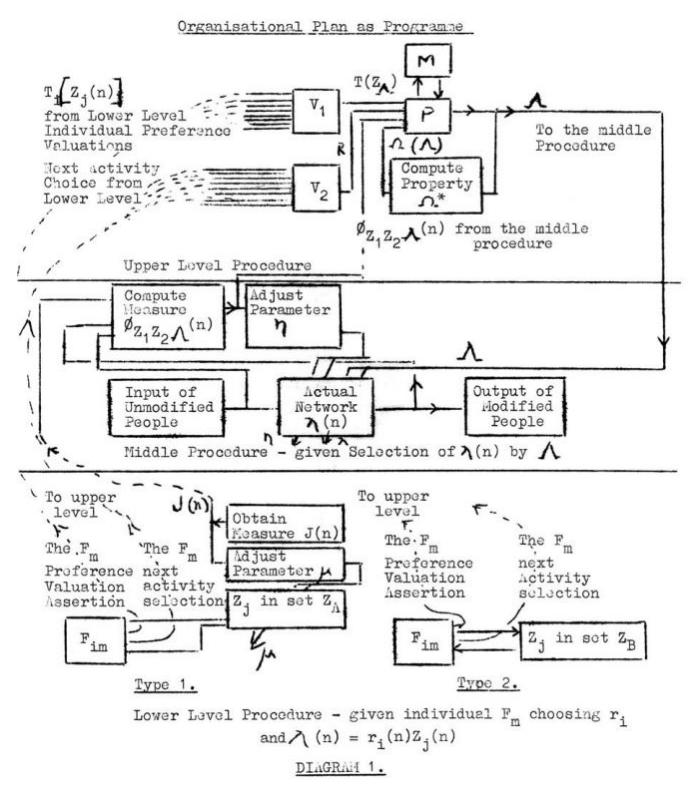


Figure 11. Cedric Price, Map of Potteries Thinkbelt Infra-

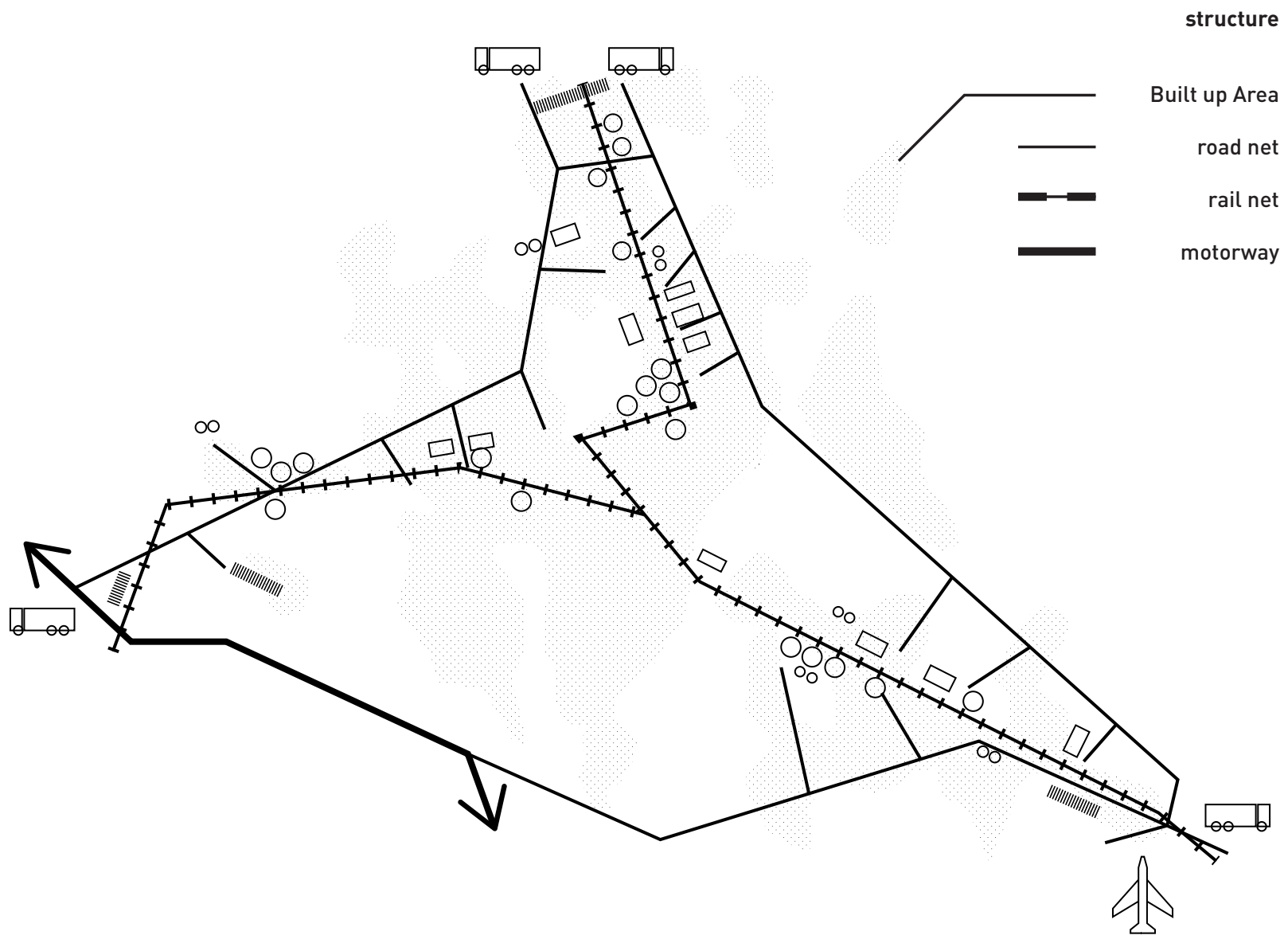

becomes a node within an architectural network in which they themselves can develop new spatial experiences for themselves through the Fun Palace as a prosthetic.
The Potteries Thinkbelt project by Price explores the leveraging of infrastructural logic adapted to existing typologies and the effect that this would have on existing institutions and systems. The Thinkbelt project's main thesis was a critique of existing educational models in Britain and their formal representation. The Thinkbelt challenges the existing spatial construction of education by utilizing postindustrial infrastructure for a potential openended educational structure, one that gets 


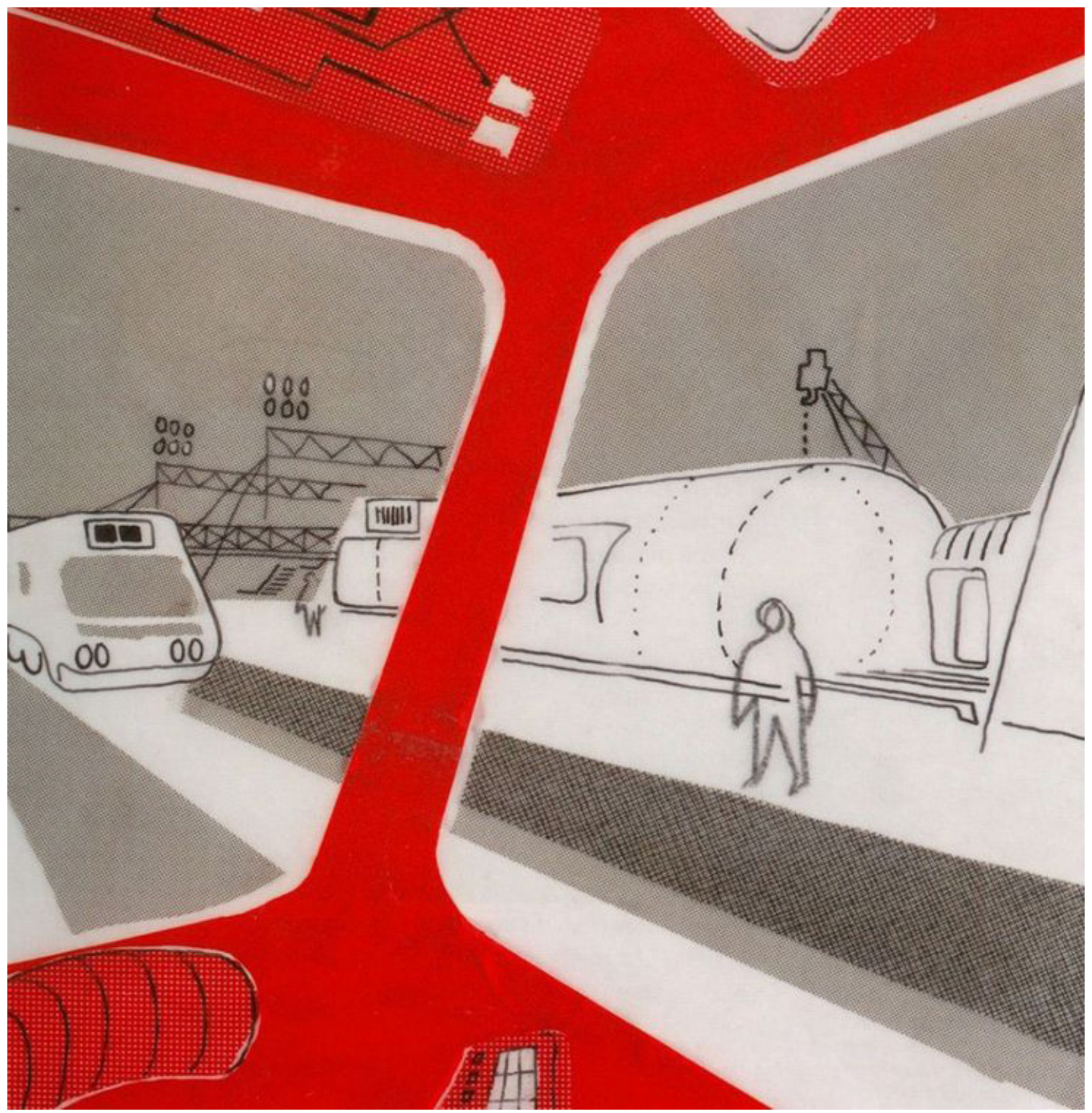

Figure 12. Cedric Price, Potteries Thinkbelt

rid of existing hierarchies. The mobile and transformable campus infrastructure was made accessible due to the ease of access to the existing rail network and its distributed structure rather than isolated in privileged geographies.
Price furthered concepts from Fun Palace by continuing to explore the possibility of cybernetics with integrated and interactive landscapes for the purposes of engendering new educational and research models. 
Figure 13. Centre Pompidou Elevation

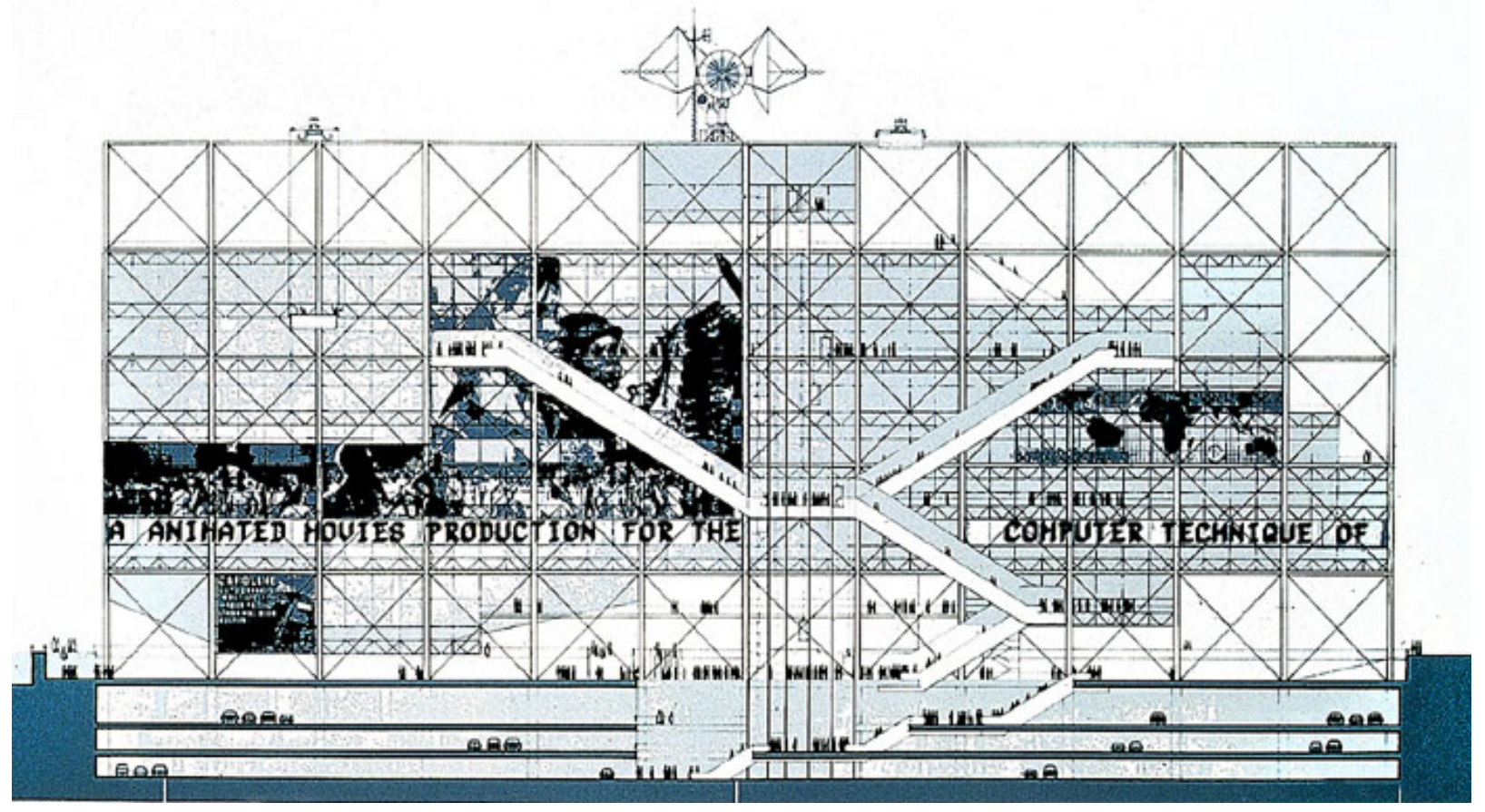

\subsection{MUSEUM FRAMEWORKS}

An iconic building from the high-tech movement in architecture, The Rogers and Piano Centre Pompidou scheme furthers core concepts found in the Fun Palace and can directly trace its lineage through Price's body of work. Perhaps the most direct line can be found in the project's manifestation of a highly flexible framework mobilized to house a multitude of transformations with the aid of highly technical means in hopes of developing an information theme park. Similarly, the architecture was also intended to be erected as a scaffolding that could accommodate all manner of changes. The most striking aesthetic features found in this project are its execution of movement, temporality, and flexibility through open structural systems and chain-like escalators that climb diagonally across the façade giving it a distinct visual aesthetic. ${ }^{21}$ This building is a compendium of ideas expressed through a series of technologically advanced systems. Adhering to the axial nature of Hausman's Paris while simultaneously providing an unfamiliar urban space, these technologically advanced systems reflects the dynamism of the Parisian urban fabric and the developing global city.

The Centre Pompidou utilized technological frameworks to create a highly flexible and autonomous exhibition framework, one that 


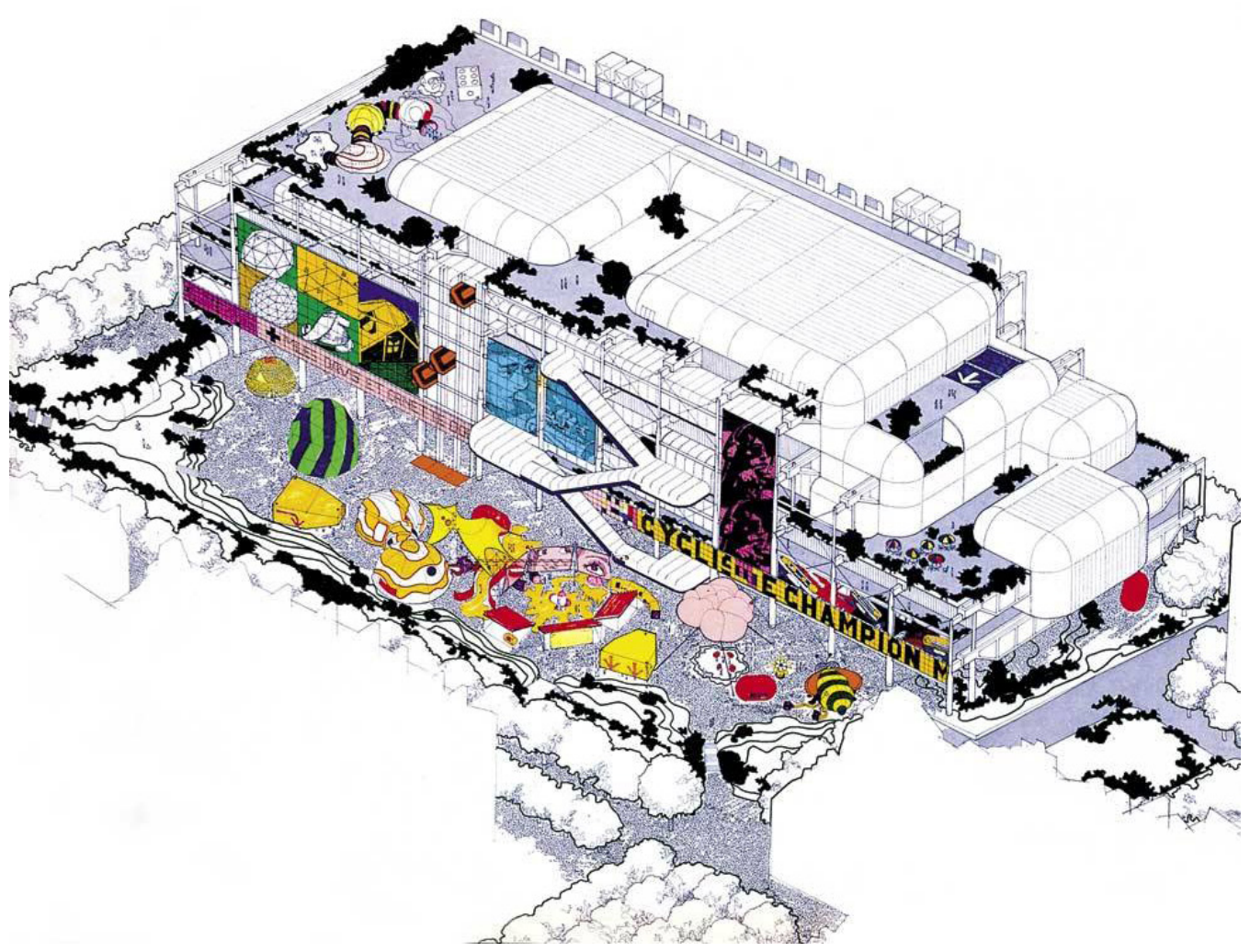

Figure 14. Centre Pompidou Information Theme Park

engendered diverse user narratives. The

flexibility in program and function was achieved by developing a long-span, space frame structure to enable uninterrupted floor plates with the ability to span the entire length of the site. This museum framework does not dictate curatorial and artifact networks thanks to its open design. The Centre Pompidou is an example of an antimuseum concept that was developed in the late sixties Modernism movement. It subverted existing cultural monuments by turning the consumption of culture into a commodity to shift the concept of museum as temple to the museum as a platform for social and cultural exchange. ${ }^{22}$ This is translated to in the massing strategy by occupying half of the available site while the other half becomes a theme park for information and entertainment. (Figure 14)

This building is most known for its technical and functionally provocative architecture. The tectonics of this building reflect on the availability of technology and resources in the context of an urban environment. It was at the forefront of advanced technology, prefabrication, and lightweight materials as they formed the basis of the overall construction process. As a result, the boundary between technologies and architectural form dissolved, and has at the same time become the epitome of a provocative boundary blurring conception of culture. This work provides an 
aesthetic framework for hard architectural

infrastructures that normally remained hidden.

The supply lines are all shifted to the exterior.

In its entirety, the Centre Pompidou realized an architectural systems approach while challenging traditional museum frameworks.

\subsection{PROSTHETIC ARCHITECTURE}

Tres Grande Bibliotheque is a competition proposal by OMA and is another body of work which builds on the discourse of buildings that map out Posthuman infrastructures. Like much of OMA's work, this project started with a critique of architectural discourse. "At the moment when the electronics revolution seems to melt all that is solid - to eliminate all necessity for concentration and physical embodiment - it seems absurd to imagine the ultimate library." ${ }^{23}$ For Koolhaas, the library program seemed to be paradoxical during the electronic media revolution and the precarity of the library book. The building is set up to represent a solid block of information with the public spaces being defined by the voids in the building diagram (see figure 15). This was meant to create a spatial isolation between the individual library units so that their own logic can dictate their construction while simultaneously occupying the same network. Instead of nondetermined spaces of a uniform flexibility that allows for all kind of changes in size, equipment, and structure of the collection, Koolhaas proposes what he calls 'compartmentalized

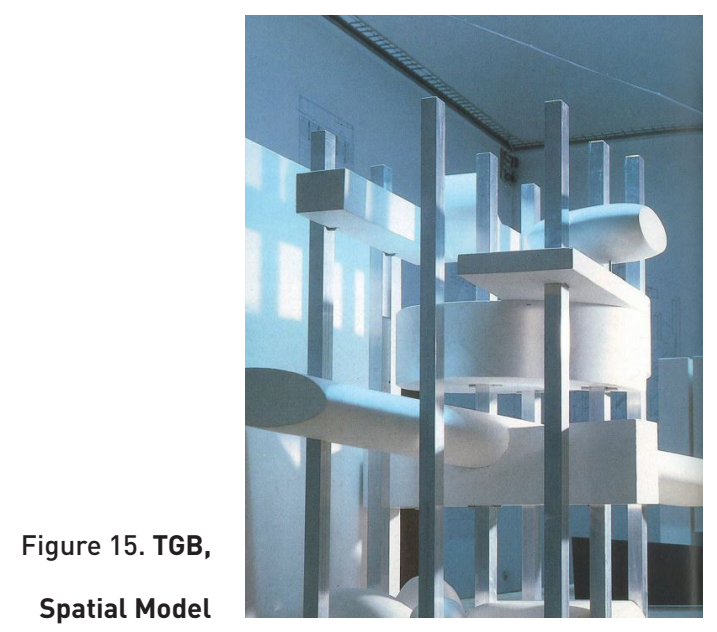

Figure 16. TGB, Spatial Model

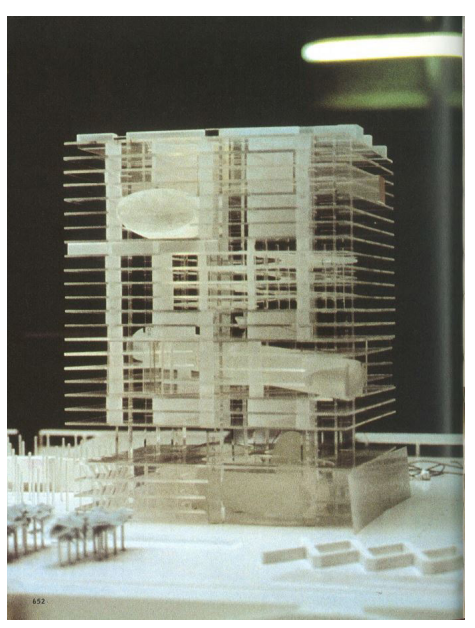

Figure 17. Superim-

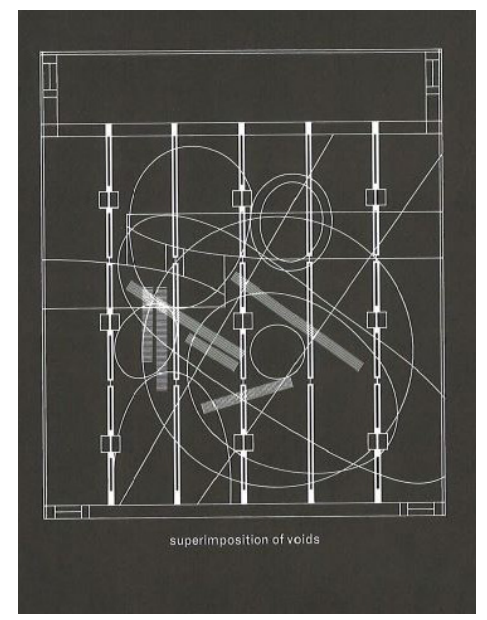


flexibility'. This concept operates with functionality clearly defined by formal units with open spaces in between wile being enveloped by a single structure. The diagram of spatial discontinuity in these spaces are constantly serviced by infrastructure such as escalators, elevators, and ramps becoming key parts of the program. Technological and mechanical systems have had profound implications on the experience of space as it turns previously disconnected areas into a singular continuum. Koolhaas layers multiple systems of operation and program to rid architecture of possibilities it can no longer sustain. Tres Grande Bibliotheque serves to aggressively explore this new-found freedom. ${ }^{24}$ Tres Grande Bibliotheque lays out a library framework that constructs relational systems between artifact and architecture. One of the major themes explored in the Grande Bibliotheque was the destabilization of program and architecture via technology. His thesis was that technology frees much of architecture from its constraints. This explains the formalism and utilization of technological infrastructures throughout the building. His conception of realizing the individual libraries as voids shaped by their own independent logic independent of each other and of the external envelope fell short in realizing the role technologies would later have on architecture. As a result, The Tres Grande Bibliotheque does not consider the inevitable networking of infrastructures that comes to define the Posthuman condition. 


\section{NOTES}

16 Le Corbusier. Modulor: A Harmonious Measure to the Human Scale and the Universally Applicable to Architecture and Mechanics. (London, Faber \& Faber 1961) p. 28

17 lbid. 60

18 Mathews, Stanley. “The Fun Palace as Virtual Architecture: Cedric Price and the Practices of Indeterminacy."

(London, Back Dog Publishing 2007) p.43

19 Mathews, Stanley. From Agit Prop to Free Space: The Architecture of Cedric Price. (London, Taylor \& Francis 2009) p.70

20 Mathews, Stanley. “The Fun Palace as Virtual Architecture: Cedric Price and the Practices of Indeterminacy."

(London, Black Dog Publishing 2007) p.44

21 Naredi-Rainer, Paul von. A Design Manual: Museum Buildings. (Basel, Birkhauser 2004) p.175

22 lbid. 176

23 Koolhaas, Rem and Bruce Mau. "Strategy of the Void" in S,M,L,XL: Office for Metropolitan Architecture.

(New York, The Monacelli Press 1998) p.606 


\section{3}

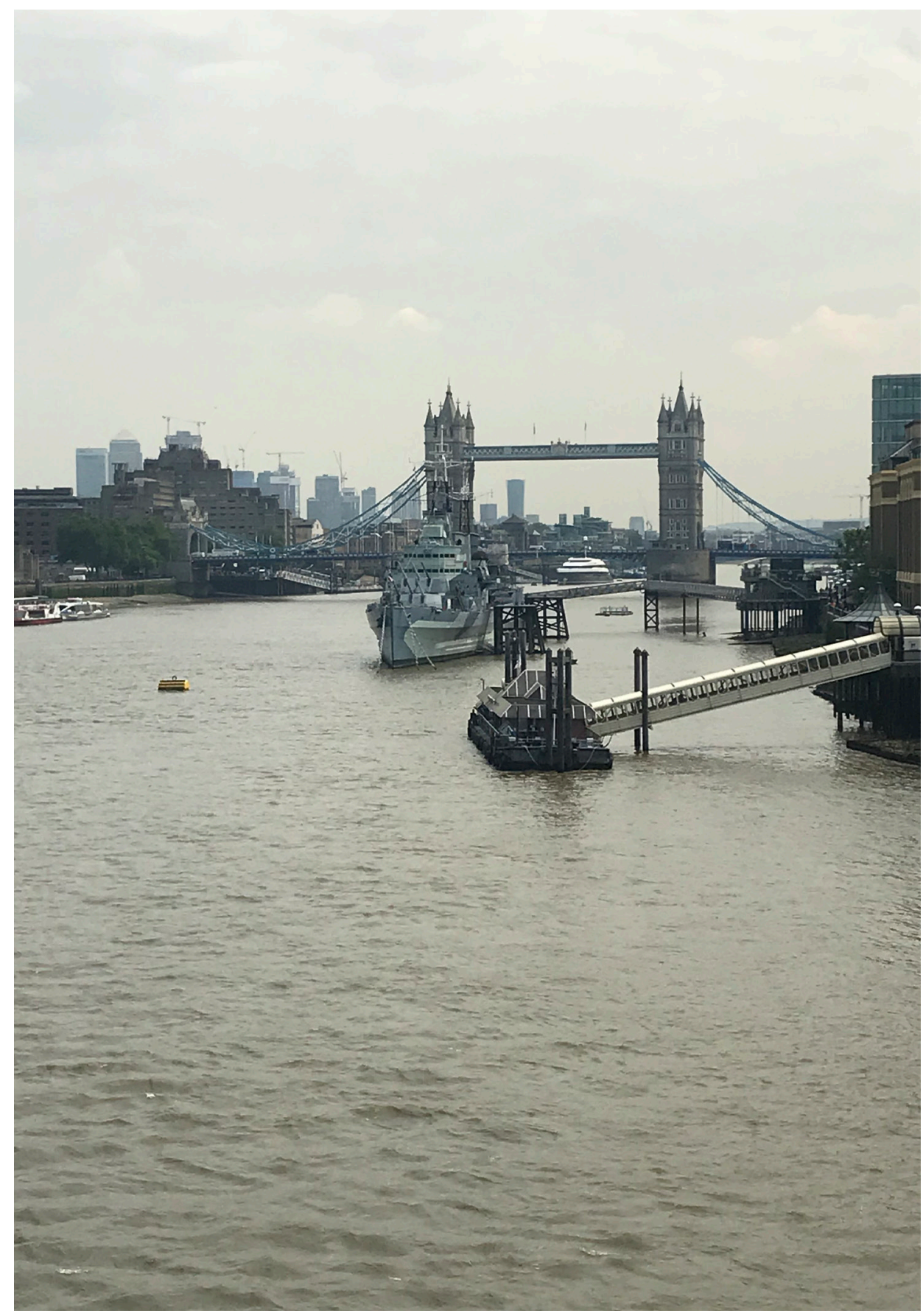

MUSEUM PARAMETERS 
In an environment with ubiquitous computing and technology there exists a hyperconnected global territory inhabited by human and non-human actors. This thesis utilizes the museum typology because of the inherent relational structures that are unpacked as a mode of operation. The nodes that constitute this network: space, artifact, and user occupy inherently different territories but coalesce into one within the architecture of the museum. As a museum infrastructure, the system utilizes these parameters to deconstruct the normative museum and speculate on the nature of a Posthuman museum and the nature of the architectural and infrastructural formal systems that would be required.

The Posthuman globalized landscape has given way to territories and networks that span the entire globe. The city of London has been identified as the site for this thesis because of its history as being one of the first cities to act as a central node for global economic and cultural migrations in the contemporary sense. Few cities symbolize urban development and globalization more than London, home to 300 different languages, and a large multinational population. Furthermore, this is reflected in a capital system where $40 \%$ of the world's foreign equities are traded on the London stock exchange. This diversity is reinforced as the United Kingdom is home to one of the largest artifact collections in the world numbering in the region of 200 million individual artifacts from every part of the world. ${ }^{25}$ Historically, The Great Exhibition also known as the Crystal Palace Exhibition held in Hyde Park is significant in the development of a global exhibition framework that would later materialize into the circuit of World Expositions that continued throughout the $20^{\text {th }}$ century and well into the $21^{\text {st }}$. Crystal Palace is also synonymous with the co-evolution of industrial process and architectural design methodologies that became much more critical in the Modernist movement and which continues largely in present day architectural discourse.

The site, adjacent to Tower Bridge, is located on the Thames river in the borough of Southwark. This site was chosen as a territory for the deployment of a museum infrastructure due to its proximity and density in a variety of already existing hard and soft infrastructural systems. The Thames river is also a natural starting point as it was a critical infrastructure that led to not only the development of London's vast infrastructural systems but also of the existing museum network. These infrastructures include the rich urban fabric that is host to a diverse typology of buildings that range from large residential clusters, to political buildings such as London City Hall and other commercial and economic hubs. The site is also rich in historic and cultural buildings and infrastructure such as Tower Bridge and the Tower of London located on the north side of the Thames river. In 
addition, hard infrastructural systems such as the expansive tube and rail network alongside the endless pedestrian and vehicular networks produces a territory rich in infrastructural possibilities. The project revolves around developing an architecture that plugs into a host of urban infrastructures that provide access to the large collection of artifacts and users found at the local and global scale.

Figure 18. Site Context 


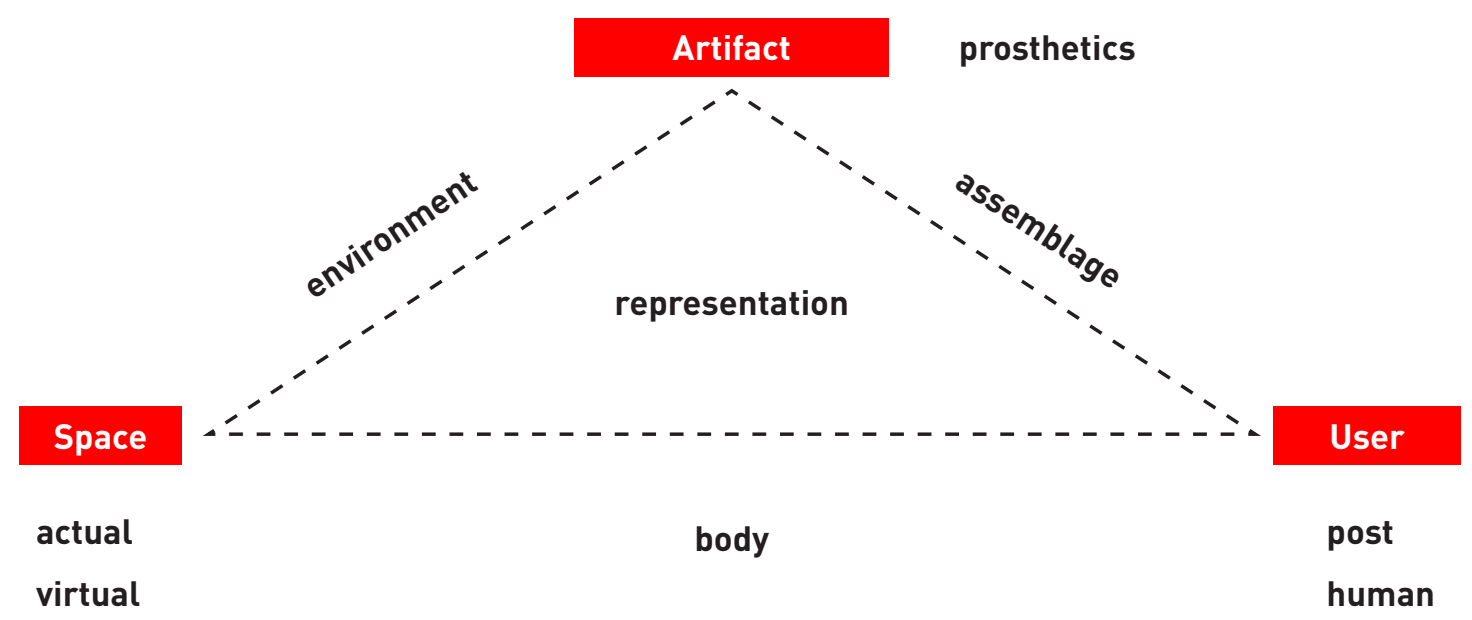

\subsection{SPATIAL CONSTRUCTIONS}

The Posthuman paradigm is radically different from a traditionally anthropocentric view, one that mobilizes the concept of the human actor as a phenomenon that occurs across multiple substrates. Ubiquitous material and informational prosthetics facilitate a wide field of spatial structures for Posthuman actors. As a result, prosthetics have become mediating tools which allow users to traverse and construct diverse spatial arrangements. This fundamentally alters traditional assumptions that space is a neutral entity that exists as separate from human actors. In a Posthuman architecture there are no spectators, only participants in evolving spatial conditions. Through technological mediation, new spatial networks emerge at a variety of scales and in virtual mediums as well. Martin
Heidegger's understanding of the relationship between the human condition and space is that there is an existential connection between the two. He believes that there is no separation between Human and Space, they coexist with one another. "When we speak of man and space, it sounds as through man stood on one side, space on the other. Yet space is not something that faces man. It is neither an external object, nor an inner experience. It is not that there are men, and over and above them, space..."26 The spatial world is constructed around the self. A Posthuman thesis suggest that our sense of self is filtered and constructed through our prosthetic extensions. Furthermore, a Posthuman view on space eliminates any notion of this dichotomy of human and space as two separate entities. 
1. Outside

(1950s-1960s)

Museum

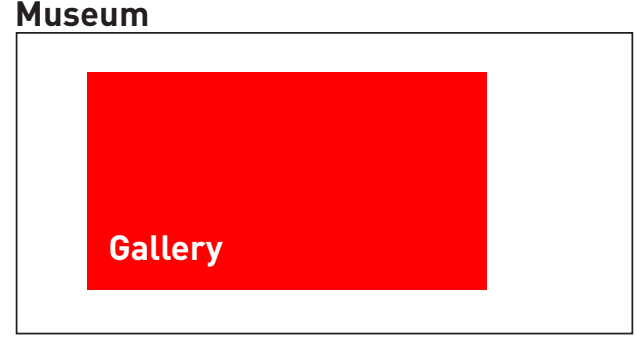

\section{Selectively Inside}

(1970s)

Museum

\section{Gallery}

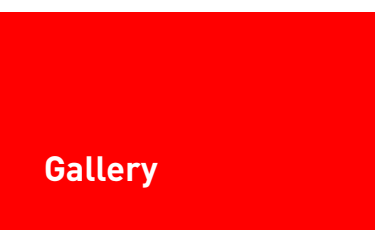

\section{Contained}

(1980s-1990s)

Museum

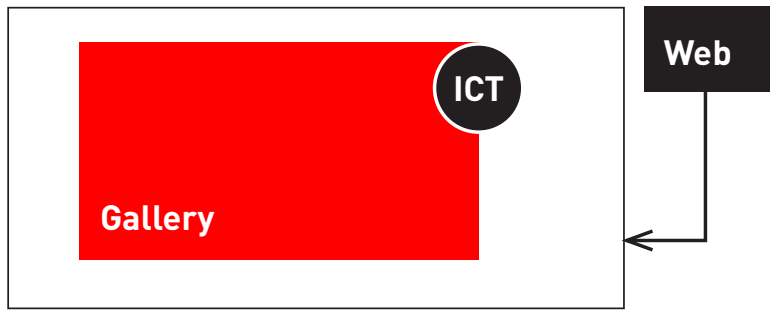

Our prosthetic enhancement and pervasive infrastructural systems allow human actors to develop their own spatial conditions and experiences. Posthuman architecture revolves around developing a spatial logistics as a prosthetic to enable this function.

In the context of the museum, spatiality only exists in relation to both user and artifact. In a Post-modern and Posthuman paradigm, where representations are constantly shifting, normative museum space has been completely destabilized. In Figure 20, from Space and The Machine we can see the increasing use of information and communications technologies in the museum

\section{Integrated}

\section{(2000s)}

\section{Museum}

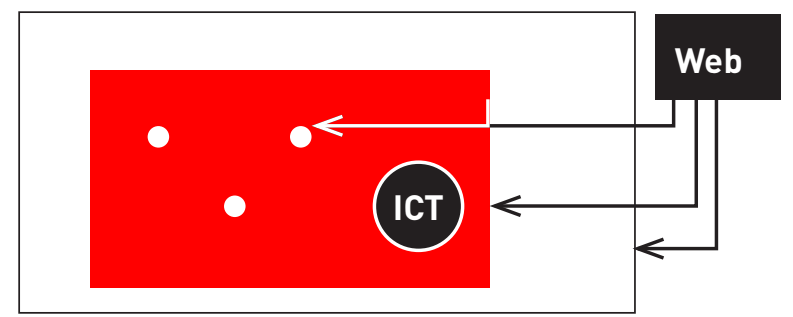

\section{Innate}

\section{(emerging)}

\section{Museum}

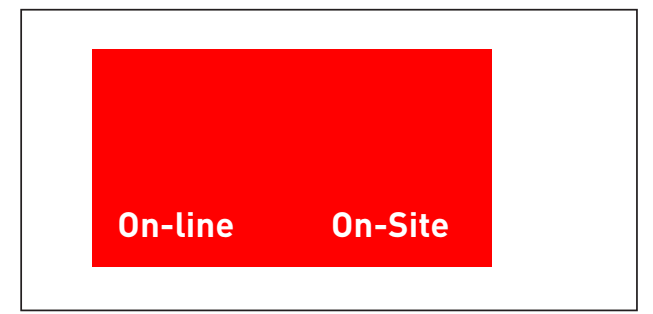




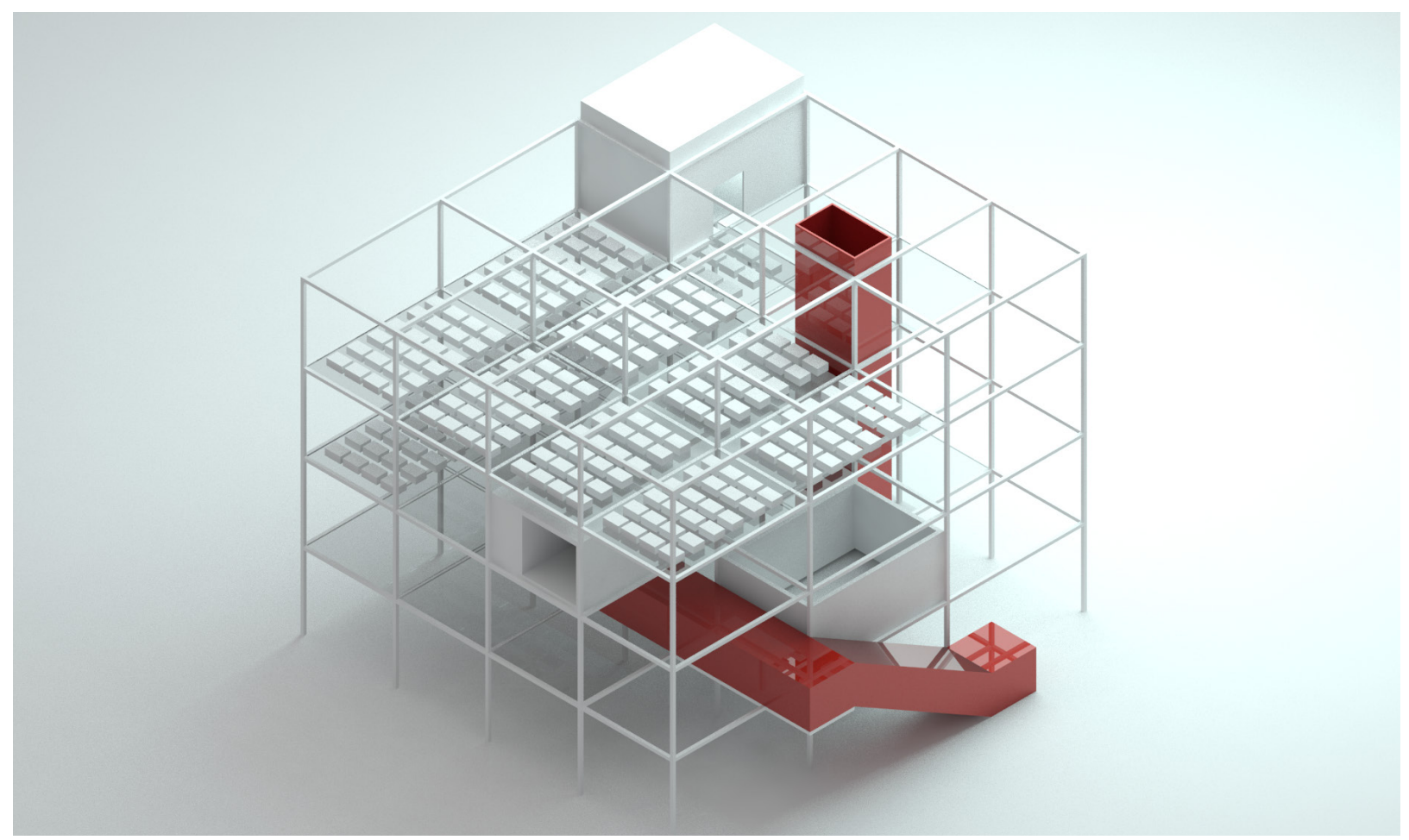

Figure 21. Spatial Concept, Iteration One

typology. ${ }^{27}$ Starting from the modern era in the 1950s where technologies began to play an increasingly important role in architecture, we have seen an exponential increase in the integration of information and communication technologies to the present day where actual spaces are simultaneously on-line and on-site. The innate museum requires us to fundamentally rethink the spatial and programmatic arrangement of the museum typology. Museum spatial strategies must intensify and constantly reconstruct interactions between space, user, and artifact rather than operating in isolation. The innate museum is uncovered and found within territories rather than developed and designed.
In the first concept iteration, the spatial strategies of the museum framework revolve around a system for accommodating growth and flexible exhibition networks. Deploying modular structural frameworks for the development of compartmentalized flexibility and organic spatial reconstructions that are in turn mediated by architectural and technological systems is an important starting point. This structural framework also provides an architectural logic for outward growth in response to fluctuations in artifact and exhibition requirements. Static spatial boundaries in the face of fluctuating artifact collections has been identified as an opportunity to open a networked connectivity 


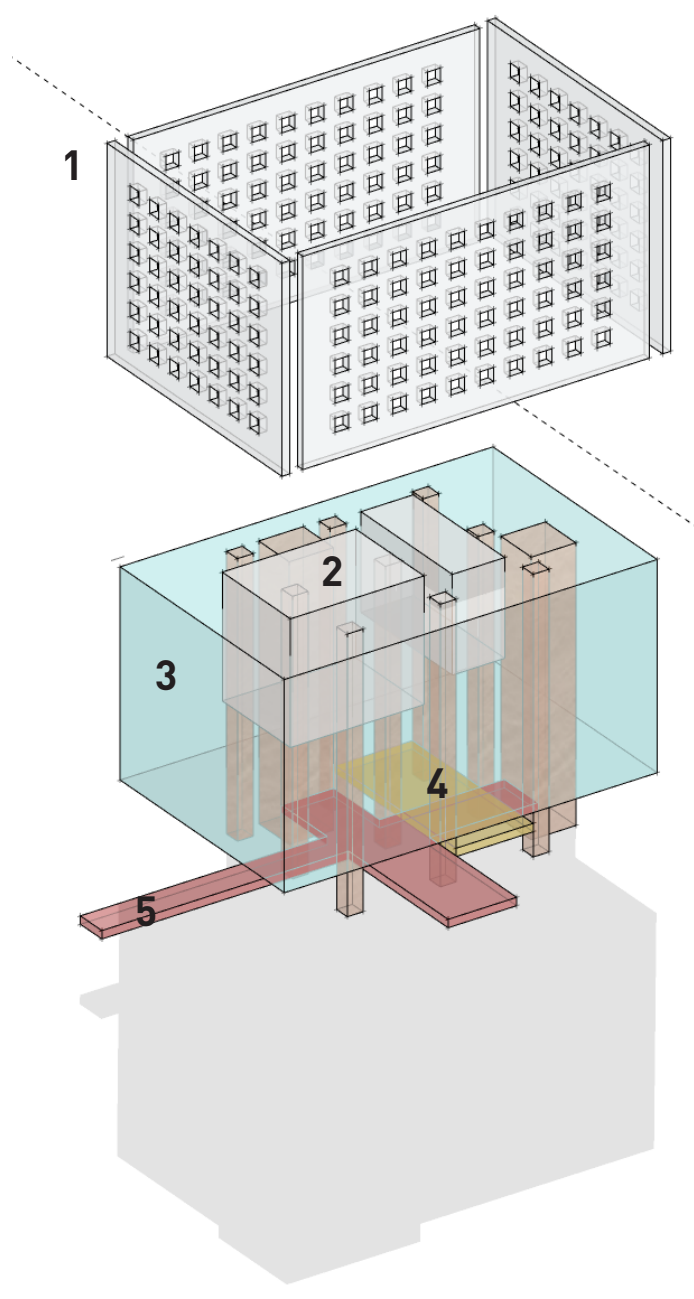

Figure 22. Spatial Concept, Iteration Two

\section{LEGEND}

$\begin{array}{cc}1 & \text { Envelope } \\ 2 & \text { Exhibition } \\ 3 & \text { Artifact Preservation \& } \\ \mathbf{3} & \text { Storage } \\ \mathbf{4} & \text { Interior Circulation } \\ \mathbf{5} & \text { Exterior Circulation }\end{array}$

within the museum. This framework makes possible further opportunities for the development of a Posthuman narrative, one that does not revolve around static curation models but rather one that revolves around shifting architectural and technological systems throughout the museum infrastructure similar to the dynamic models utilized at the Centre Pompidou.

Furthering important themes found in the first iteration of the spatial strategy, the project establishes through programmatic relationships, a new operating strategy that lends itself to infrastructural logic. The main block of program will be the storage and preservation of museum collections and artifacts. This provides a framework for carving out and developing exhibition space that are responsive to collection fluctuations while also reterritorializing the relationship between artifact and exhibition room. The programmatic arrangement also engenders a dynamic museum narrative that is facilitated by traversing artifact storage areas rather than curated and static exhibition frameworks. Most importantly, this spatial strategy provides opportunities for the architectural tectonics to mediate between the environment and user-artifact network rather than continually reinforcing the isolation of these interconnected systems found in the contemporary normative museum. As a result, the Posthuman museum develops an architectural infrastructure system 
that gives agency to both human and non-human actors in the network. Spatiality is no longer an exterior entity to artifacts and users but rather is a product of their constant fluctuation and assembly.

\subsection{ARTIFACT}

Posthuman perspectives have had profound impacts regarding how we develop and understand cultural artifacts. Marshall McLuhan suggests that important parts of people all become things, in affect constituting a translation of the human being into alternative forms. ${ }^{28}$ If a civilization in the distant future were to study Posthuman artifacts, what could they infer about the civilization that made and used them? In determining the cultural landscape artifacts map out, they would discover embedded in each Posthuman object the global economic and manufacturing processes behind them. A key characteristic of how we produce and manufacture cultural artifacts today, including architecture, is the reliance on autonomous tools and non-human actors.

\section{Michel Foucault proclaims that libraries and} museums are heterotopias because they present utopian, unreal conditions in real sites. ${ }^{29}$ Museum spaces are determined by a clear set of cultural values and as a result form a boundary condition, one defined by an inside-outside threshold relationship. This is further compounded because museums perform a complete break with the common notions of time by presenting different slices of time simultaneously. ${ }^{30}$. Historically speaking, an artifact is anything created by humans which gives information about the culture of its creators and users. They offer insights into technological process, means of economy, and most importantly social and cultural structures. Anywhere an artifact has cultural meaning, it gets significance from and contributes significance to the qualities of the locations it occupies and the other inhabitants of those spaces. That is why the contemporary museum is both on-site and on-line to facilitate multiple levels of interaction. In the Post-Modern condition, the multiple representations and readings of an artifact become an important part in understanding what constitutes the artifact assemblage in its entirety and therefore its cultural significance. The Posthuman is so intertwined with the artifacts of everyday life which themselves inscribe in them the predominant technological process, social and economic structures that they have become perfectly embedded into those very things. Thus, the Posthuman identity is defined by the assemblages it embodies. The Posthuman museum will not only house and display actual artifacts but also immaterial virtual artifacts that exist in the virtual networks and digital landscapes in our everyday culture. By pursuing a museum infrastructure in which both spatial assemblage and artifact networks are rendered 
legible, interaction by Posthuman actors allows them to engage in this territory and explore their prosthetic body. These systems as a result trace the Posthuman contours. 


\subsection{FROM USERS TO ACTORS}

In the Posthuman there are no essential differences or absolute demarcations between bodily existence and computer simulation, cybernetic mechanism and biological organism, robot teleology and human goals.

\section{N. Katherine Hayles, $1991^{31}$}

In increasingly networked environments that are populated by more non-human than human actors, it is important to understand what agency a Posthuman actor has in this system. Central to Posthumanist theory is to eliminate the boundaries between human and non-human actors. As such, these alternative compositions and bodies produce multiple identities and ontologies. Lived experience is increasingly mediated by technological artifacts. Subsequently, we continuously traverse multiple thresholds between user and artifact, human and thing. Posthuman identity is constituted by semiosis, the represented body that, mediated by technology, overlaps with the enacted body. This critical moment in Posthuman construction occurs when the individual is inserted into a network where the enacted bodies and represented bodies join. Thus, the Posthuman user represents a node in larger networks able to operate at multiple scales. Architectural frameworks are part of this larger network where new spatial assemblages are constructed in dynamic processes. The Posthuman museum must develop architectural infrastructures that give agency to both human and non-human actors. The image, figure 23, from Army Logistician published in 1983 links buildings, objects and data with computational logic and inserts them into their protocols and data sets. ${ }^{32}$ The presence of the human operator as an exterior entity to that logic falls short in exactly how entangled the body is within these larger systems. Figure 24, expands on this image and includes the human operator as an equal data set in the spatial assemblage portrayed. Users shift to actors within architectural systems because prosthetics places the body simultaneously in physical and informational systems.

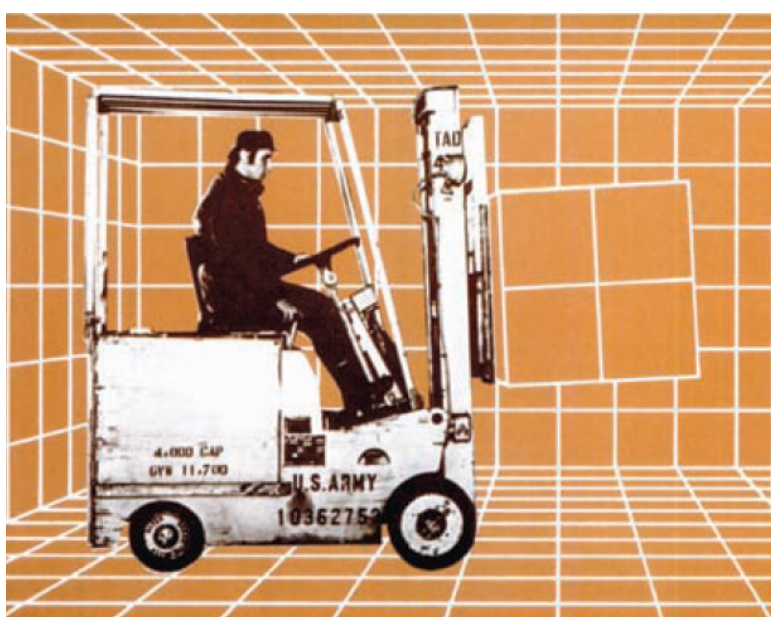

Figure 23. Modeling the Wholesale Logistics Base 


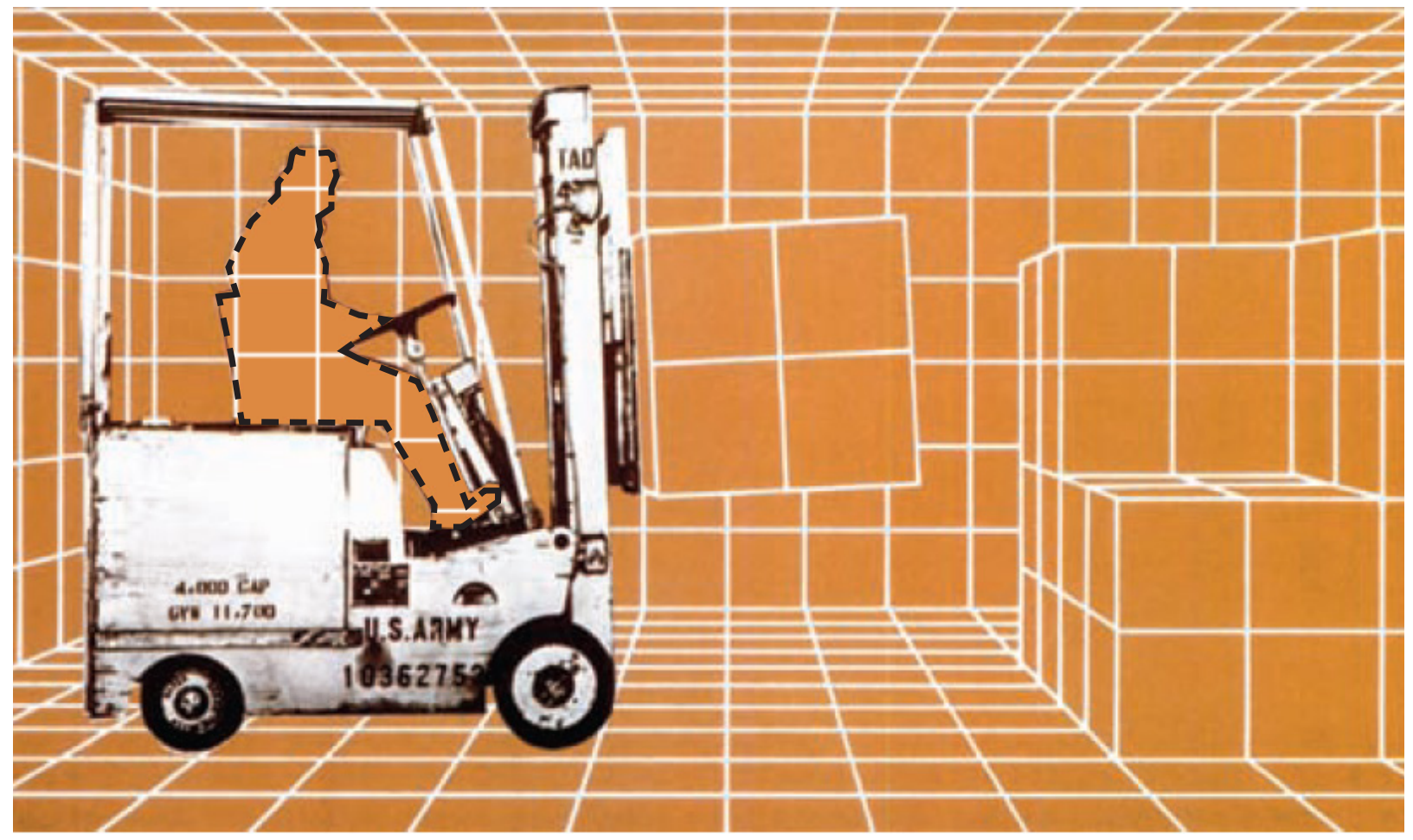

Figure 24. User as Data within the Environement

\section{NOTES}

25 Keene, Suzanne, ed. Collections for people: Museums' stored collections as a public resource. (London, UCL institute of Arcaeology 2008) p.40

26 Leach, Neil. "Martin Heidegger ." In Rethinking Architecture: A reader in cultural theory,

by Neil Leach (New York, Taylor \& Francis e-library 2005) p.101

27 Parry, Ross and Andrew Sawyer. "Space and the Machine: Adaptive museums, pervasive technology and the new gallery environment." in Reshaping Museum Space. (New York, Routledge 2005) p.45

28 McLuhan, Marshall. Understanding Media: The Extensions of Man. (New York, McGraw Hill 1964) p. 23
29 Bock, Ingrid. Six Canonical Projects by Rem Koolhaas. (Berlin, Jovis 2015) p. 676

30 lbid. 678

31 Hayles, Katherine N. How We Became Posthuman: Virtual Bodies in Cybernetics, Literature, and Informatics. (Chicago, University of Chicago Press 1999) p. 45

32 Lecavalier, Jesse. The Rule of Logistics: Walmart and the Architecture of Fulfillment. (Minneapolis, University of Minnesota Press 2016) p. 32 
4

POSTHUMAN PARAMETERS 


\subsection{MUSEUM INFRASTRUCTURES}

In the past two decades, the concept of network cities or urban networks is due to discussions situated within larger discourses around the notion of the network society. ${ }^{33}$ Networks mobilize technical instruments to engineer large-scale urban territories. What is equally important is identifying and understanding inherent museum networks and artifact territories existing in the city of London. Only once these two systems have been reconciled and brought into focus can a museum network engineer urban territory. By utilizing embedded logic found across urban areas, existing networks have the capacity to integrate different institutions, museums, and user groups forming unique relational structures. Urban infrastructures should be able to accommodate a diverse set of conditions that promote different scales of activity to flourish. Infrastructural systems consist not only of physical structures but also their encoded operation procedures, administrations, bylaws, natural processes, and end users. The project as a result is focused on an intervention that is multi-dimensional, multisectorial, and multi-scalar to enhance existing networks and facilitate new networks. Spatial strategies discussed in earlier chapters not only revolve around reinterpreting existing museum structures but also creating and reinterpreting the existing logic of the territory. Network is used in this thesis as a strategy for the local, taking advantage of large systems to identify the potential of the place to change a space that is reprogrammed into a place of contact, as nodes with the capacity to re-codify and change over time, injected with the ability to receive new inputs and produce new outputs as a result.

Understanding the existing museum landscape within the City of London is vital in order to further develop an infrastructure system in its service of that. This study was undertaken by University College London to understand a vast collection of 200 million artifacts are mapped out across the United Kingdom and how they are being utilized. Central to the idea behind developing a museum infrastructure is to change the concept of museums believing that their collections are private property to the idea that their collections are a public resource and therefore should become a layer of public infrastructure. The spatial dilemma of the museum is the constant negotiation between fixed exhibition areas and fluctuating collection sizes. As a result of this research, when investigating what the key obstacles are to the greater use of artifacts, $62 \%$ of museums respond that space is a main obstacle. Furthermore, $43 \%$ of museums recognize that user connections make the most difference to the maximum use of the collection. Although many factors affect the dynamic relationship users have with artifacts in the normative museum, the study points out two key architectural 
problems that this thesis proposes to address. The study indicates that $95 \%$ of collections were kept in storage. With museums providing access to only $5 \%$ of artifact collections, it is clear that static museum structures are unable to accommodate dynamic fluctuations. This is a fundamental priority for developing the museum as infrastructure, one that responds to fluctuations in the museum network. Stored artifacts have been chosen as the primary collection to be processed within the Posthuman user because demarcations such as stored and exhibited fundamentally create isolated systems rather than opening up networked possibilities. This Is achieved by developing the museum as an off-site artifact centre that organizes within broad collections. This is found to be more stimulating and eliminates the need for curatorial structures allowing for the development of organic user narratives. How does the coupling of museum networks and infrastructural logic coalesce into a potential museum infrastructural logic? Infrastructures driven by information are more adaptive and can reconfigure themselves in response to supply and demand. This integrated system allows supply, consumption, and control of many styles or locations helping with redundancy and the resiliency of the overall system. Museum as infrastructure in the City of London supports the flow and processing of under utilized artifacts and as a result strips away existing curatorial and exhibition structures that are instead constructed by user narratives. 


\subsection{DESIGN STRATEGY}

An operative strategy was designed utilizing parametric scripts for the purposes of analyzing and redistributing existing museum nodes. Parametric scripts in grasshopper were identified as an optimal design tool because of the capacity to integrate multiple data streams in the pursuit of developing an architectural logic, refer to appendix A for further detail on the structure and operations involved in the grasshopper script. The operative strategy was developed in three distinct parts:

1. Identify and quantify existing museum nodes within the city of London.

2. Cross-reference existing museum stored collections and redistribute artifacts to multiple sites.

3. Through combinatorial iterations develop dynamic infrastructural logics that form the foundation for a museum project. 

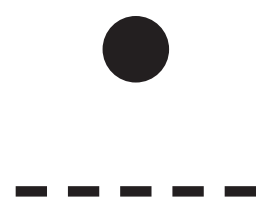

8 km Radius

Tube Network

\subsubsection{STEP 1: IDENTIFY MUSEUM NODES}

The first step to approaching the developing of an infrastructural logic was to identify existing nodes within the museum framework in the City of London. The plotting and categorization of collections in each museum through the cross-referencing of data from the University of College London study allows for a network of stored artifacts to emerge. Figure 25, maps out 55 major museum buildings in London for the purposes of quantifying their geographic proximity in relation to Potters Fields park. The map also plots out network relationships such as the density of museums located in close proximity to the Thames River and also the scarce density found in the East end. This mapping also brings forward already existing relationships between museums and urban infrastructures such as the tube system and Thames river. It should be noted that this map does not plot out galleries or art show rooms because they are outside of the scope of this thesis. Appendix A has a more detailed breakdown of how this map was constructed. 


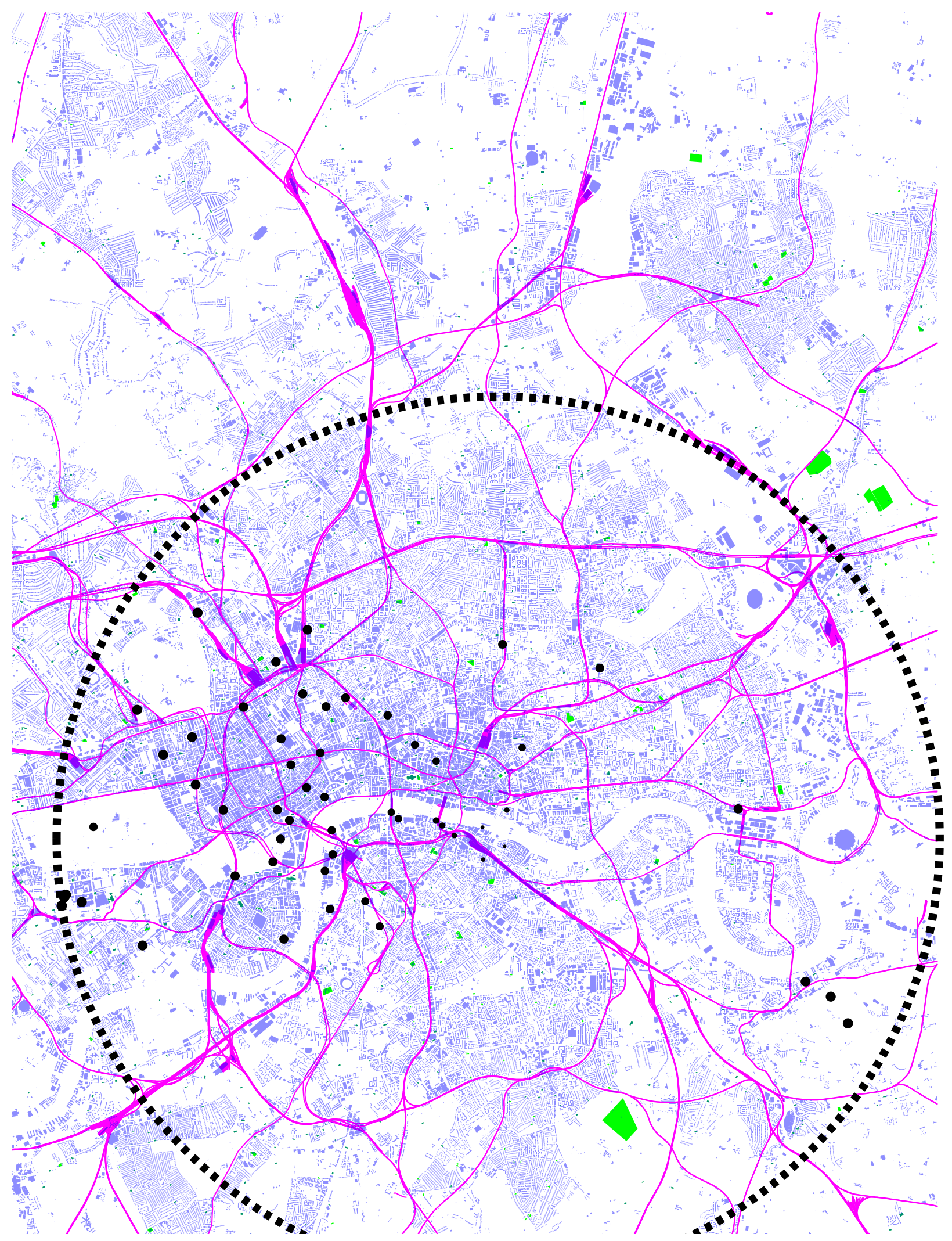




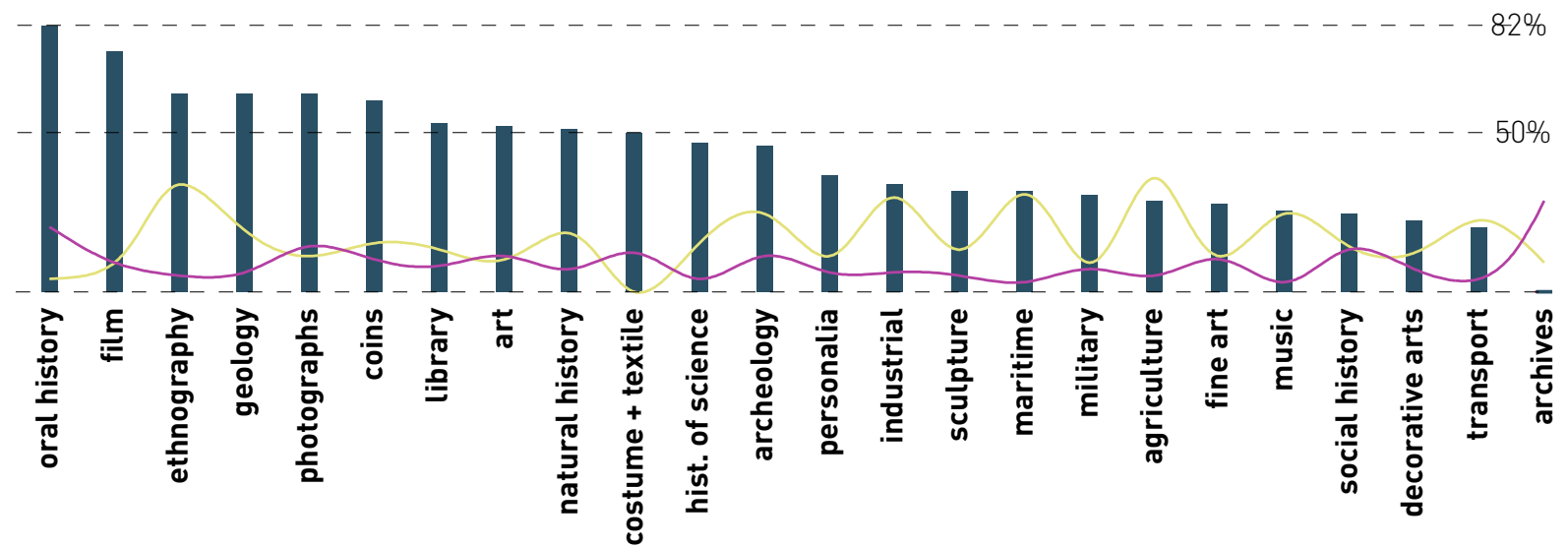

AVG. IN STORE

AVG. OFFSITE

$\%$ OF MUSEUM

Figure 26. Artifact Storage Data

extracted from the UCL study that documents artifact collections across the United Kingdom. This plots relationships between museums and their collections use.

\subsubsection{STEP 2: REDISTRIBUTE THE NETWORK}

Following the plotting out of existing museum nodes on the London urban territory, the next step involves the redistribution of artifacts throughout the city based on geographical proximity to potential sites engendering new museum territories. The redistribution logic is primarily based on geographic proximity relationships plotted out in step 1. Collections further away from the central node are given a greater weight as opposed to collections that are closer to the intended site. The intention behind redistribution logics based on geographic proximity is to facilitate increased representation of collections across an urban territory and reterritorializing artifacts into new spatial assemblages and contexts. This parametric logic is non-determinate and open ended. The process is developed as a potential urban logic that can be applied to a diverse number of sites across the city. This deploys an artifact network across the city while also being dynamic and responsive to fluctuations in collections sizes across the existing city museum network as they determine the overall collection of this new museum. 


\begin{tabular}{l}
\hline coins \\
\hline archives \\
transport \\
industrial \\
\hline agriculture \\
\hline
\end{tabular}

archeology
history of science
geology

oral history personalia
ethnography maritime
library

film
photographs
art
costume + textile
sculpture
fine art
music

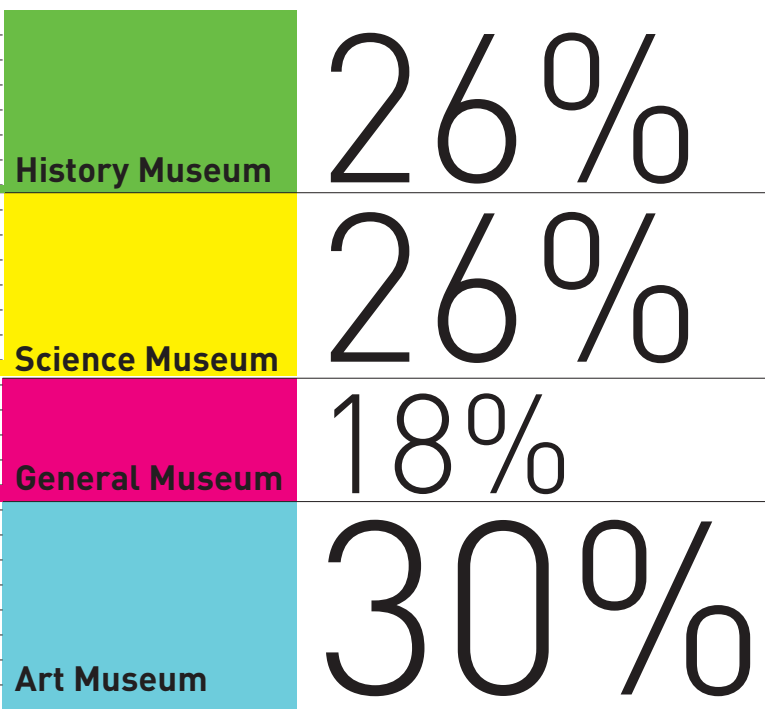

Figure 27. Museum classifications

Classifications are broken down in the redistribution process. Using open-ended classification systems allows for more stimulating exhibition structures allows for organic

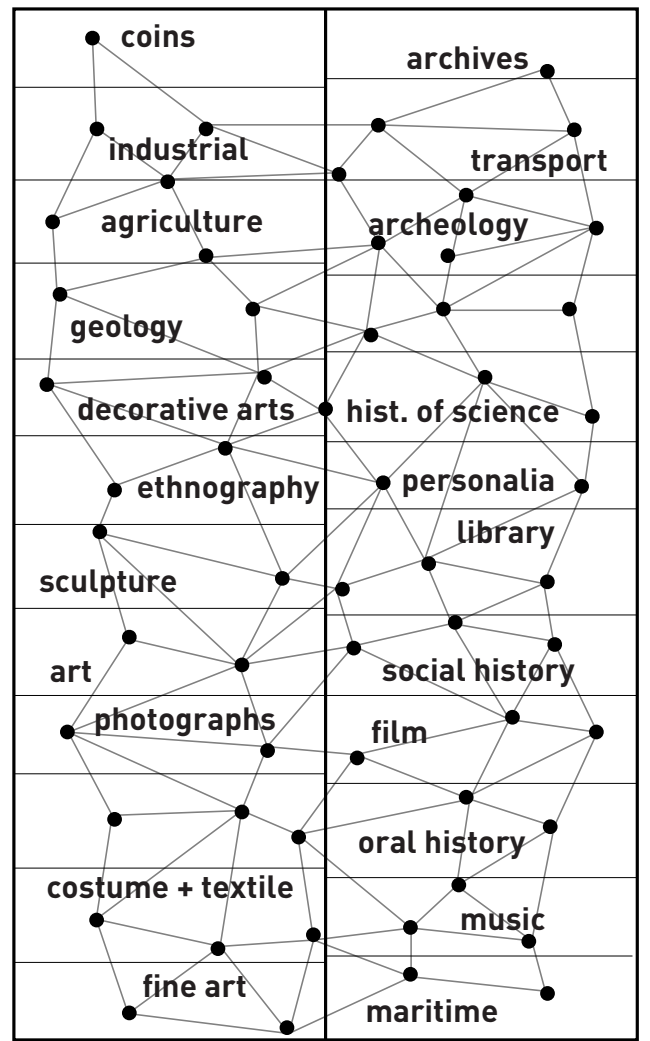

user narratives

Figure 28. The Redistributed museum

This network brings forward new posibilities for artifact collections that are traditionally kept seperate. 

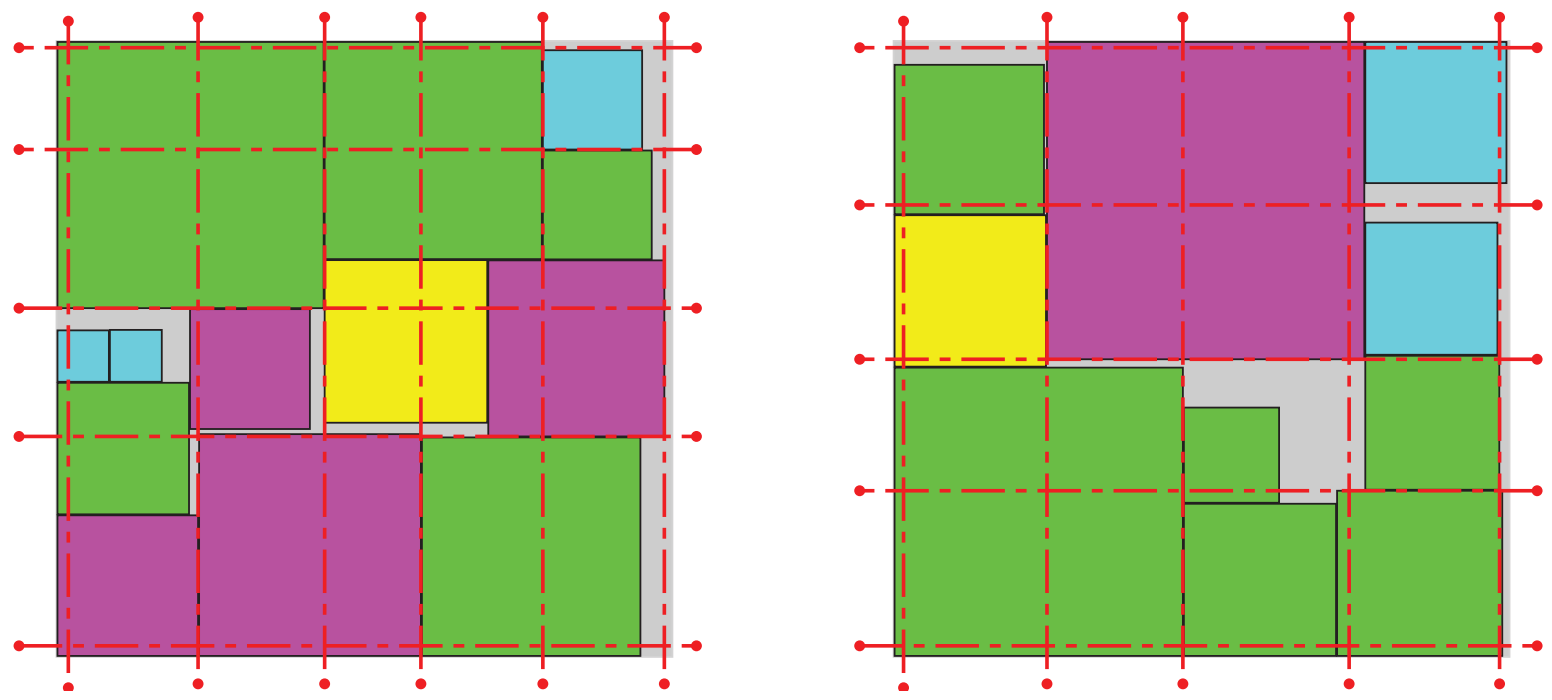

Figure 29. Combinatoric Iteration 1

\subsubsection{STEP 3: COMBINATORIAL SYSTEMS}

Finally, the combinatorial nesting of collections on the site provides the framework for the development of the museum as an outcome of infrastructural logics. The museum is extended beyond the outline of its shape but also the infrastructural matrix space that buildings occupy. The nesting exercise was iterated into several forms that began to illustrate efficiencies and logics that would arise and develop. Hard and soft architectural infrastructures such as structure and programmatic arrangement as a result become emergent properties of the combinatorial logic implemented in the design strategy. The museum network was divided into four classification systems that gave an

overall broad structure to artifact collections. They were organized into the general museum, the history museum, the art museum and the science museum. It has been noted that classification of objects has had a direct bearing upon curation and strict exhibition structures. In addition, the UCL study also points out that the complex artifact classification system affects the profile of distribution. ${ }^{34}$ Categorical structures are evolving structures subject to debate and fluctuation changing the nature of object relations. A museum as an infrastructural logic has the capacity to adapt. Using open-ended classification systems allows for more stimulating exhibition structures and eliminate the need for curations allowing for the development of organic user narratives. 

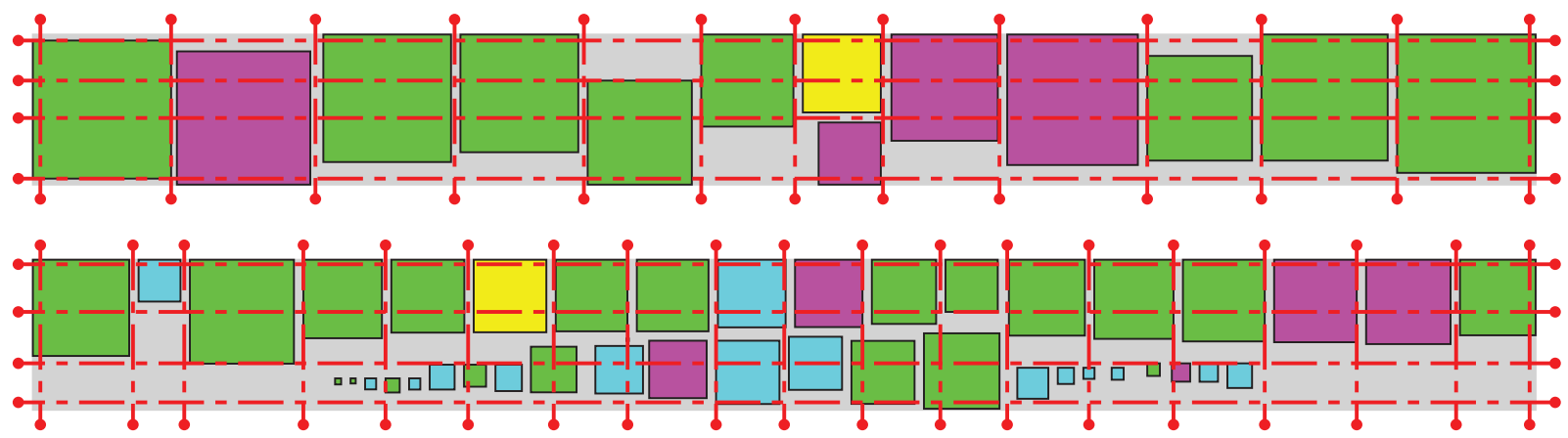

History Museum

Science Museum

Figure 31. Combinatoric Iteration 3

\section{GeneralMuseum}

Art Museum
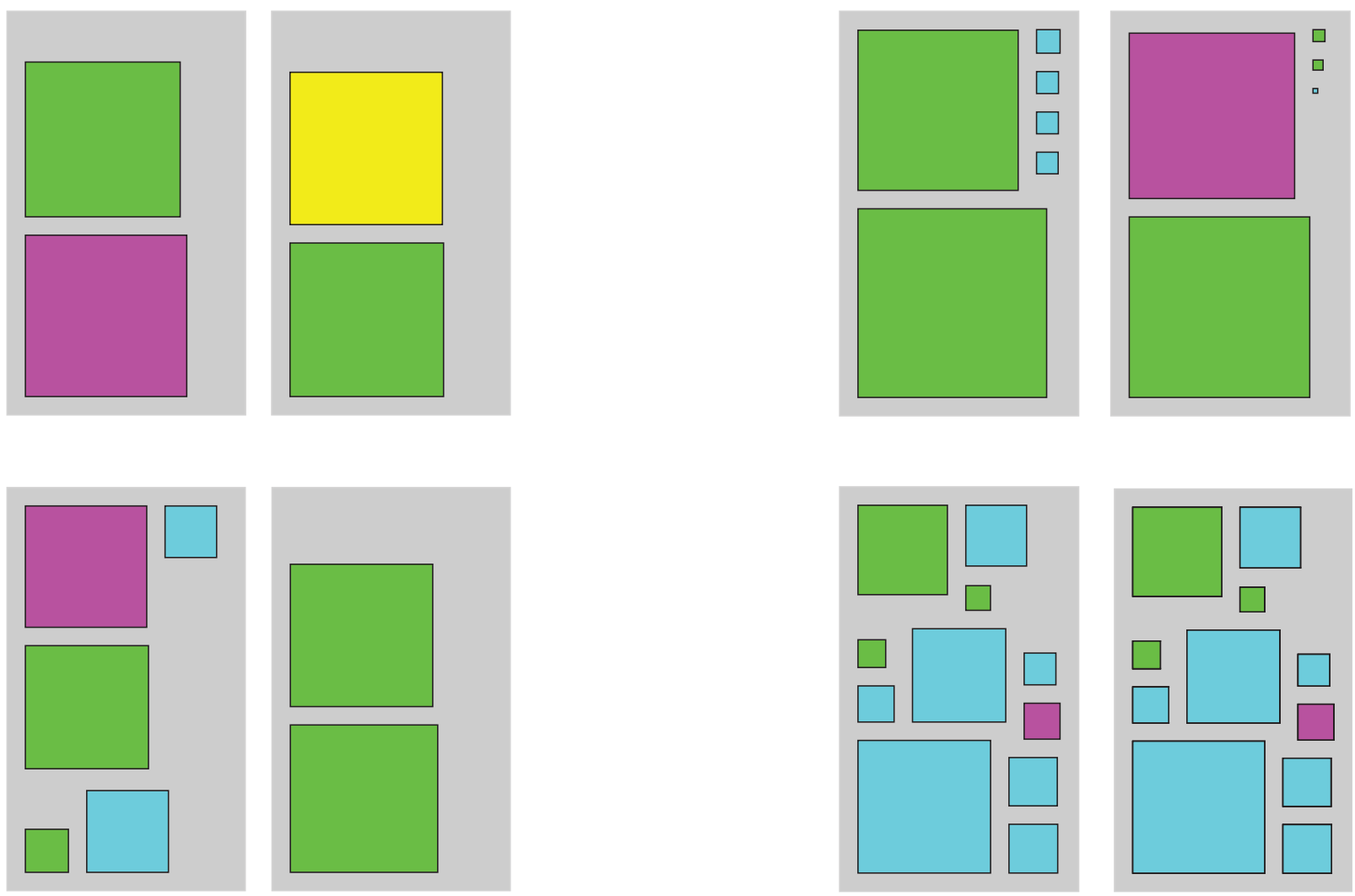

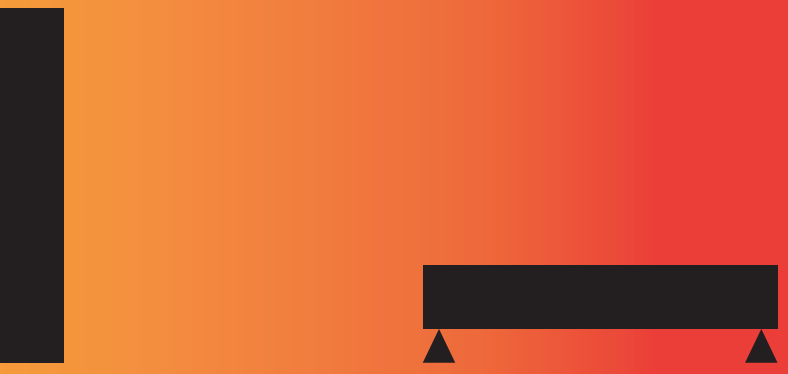

Barge

Figure 32. infrastructure explorations

\subsection{INFRASTRUCTURE SYSTEMS}

Once an operative logic was developed, an iterative process of developing new museum frameworks was undertaken to analyze the museum typology in new spatial compositions. Each iteration revolves around critical typologies in the city of London. Utilizing the operative logic, the museum was iterated as a point tower structure, a barge system along the Thames and a bridge. Each iteration provides new perspectives into the functioning of a Posthuman museum construct. These iterations utilize space frame structural systems to give form to an architectural expression moving forward. 


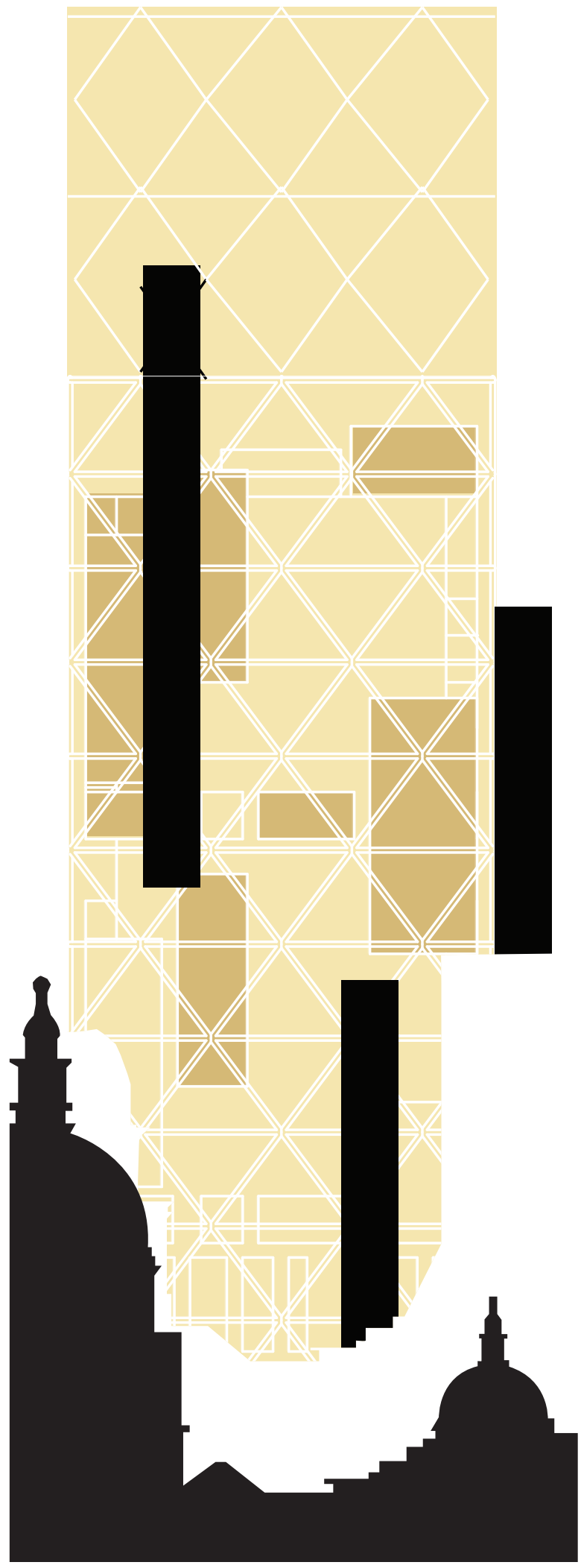

\subsubsection{TOWER}

London's skyline is iconic, dynamic, and a work in progress reflecting competing political and social trajectories. Iconic towers such as the Gherkin, the Shard, and the Heron tower produce a skyline reflective of its global economic status. A skyline although, is not merely the silhouette of an urban territory but also embodies dynamic local and global trajectories. Vertical towers also transcend the boundaries of their own city and assume the representation of nationhood. That is why the tower was one of the first typologies explored for a possible museum structure.

Coupling $21^{\text {st }}$ century concepts of urban towers as representations of global status with traditional colonial symbols of power such as the museum generates. Verticality is the main strength in this typology as it can respond to ongoing fluctuations in both the flow of users and artifacts by extending frameworks higher. The point tower is also a symbolic representation of nodes that plug into urban infrastructures.

Figure 33. Museum as Tower in the London Context 


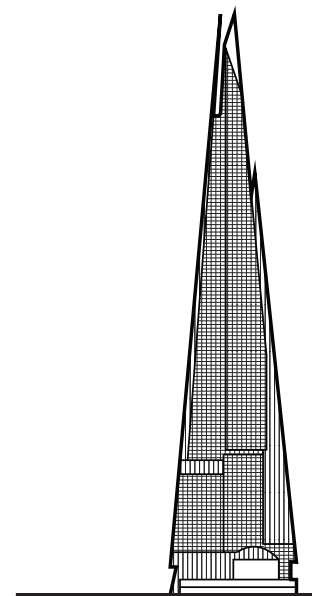

The Shard

$310 \mathrm{~m}$

Comm/Res.

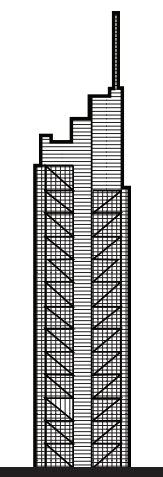

Heron Tower

$202 \mathrm{~m}$

Comm.
122 Leadenhall St. $\quad 30$ St Mary Axe.

$224 \mathrm{~m}$

Office.

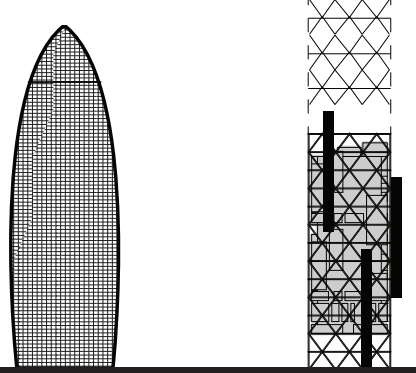

Tower Museum

$135 \mathrm{~m}$

Museum.

Figure 34. Museum as Tower in the London Context
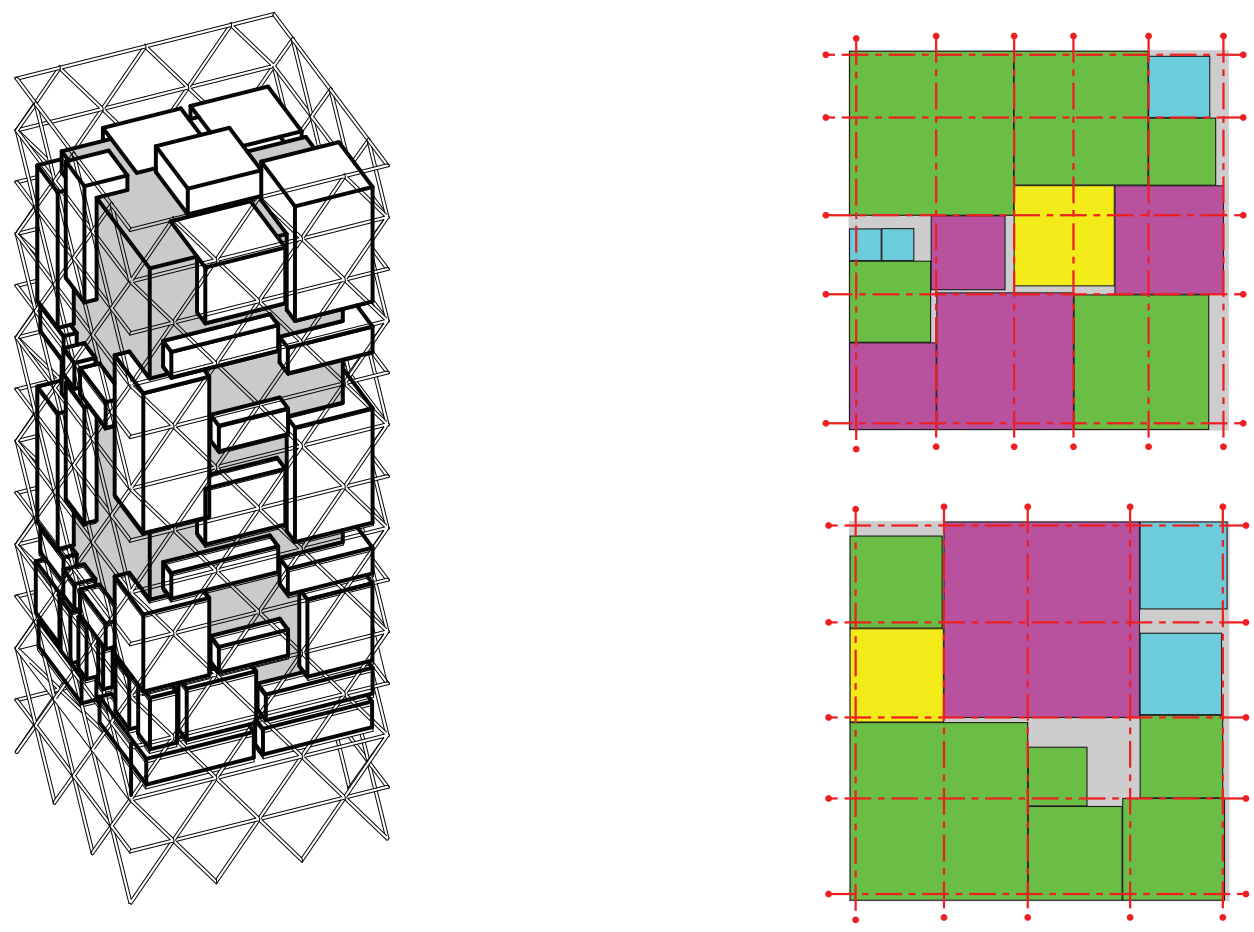

Figure 35. Tower Combinatorics

Figure 36. Museum Tower Frameworks 


\subsubsection{BARGE}

The next iteration revolved around utilizing the Thames river system and museums near the water. The museum-as-barge concept originated from the historical role of the Port of London had on the Thames river as the destination for international shipping routes bringing in artifacts from the far reaches of the British empire. This iteration highlights the potential in utilizing the operative logics described in detail above and their versatility. Figure 38 showcases the possible combinatorial arrangements a barge museum could take and it becomes a dynamic model for the territorialisation of artifacts across vast networks. One of the real opportunities with this system is its potential for growth and the ability to bring museum collections to areas that are underserved. Like the Potteries Thinkbelt, the museum-as-barge challenges the existing spatial construction of museums by utilizing infrastructure for a potential open-ended museum territory. Why do normative museums continually develop finite boundaries for dynamic collections? What if the museum instead leverages mobility and infrastructures by finding a more adaptive system for expanding access to their collections. The Thames river provides a malleable substrate to achieve this.

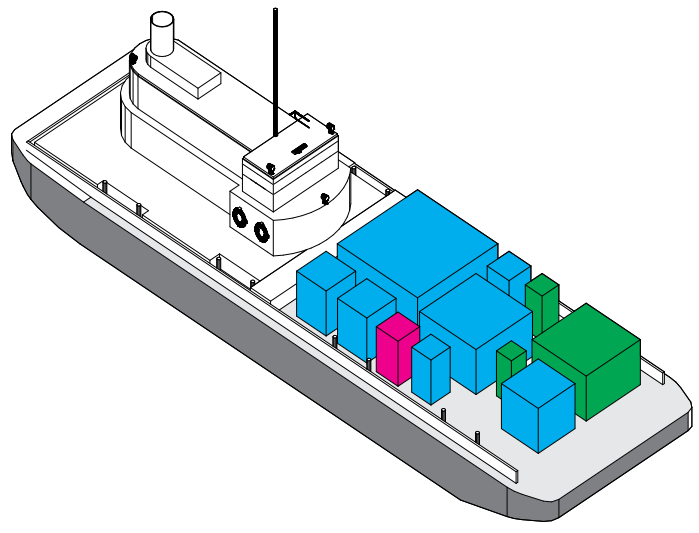

Figure 37. Museum as Barge
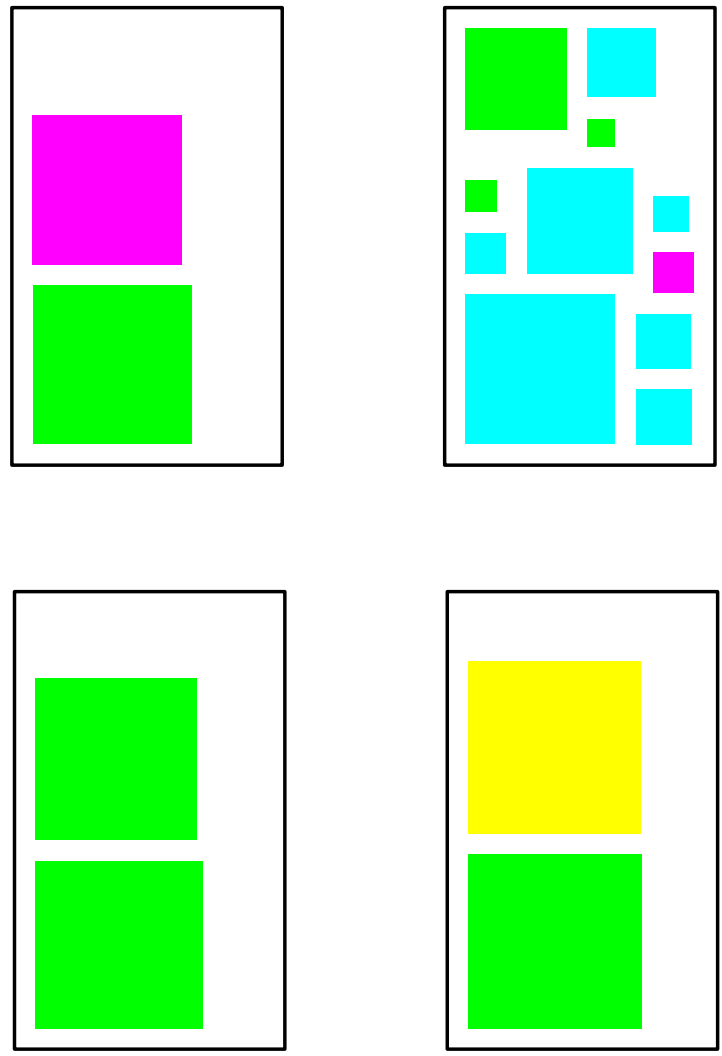

Figure 38. Barge Combinatorics 


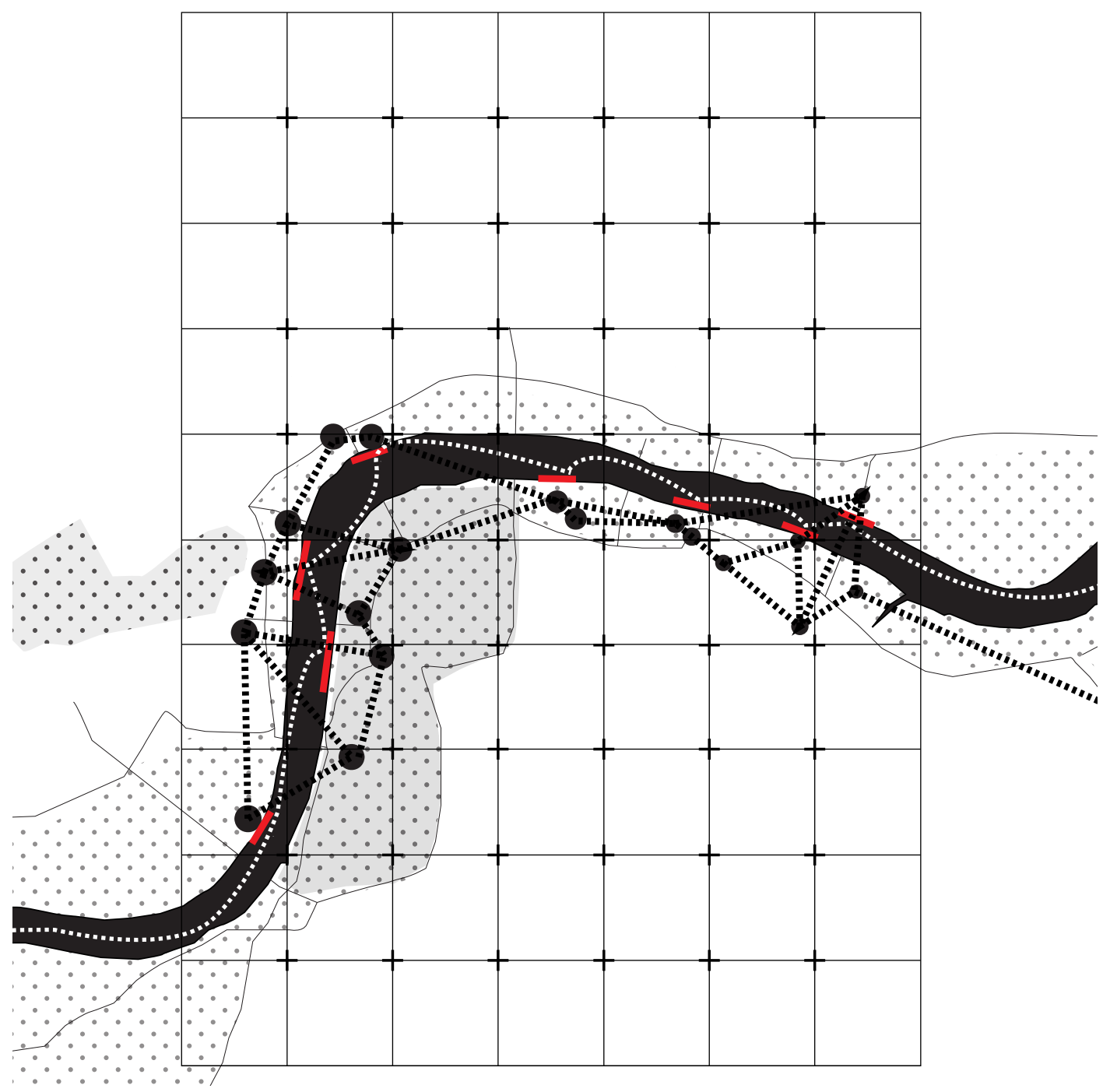

Figure 39. Museum Infrastructure Growth

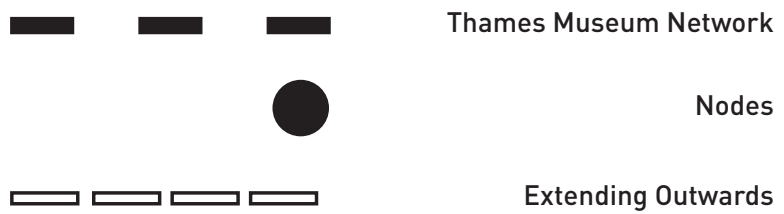




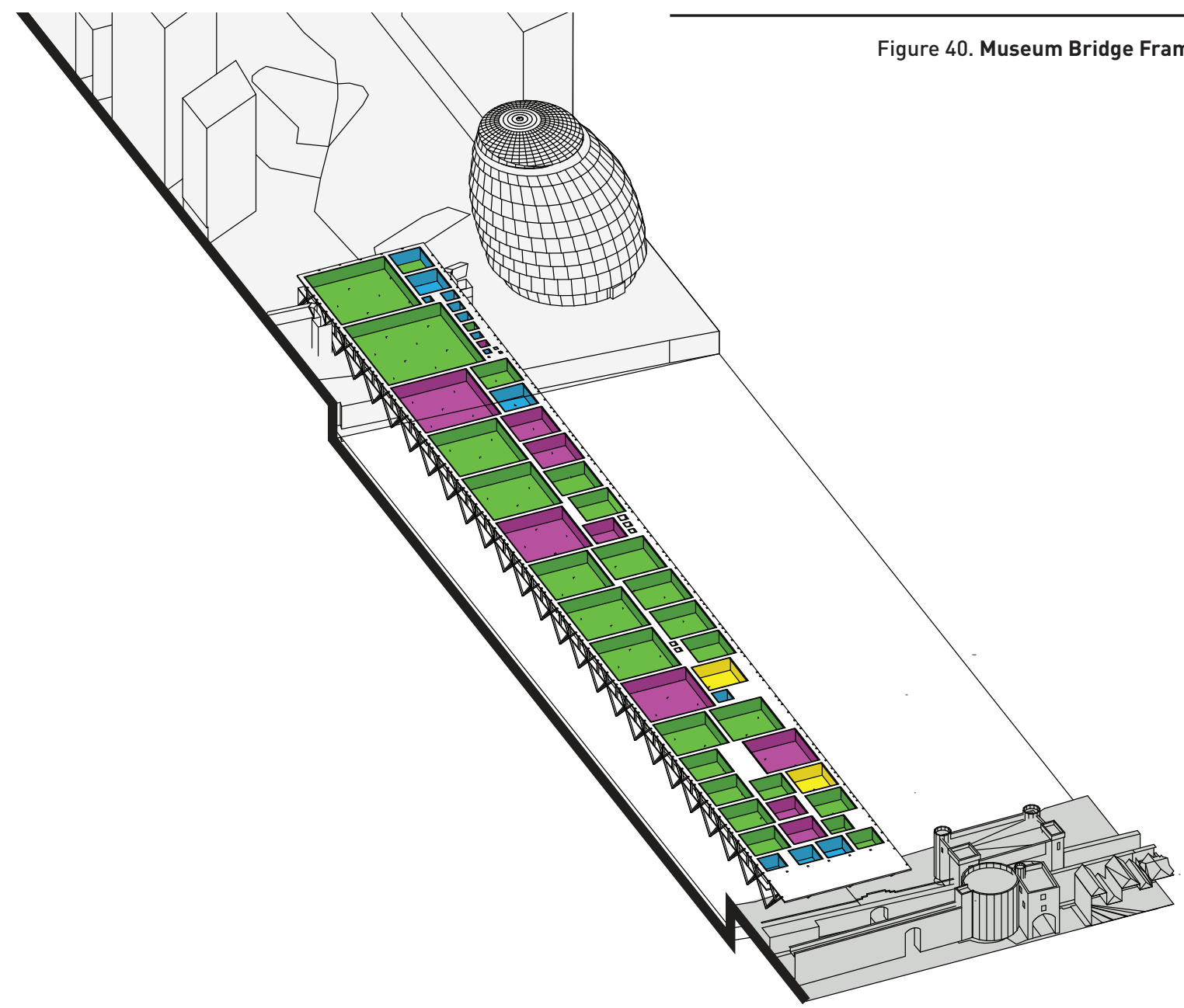

\subsubsection{BRIDGE}

Continuing to iterate around the Thames river as the hub for a museum network, the bridge as an infrastructure was explored for a possible museum framework that ties into existing infrastructural networks. The bridge is the clearest manifestation of an infrastructure being utilized for a museum typology. One of the real opportunities for the Museum as Bridge Infrastructure system is the potential of it to act as a conduit, regulating the flow of artifacts throughout the network rather than simply an object of accumulation. By its very nature the bridge has to negotiate aquatic circulation therefore raising the potential for leveraging external infrastructures such as the barge and ferry transportation for the movement of artifacts and users. 

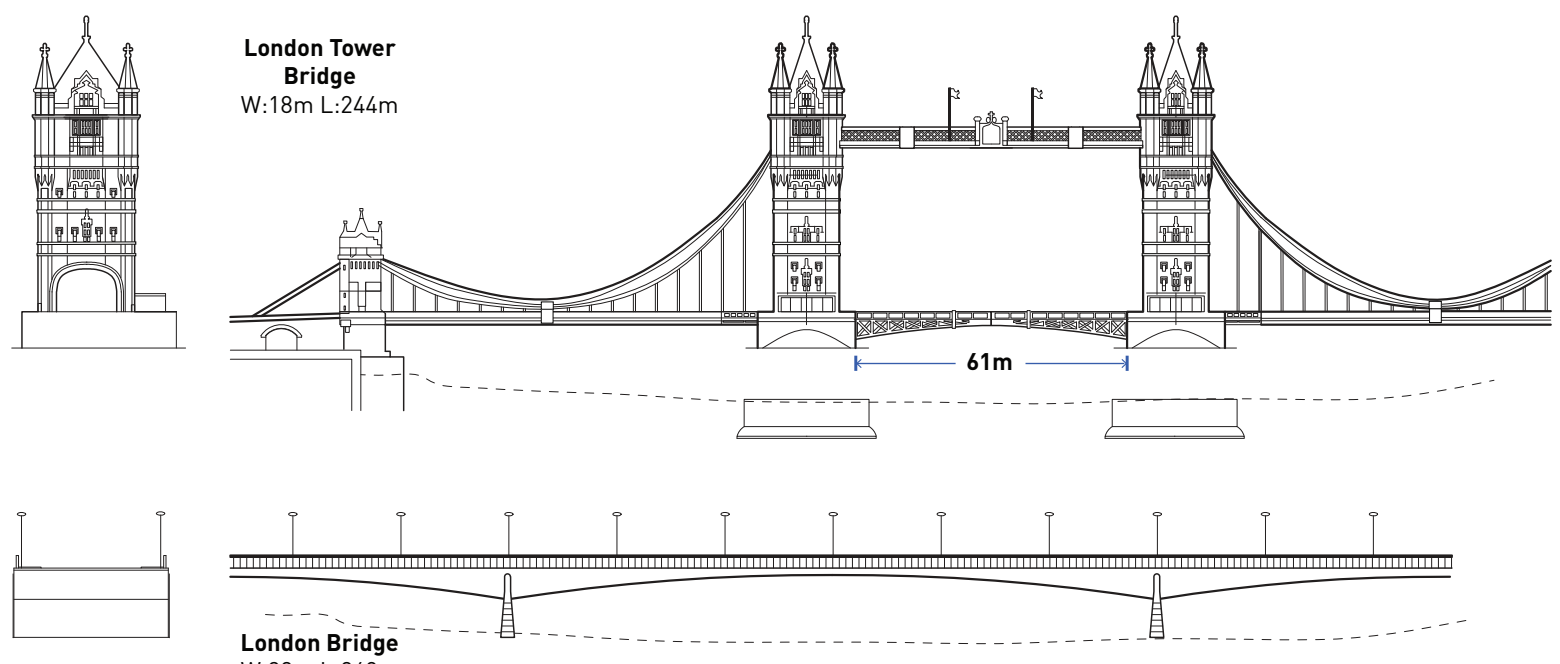

W:32m L:269m
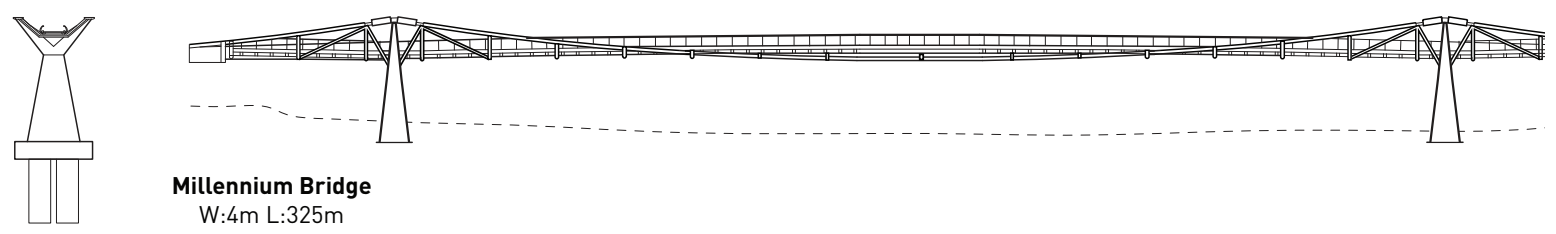

Millennium Bridge

W:4m L:325m

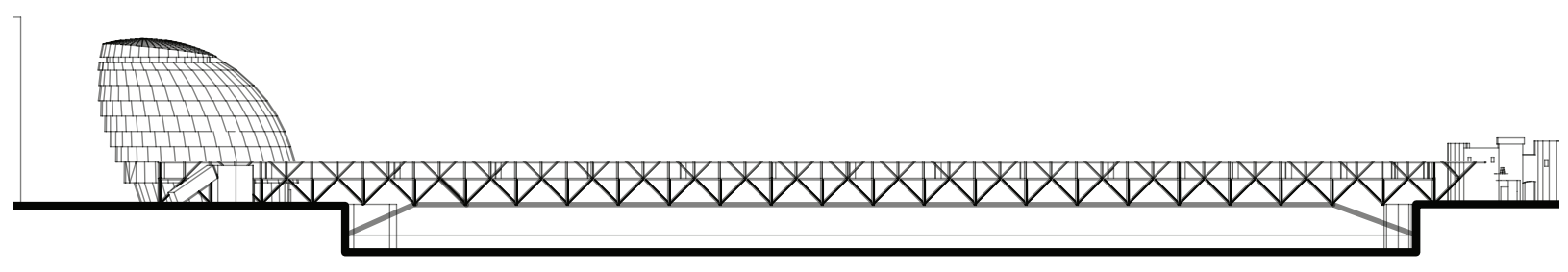

Figure 41. Museum as Bridge in the London Context

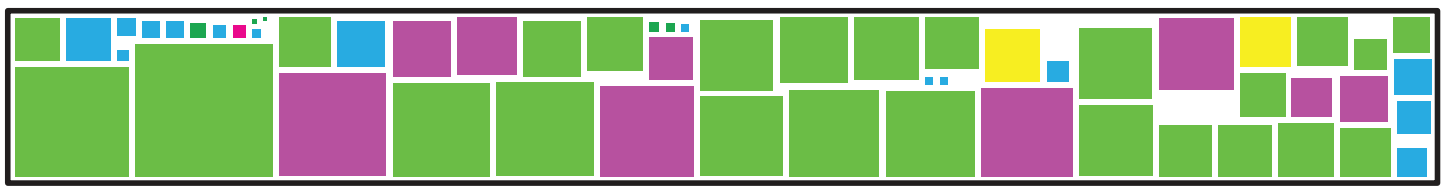

Figure 42. Bridge Combinatorics 


\subsection{BRIDGE SYSTEMS}

Out of the three iterations, the bridge has been chosen as the framework for the development of the Posthuman museum. The bridge explores the notions of infrastructure at a variety of scales. It offers opportunities for architectural frameworks to address local contextual territories while simultaneously working on the macro scale in its connections to broad city networks. By its very nature the bridge is also a threshold, a liminal space between multiple terrains or entry points. This proposes an interesting model for the museum as a threshold space which fundamentally removes any structures of isolation but rather renders a diffuse museum assemblage full of permutations. The bridge as a manifestation of infrastructure is defined by a palimpsest of densely layered bodily, local, national, and global processes. The bridge looks to de-territorialize existing artifact collections and re-territorialize them through metabolic circulatory flows, organized as a social and physical conduit.

Located strategically near the site of Tower Bridge, the museum bridge takes the form of a $240 \mathrm{~m}$ long pedestrian bridge spanning the Thames river connecting Potters Fields park to the Tower of London. The juxtaposition between Tower Bridge and the museum bridge brings into focus the potential use of infrastructure as a representation of cultural and social development. To the North and South of the site it is rich in a highly dense network of urban traffic and circulation systems. The north side of the Thames river has a docking station called the Tower Pier which shuttles commuters along the ferry service that connects it significant sites such as the Canary Wharf district. As explored in earlier iterations, the connection with the ferry service on Tower Pier can be double-purposed to act as a docking station for artifact transportation along the museum network along the Thames river, facilitating connections to the bridge as a node in the larger city context.

The dynamic logic developed as the operating sequences for the bridge museum is intended to destabilize traditional museum program and instead develop spatial assemblages around sites of accumulation that attract occupation. Occupation in program and space is less about traditional design logic and more about imaginative, ad hoc appropriation based on a systems logic. ${ }^{35}$ Program in the traditional sense of the Posthuman museum revolves less around rigid demarcations but rather becomes an emergent property of new and existing museum infrastructures. As Michael Batty suggests, building program will be a continually configuring cluster of spatial events characterized by duration, intensity, volatility, and location. The diagram for the program of the Posthuman museum takes this 
idea on and is developed as a logistics diagram, consisting of an array of functions and decision nodes that reduces museum activities to a systematic flowchart that treats both user and artifacts as equivalent sources of data. This logistics diagram describes key operative stages for the integration of user and artifact data, data collating and sorting, computing storage assemblages, and the overall spatial conditioning throughout the network. Logistics is crucial as it primarily focuses on the management of things in space and time. In addition to this, logistics also concretizes space and time through its material realities. ${ }^{36}$ The museum in this instance is the concrete manifestation of the larger museum infrastructural network derived from the Greater London Area. The process diagram represents the logic that dictates the flow of information throughout the museum. Posthuman architecture revolves around rendering legible this process diagram by utilizing architectonic tools and systems. Logistics mediates between abstraction and concreteness. As a result, the building loses its status as an isolated system but becomes a site of mediation within the larger entangled network. Understanding Posthuman architecture as an infrastructural framework conditions the way its material apparatus is understood and deployed. The process diagram is inherently characterized by an ability to render matter discrete and continuous simultaneously. This requires that constituent elements be granular enough to be tracked to high degree of resolution. To achieve a high degree of resolution, logistical behavior collapses object and field as all elements in its scope become data to be collated, sorted, and ultimately distributed. The museum as an infrastructural prosthetic works to overcome territorial and spatial obstacles that would most be associated with the normative museum. All elements from the artifacts, spatial tools, and users are marked with specific information that allows their tracking and monitoring throughout the system. This system makes no distinctions among the kinds of objects it tracks. As a result, the logistics diagram was a starting point for the design of this museum because if architecture is to engage in the construction of Posthuman space, it will increasingly need to expand and share infrastructural protocols that have come to define material-informational constructs. 


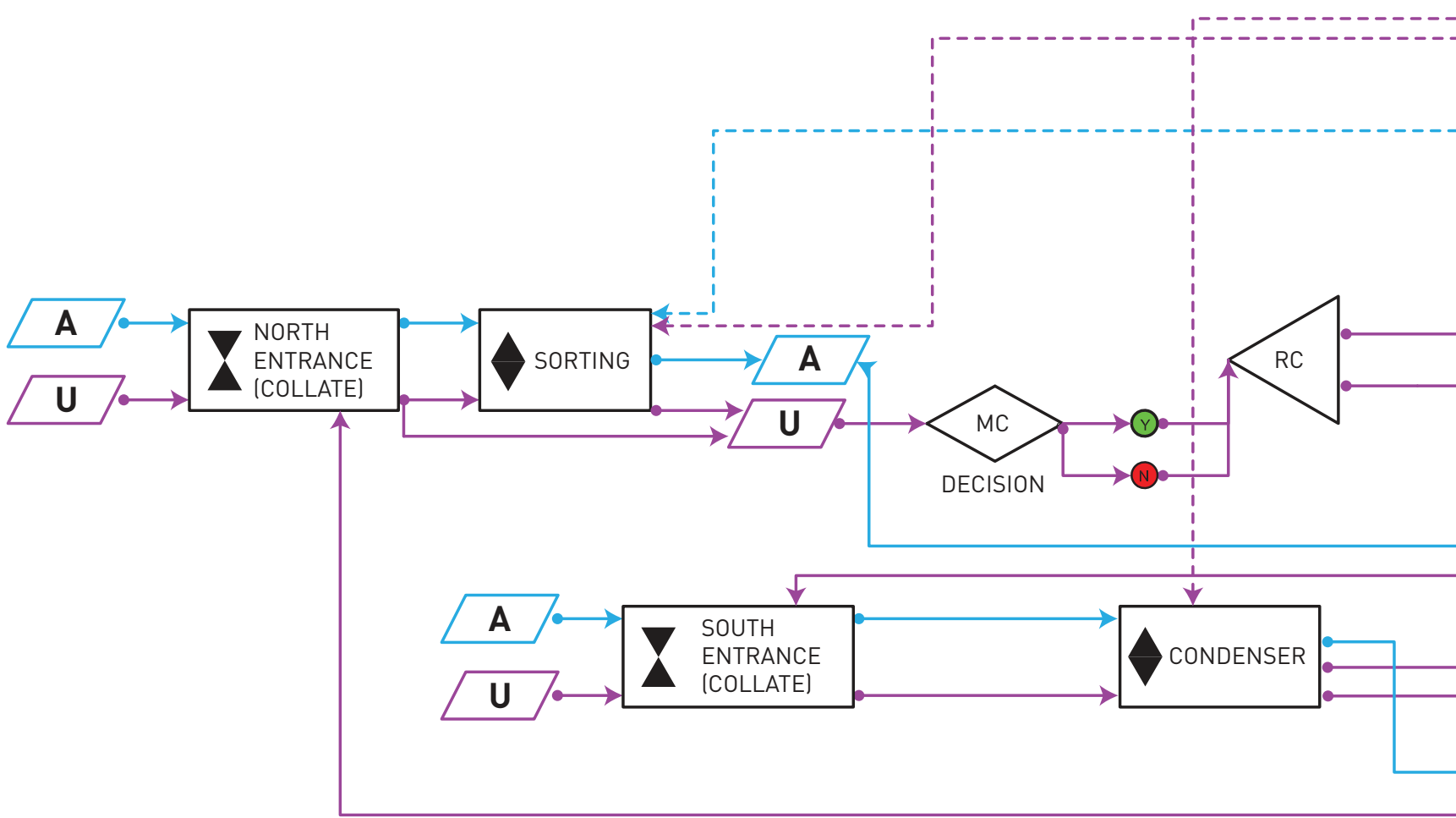

The primary inputs to the diagram are the artifact and users. Prosthetics and technology transform the user and artifact to an equal piece of information for input into systems at a variety of scales. The barcode for example has the capacity to turn any object into quantifiable information. (see figure 88) Technologies, new and old, allow objects and users within the museum to become constituents in a moving system. They operate on the same space-time continuum. This capacity for an object to become a piece of information allowed the material in question to be understood in abstract terms, both spatially and temporally. The nature of a logistical architecture tends to emphasize a horizontal organization over vertical expression thereby associating these built elements with our traditional conception of infrastructural systems. The bridge accommodates significant material flows, including a constant stream of artifacts and people. Artifacts are delivered by barge or truck from potential local, national, and global museum networks. They are then brought to the sorting facility, transported throughout the museum by staff in concert with autonomous warehousing technology for further distribution throughout the museum. As both conduit and container, the bridge is simultaneously enclosed and a passageway in which an exterior is both reinforced and undermined. As the logistics 


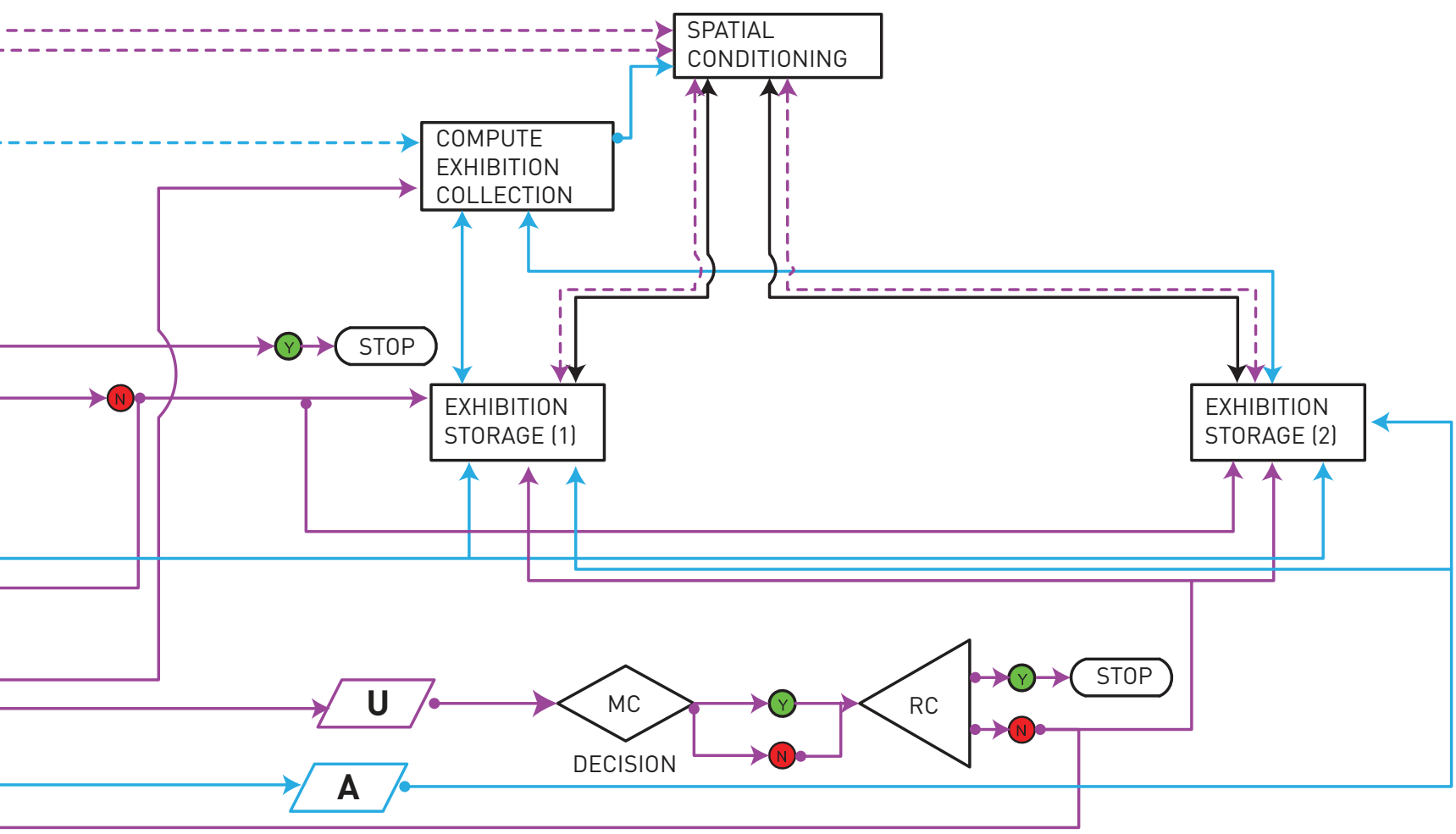

Figure 43. Logistics Diagram - Infrastructure Logic

Logistics Diagram Legend

A INPUT [artifacts]

$\mathbf{U} \quad$ INPUT [users]

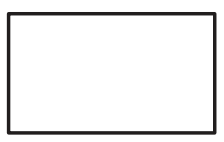

PROCESS

$\checkmark \mathrm{RC}$

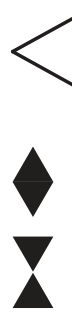

CONDITION [river circulation]
$\mathrm{MC}$

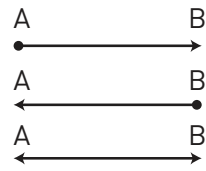

$\mathrm{MC}$

DECISION [museum circulation]

SORTING

COLLATE

PROGRESSION PROCESS

- - - - - - CONCEPTUAL RELATIONSHIP 
10

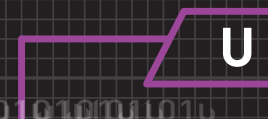

\section{$\mathbf{U}$}

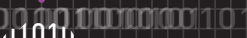

100101 mojatoroo

01100 midotion

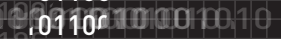

i1 1001010 ,

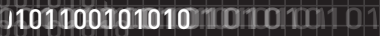

i 001010101010120121010

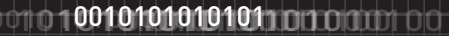

01611010101010100 monomorito

01818010101010101irmmo to is

010101001010 inmom

01010101100

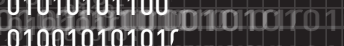

(10100110

S1010101010170100 10

101100010

910100107ว a

079.900101010 -01707 01 .

1010010101010 :10.10:100

1019901010101010101.01

(1) 197 1010100110 minto

0101011 Commento iff

1001011 momentio

011001 frammoo 1 r

0110010 ismonita

10101010101

ใิ

10 107rorertoti

\section{A}

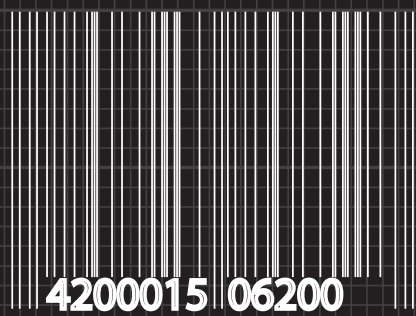

Figure 44. User and Artifact as Homogeneous Data 
diagram showcases, the design of the museum started with a design of inflow and organization of information, while a thick perimeter zone, what we would refer to as the envelope, is more malleable and establishes an intermediate layer of program. This museum is not built to accumulate material but to amass and dispense it cyclically. The Posthuman museum operates as a conduit and valve, capable of renewing and modulating the flow of material. ${ }^{37}$

Infrastructure systems through their constant communication with external networks map out new territories through their continued use. The territory emerging from the infrastructure of the museum is epigenetic in so much as the differentiated form emerges from a formless and homogenous environment. Urban and museum forces, data, and information are continually scripting its performance utilizing the logistics diagram as a base programing language. Architecture emerges as an exercise in spatial programming rather than traditional exercises in form making. The logistics diagram is the first step in writing the spatial program in which the architectural system takes form. Given the scale and fluid nature of territories, the infrastructure of the museum also becomes an analytical tool in apprehending the forces at work in the Posthuman assemblage. The architecture of this museum is an actor and protagonist in developing territorial boundaries and operations at a variety of scales rather than simply responding to them. 


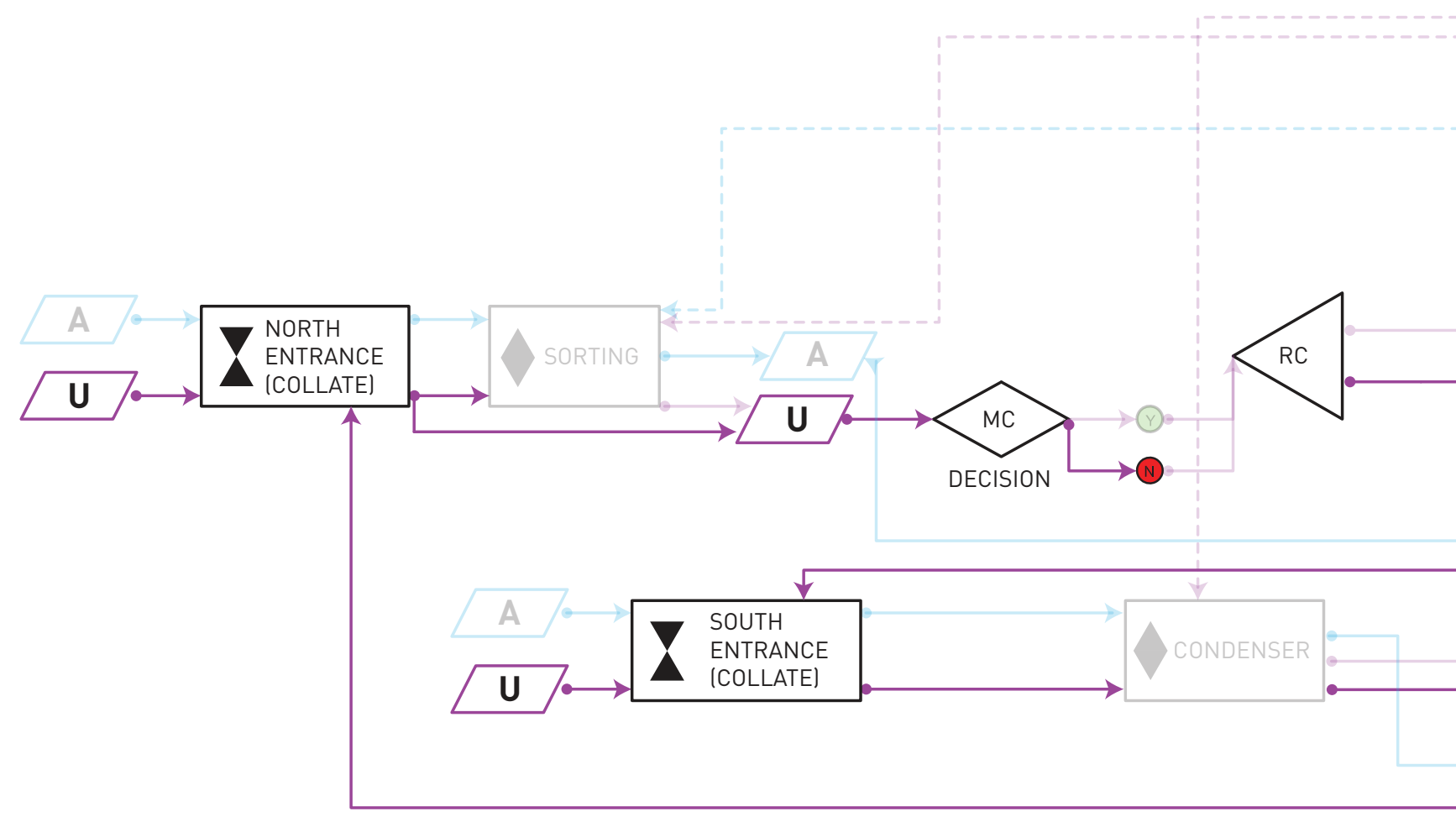


059
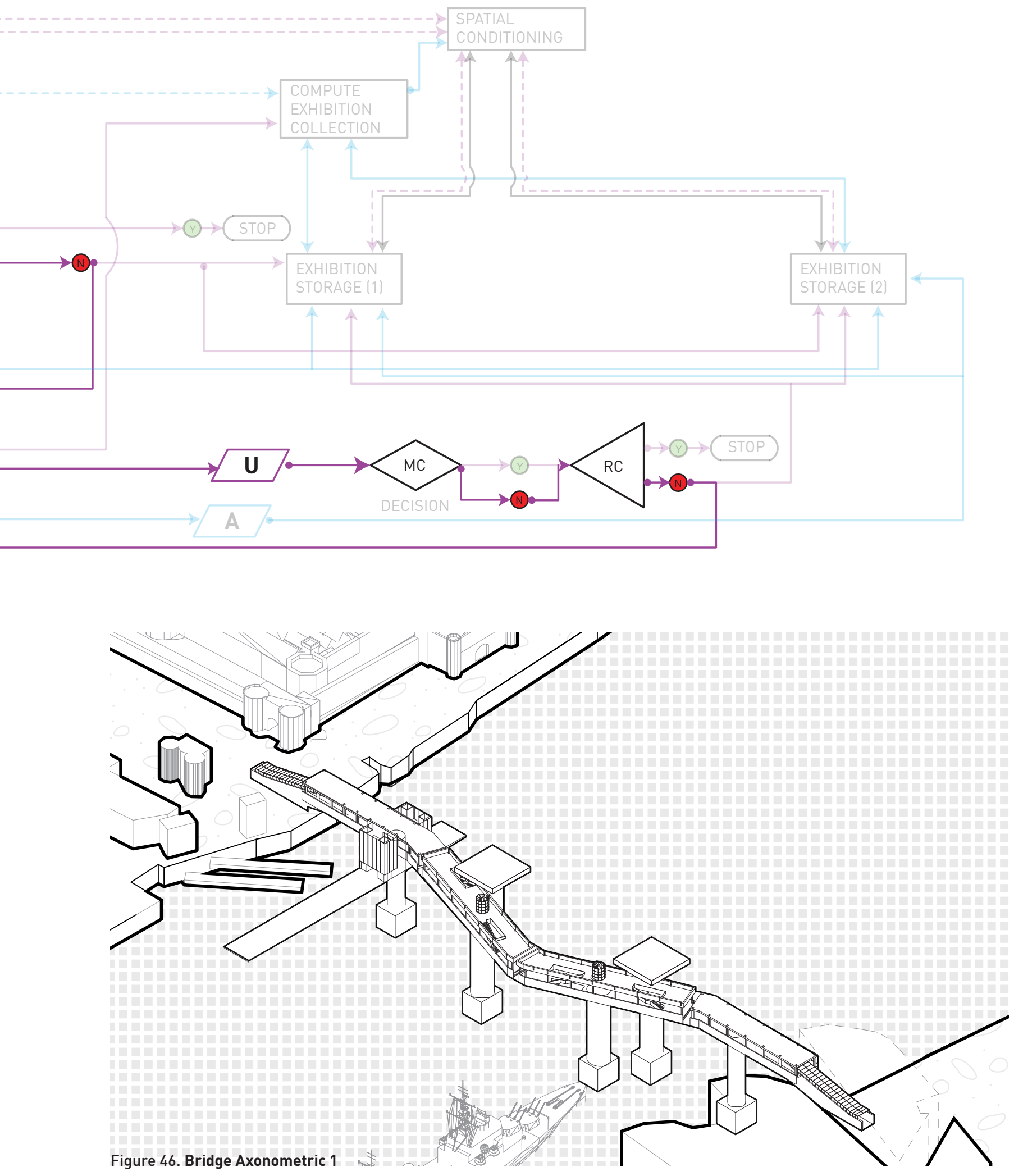


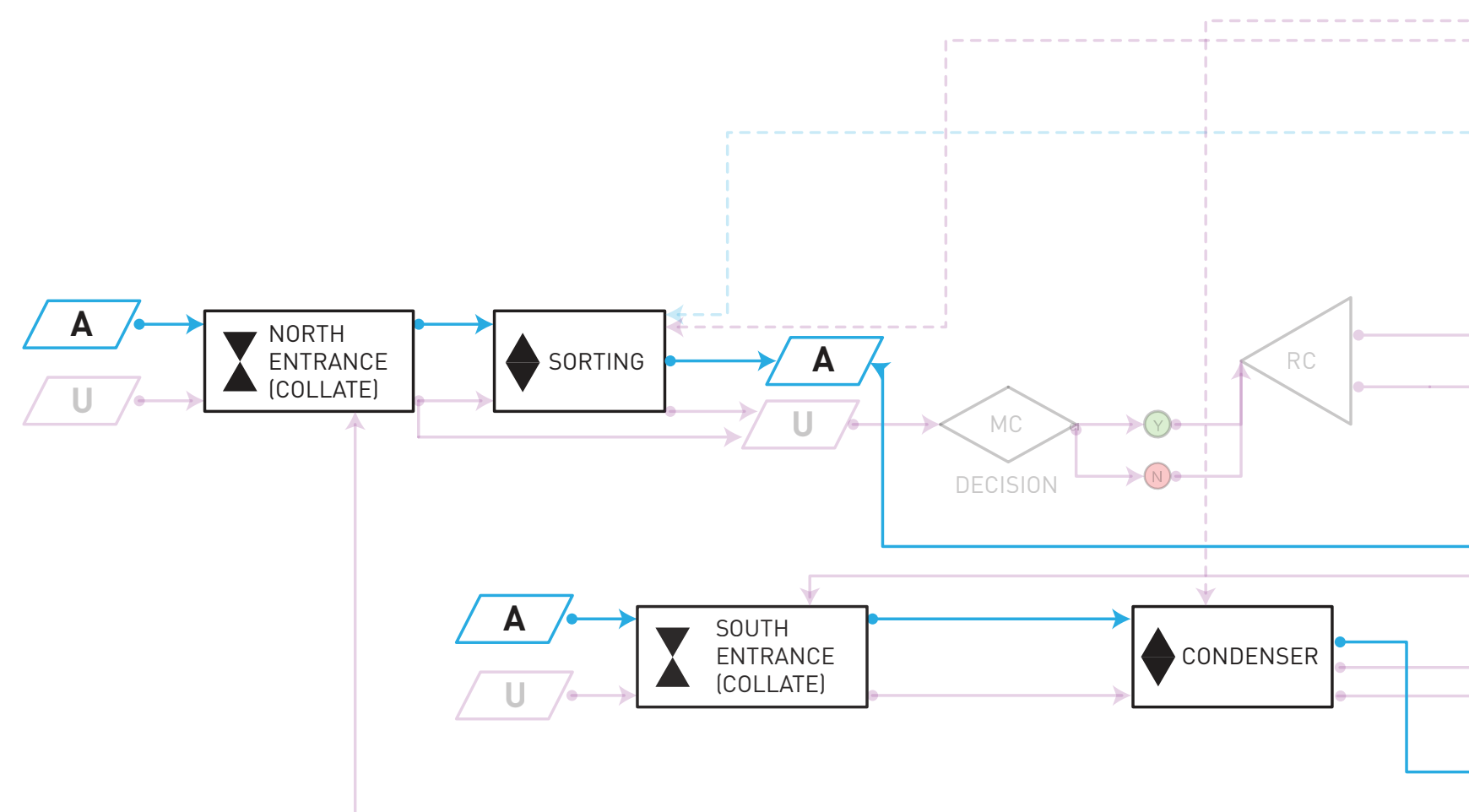


061
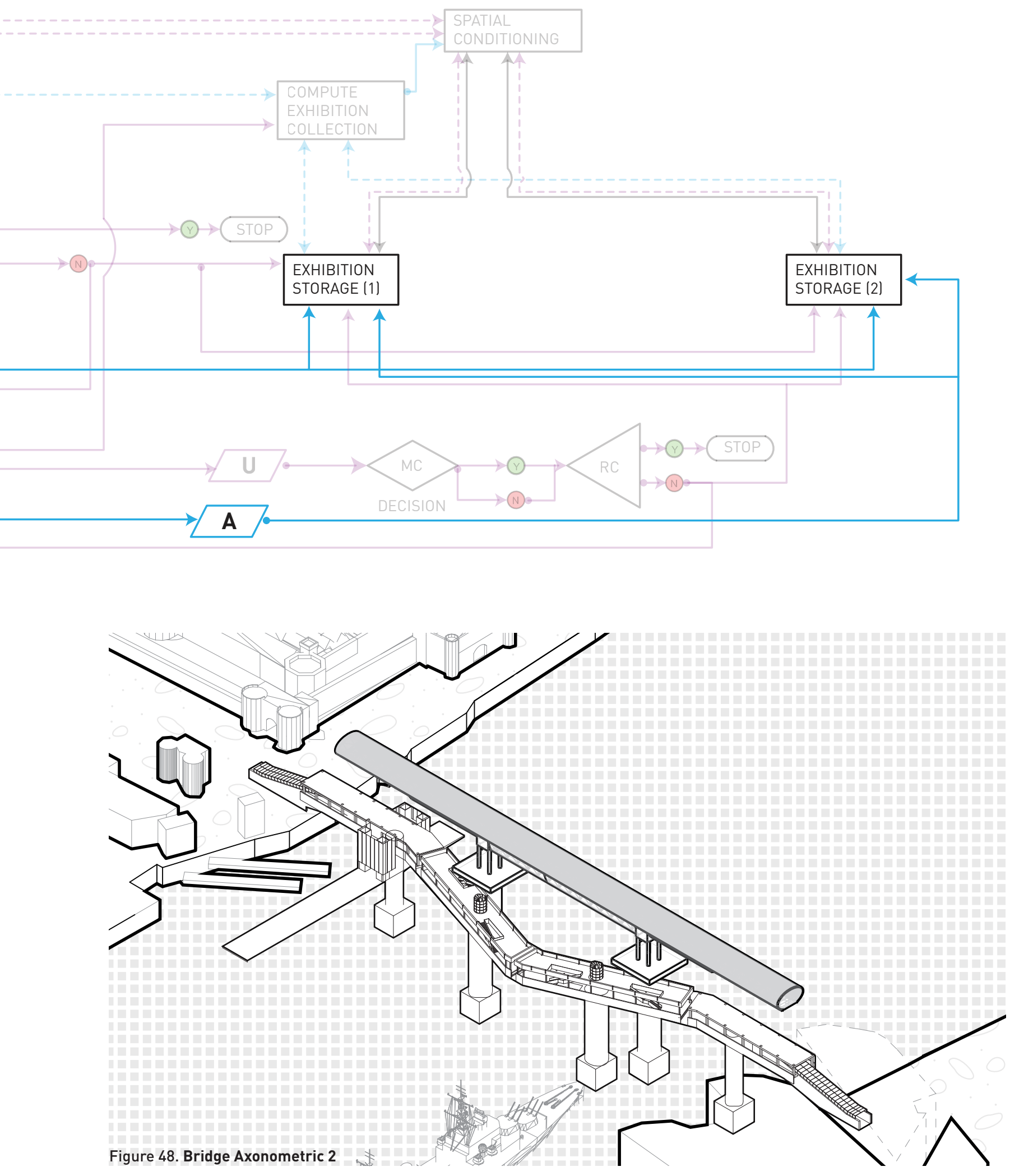


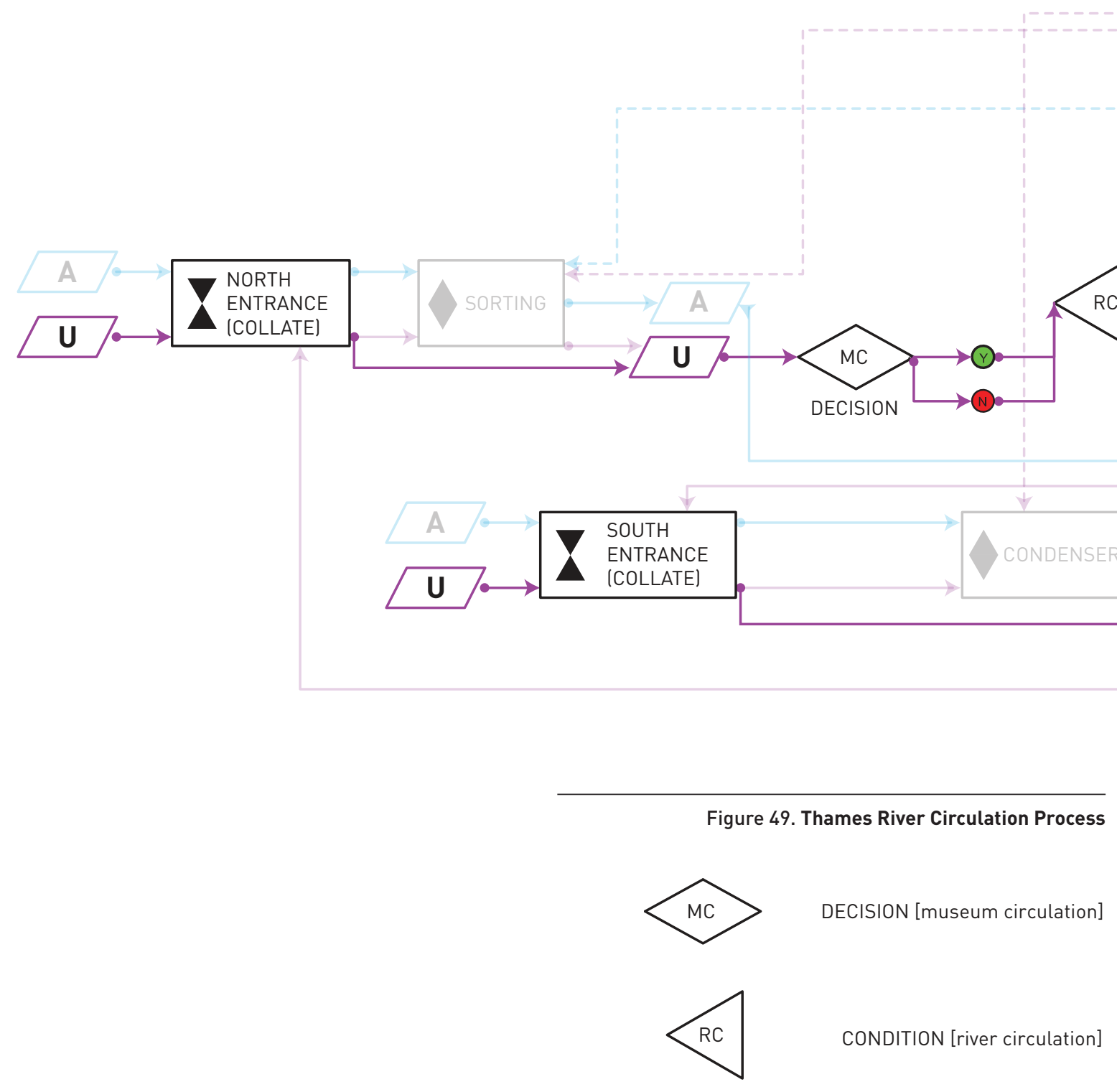


063
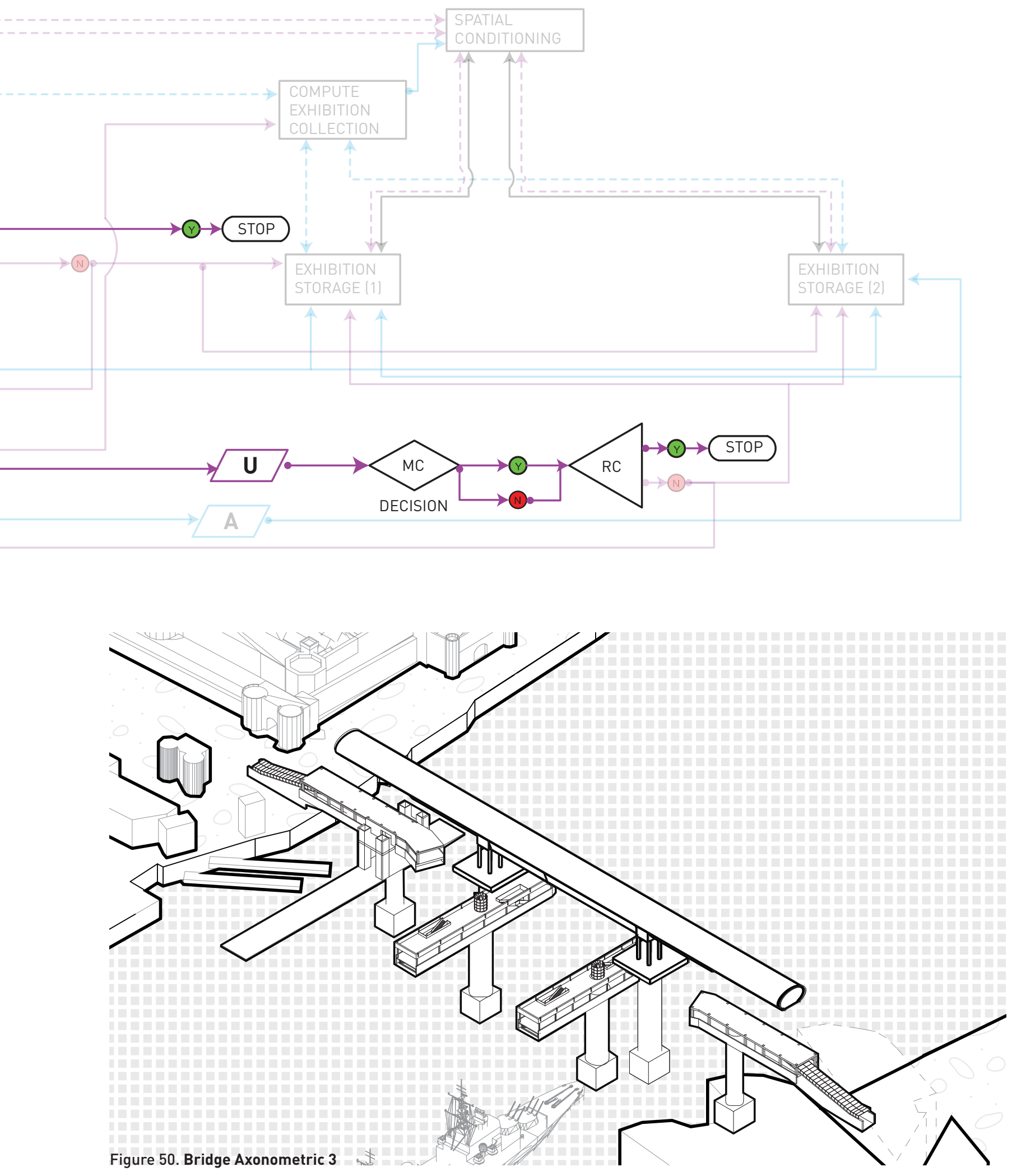


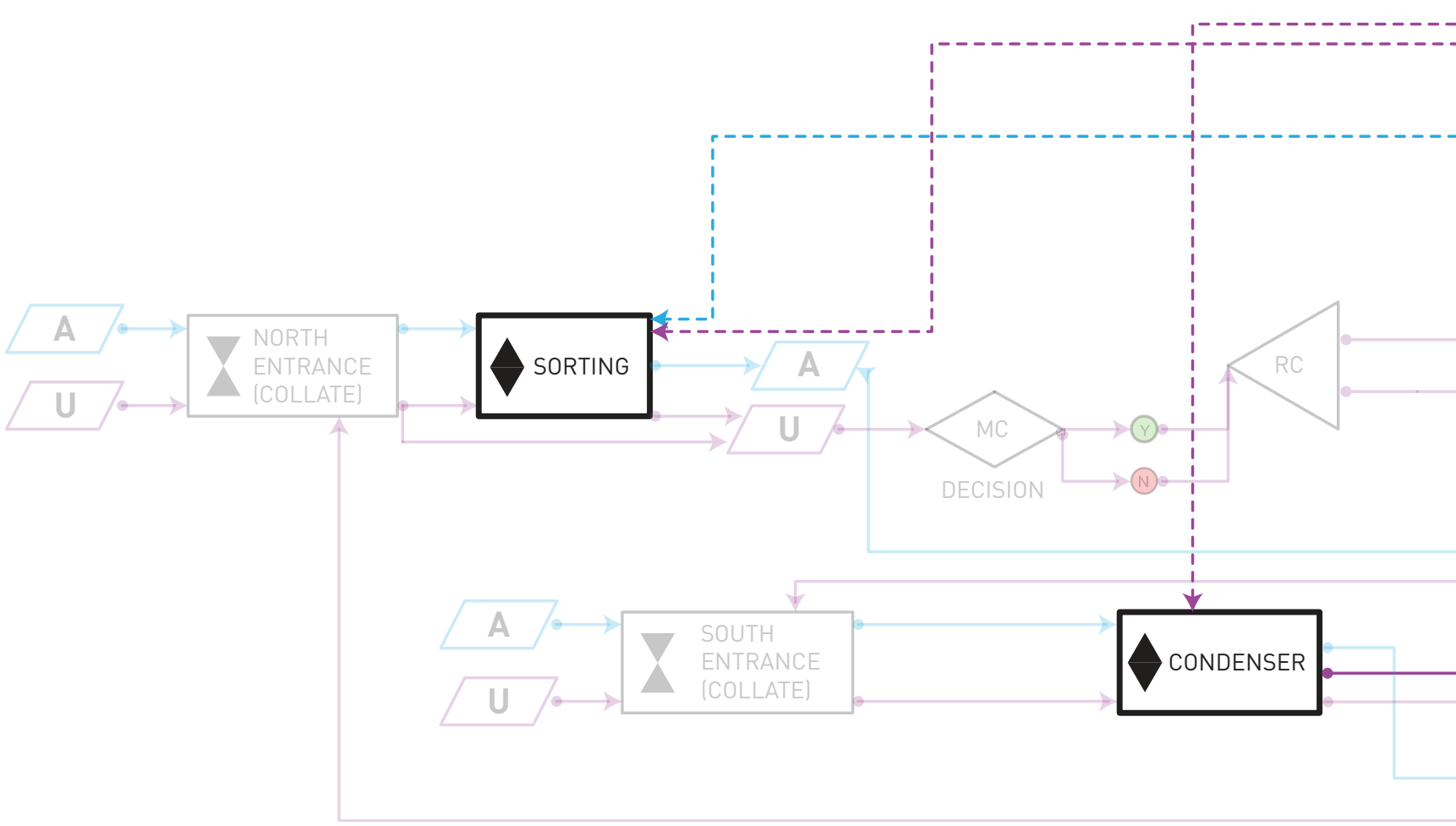

Figure 51. Process Pavilions

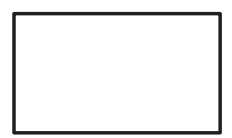

PROCESS 

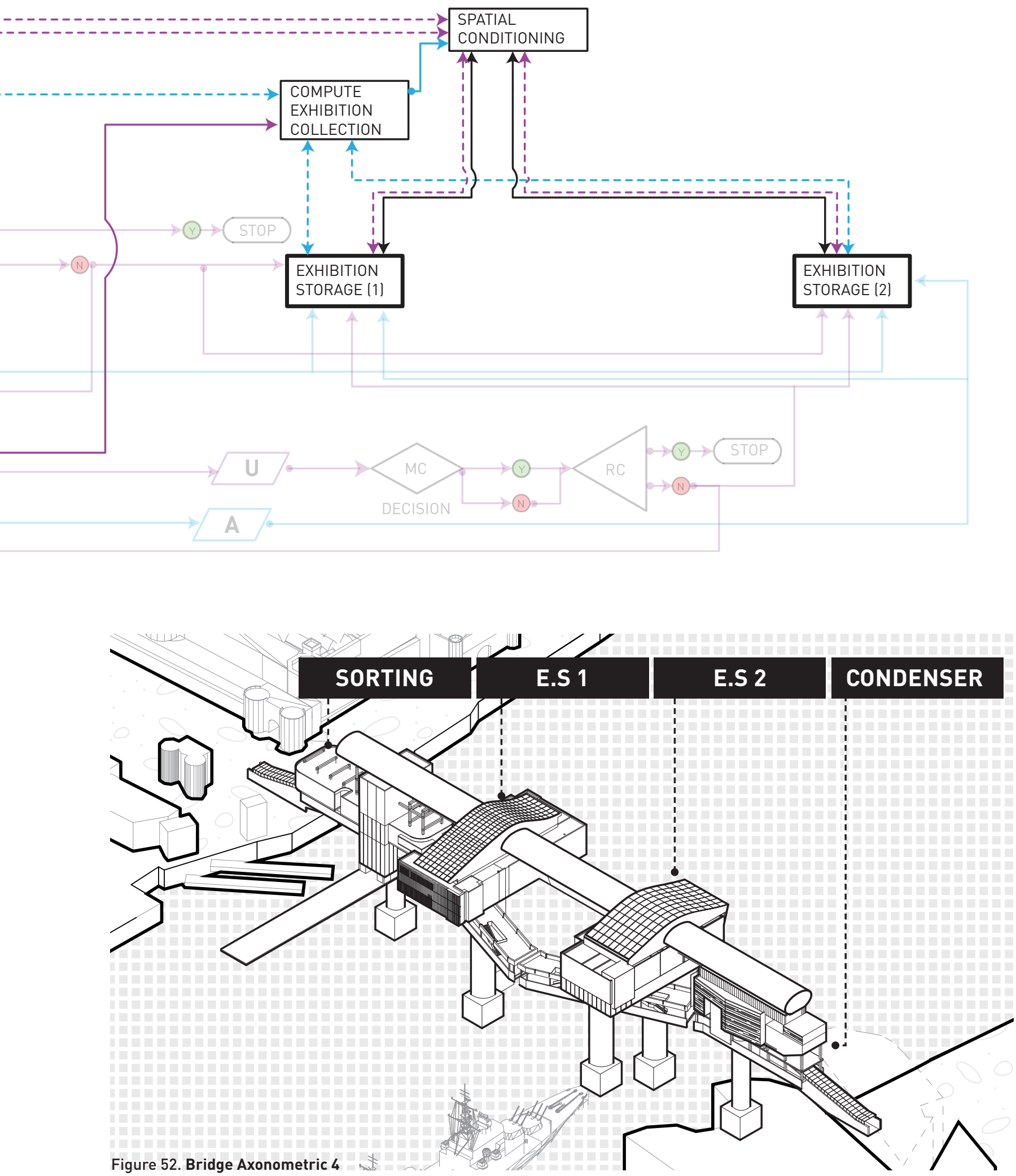


\section{NOTES}

33 Vernelis, Kazys. and Anne Friedberg. “Place: The networking of Public Space." (Mass., University of Michigan 2008) p. 25

34 Keene. Collections for People. Museums' stored collections as a public resource. (London, UCL Institute of Archaeology 2008) p. 17

35 Mltchell, William J. “Against Program." In Architectural Theories of the Environment: Posthuman Territory, by Ariane Lourie Harrison (New York, Routledge 2013) p. 157

36 Lecavalier, Jesse. The Rule of Logistics: Walmart and the Architecture of Fulfillment. (Minneapolis, University of Minnesota 2016) p. 134

37 Ibid. p.210 


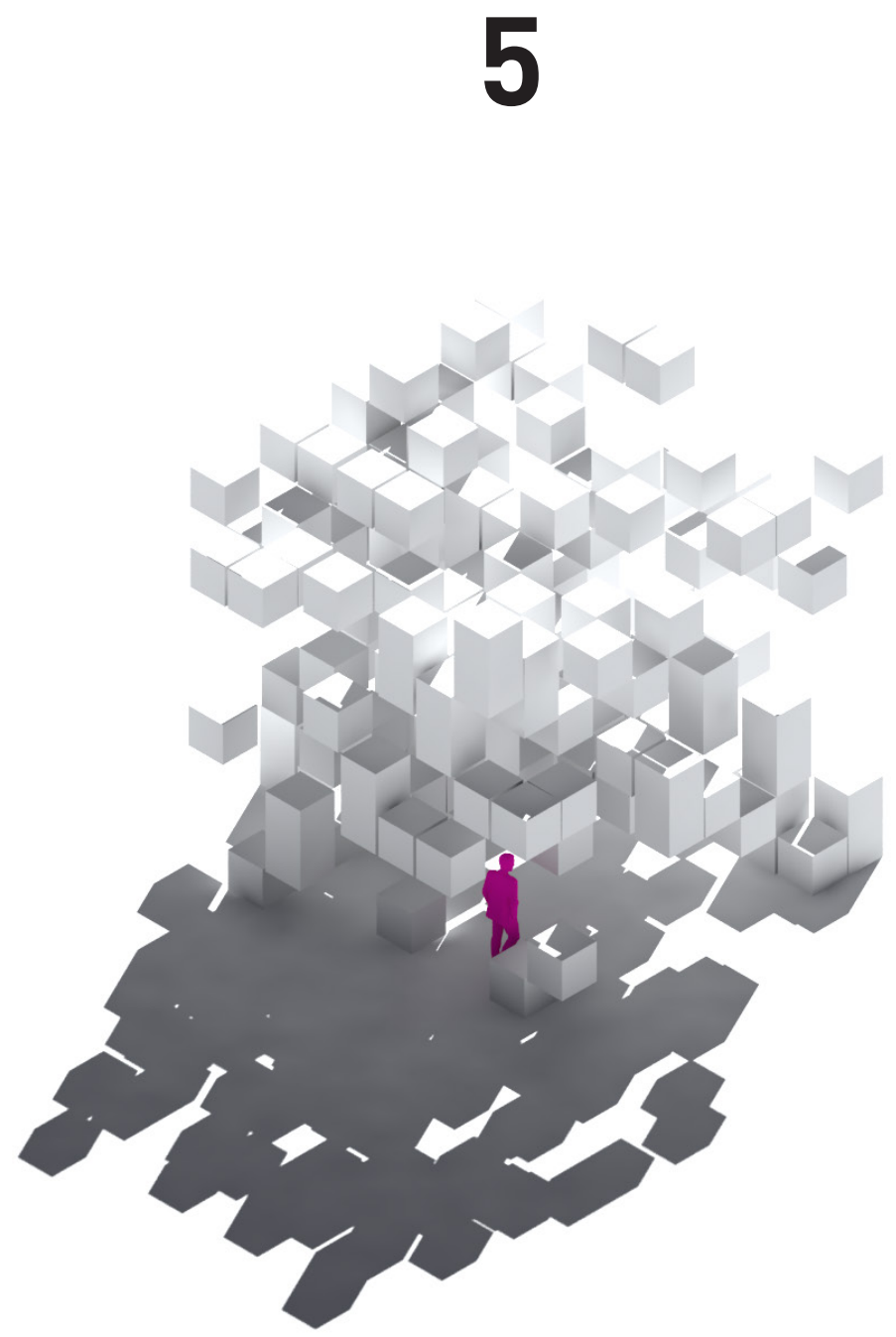

Figure 53. Posthuman Assemblage

Infrastructural space is a form, but not like a building is a form; it is an updating play form unfolding in time to handle new circumstances, encoding the relationships between buildings, or dictating logistics. There are object forms like buildings and active forms like bits of code in the software that organizes building. Information resides in the oftenundeclared activities of this software-the protocols, routines, schedules, choices it manifests in space.

Keller Easterling in Extrastatescraft: The Power of Infrastructure Space. ${ }^{38}$

\section{THE POSTHUMAN MUSEUM}


The Posthuman Museum explores ways in which architectural infrastructures can mediate between the multiple museum and Posthuman parameters explored in previous chapters. Through the museum as bridge, this thesis reconstructs and addresses three key museum relationships: how can formal architectural systems mediate between context and artifact? How to develop dynamic spatial and curatorial frameworks utilizing architectural systems? Finally, how the user and artifact are spatially and temporally related through these frameworks? These three questions are explored through the bridge to understand how architectural systems construct a Posthuman assemblage. At the heart of these questions is a shift in operational scale and our understanding of architecture as a system rather than an isolated object.

One of the major themes that a Posthuman construct brings to the understanding of architecture is the exponential change in scale of operation evident in the wide networks and territories that are drawn out across urban territories. In Rem Koolhaas' seminal book $S, M, L, X L$, he addresses the shortcomings of architectural discourse and dealing with issues of scale. Koolhaas believes that beyond a critical mass architecture acquires the properties of Bigness. ${ }^{39}$ Because Posthuman architecture operates on a large territorial scale, addressing the problem of the large is at the forefront of any Posthuman architectural theory. The design strategies in chapter 4 highlight that it is more fruitful to take Koolhaas' theory of bigness one step further. Rather than bigness being a property of a critical mass of the architectural object, it is a property of the networks and territories that an architectural system is trying to represent. The museum network drawn out across London finds itself manifested in the museum as infrastructure. As a result, such a system must be representative of the assemblage rather than subject itself to the control of a single architectural gesture. Using the logic of the infrastructure diagram as a framework for the development of the museum's formal strategy engenders a certain autonomy of architectural materialisation of parts throughout the system. In their entirety, architectural tectonic systems offer the appearance of spatial stability for objects while simultaneously acting as conduits for the flow of artifacts and users. Together, with all these breaks - with scale, and with architectural composition-Posthuman architecture is no longer preoccupied with a contextual relationship between site and building. Rather, the museums relation to context is mediated by its interaction with the larger museum network that services the bridge framework. 


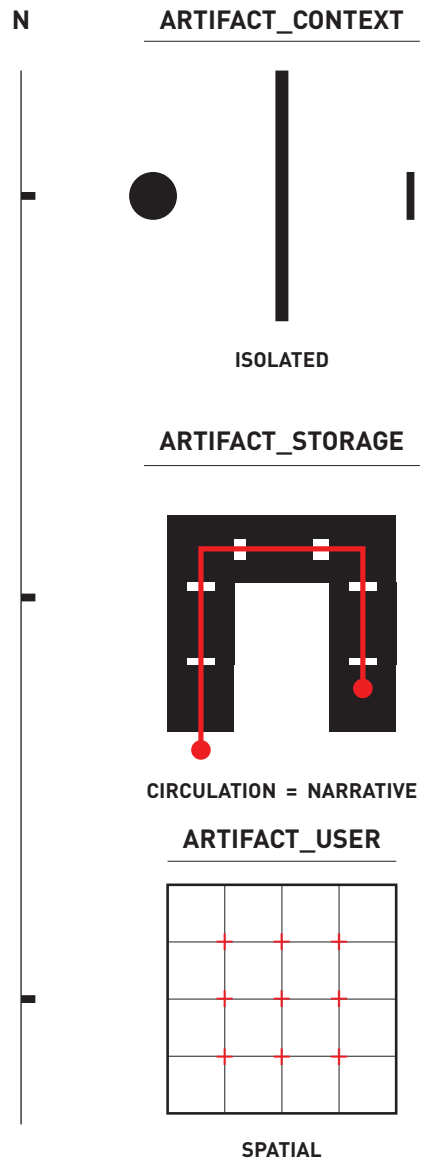

Figure 54. Museum Relationships, Comparing the Normative museum to the Posthuman Museum

\subsection{CONTEXT_ARTIFACT}

There has always been a relationship between that which is exhibited and the architecture that houses it. Museum building in Modern architecture primarily relied on the 'neutral' envelope often called the white cube as a way of foregrounding the artifacts it houses. However, the neutral envelope instead isolated artifacts by stripping them of context which subsequently isolated the observer. New

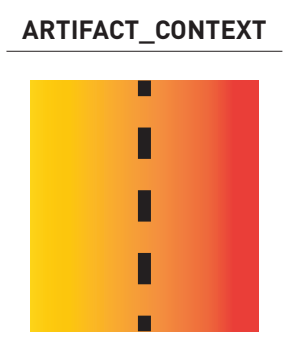

MEDIATED

\section{ARTIFACT_STORAGE}

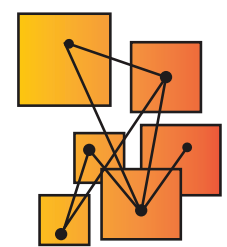

CIRCULATION $\neq$ NARRATIVE

ARTIFACT_USER

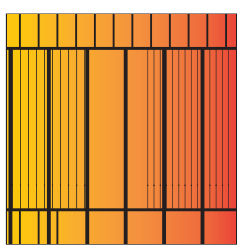

TEMPORAL 
percentage of artifacts are kept suspended in time, away in temperature controlled and isolated facilities for future cycling throughout exhibition spaces. (See figure 54) The sum of these parts equates to an architecture that acts as a tabula rasa for collection assemblages. The normative museum construct requires hermetic boundaries where artifact and user narratives do not cross-contaminate because of its static nature and inability to adapt. To reconstruct existing museum relationships where artifacts are contextually represented, a Posthuman architecture must provide a framework where the artifacts and users that are drawn out from the museum network are given the potential assembly of maximum difference. To achieve this, the design utilizes programmatic hybridizations, proximities, overlaps, and super-positions to constantly construct relationships between userspace-artifact to sustain the larger network. The architecture becomes the prosthetic for this Posthuman narrative to constantly unfold. The envelope for such an assemblage takes on a more technical role in mediating artifact spatial conditions and their constant fluctuations. Although this is not a new technical requirement for the envelope, its representation is not derived from purely formal aesthetics, but rather the inner machinations of program hybridizations and network logistics unfolding over time throughout the interior space. The envelope and the further manifestation of network logistics are supported by autonomous spaceframe modules that are connected to the larger museum network through separate pedestrian and artifact conveyor belts. The space frame is utilized because it acts as a skeletal structure on which prosthetics are built while providing the potential for future customization and expansion. The space frame is latent with possibilities and accommodates fluctuations in artifact and user assemblages throughout the museum network. The massing diagram (1) highlights four separate pavilions as highlighted in the logistics diagram each utilizing their own structural logic while being interconnected and supplied by the pedestrian and artifact bridge. The envelope for the individual program function is designed to be wrapped around the storage structures while accommodating future fluctuations throughout the storage structures. The envelope takes on a layered aesthetic using screens and envelope systems to mitigate the functional issues of designing transparency onto a museum interface. The layering and overlapping of envelope materials also serves to highlight interior artifact cross-sections and assemblage differences. 


\subsection{ARTIFACT STORAGE}

The frameworks and architectural systems deployed for the museum as bridge infrastructure challenges existing museum frameworks that have strict circulation patterns that structure overall exhibition patterns. Rather than having an architectural framework that dictates exhibition paths, frameworks are installed to allow users to take a bottom-up role in configuring their surroundings and their unique narratives. Posthuman architecture allows users to negotiate space and construct their own narratives with the help of prosthetic networks. Interactive architectural systems

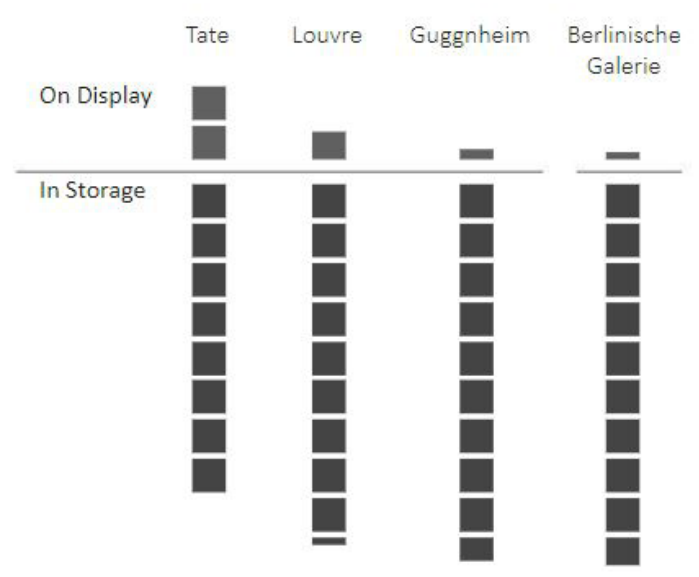

Figure 55. Relationship between exhibited collections and collections in store. become integral components in developing continuous feedback loops for the overall network to learn and adapt. As outlined in previous chapters on the spatial relationships throughout the building, the main programmatic block in the Posthuman museum revolves around the preservation and storing of artifacts rather than traditional exhibition structures. Open access storage systems allow users to construct their own museum narratives as they circulate throughout storage space. This model allows for a break from traditional museum models where circulation is traditionally linked with the narrative structure. The museums logic diagram dictates that storage structures constantly adapt to artifact collections flowing through the network. Storage structures within this museum are based on the fundamental idea that architectural frameworks are representative of the supply chain that enables artifacts to develop into dynamic storage structures. As a result, circulation networks throughout the museum are not pre-determined but rather update in tune with the larger network. Circulation as a concept throughout the museum is developed as an epigenetic territory, one in which forces, data, and information are continually scripting its structure. Circulation, and by extension narratives, develop as a rhizome in form which emerges from the formless heterogeneous museum environment. By decoupling circulation from narrative, the Posthuman museum enables user agency in 
Figure 57. Pedestrian Bridge Floor Plan

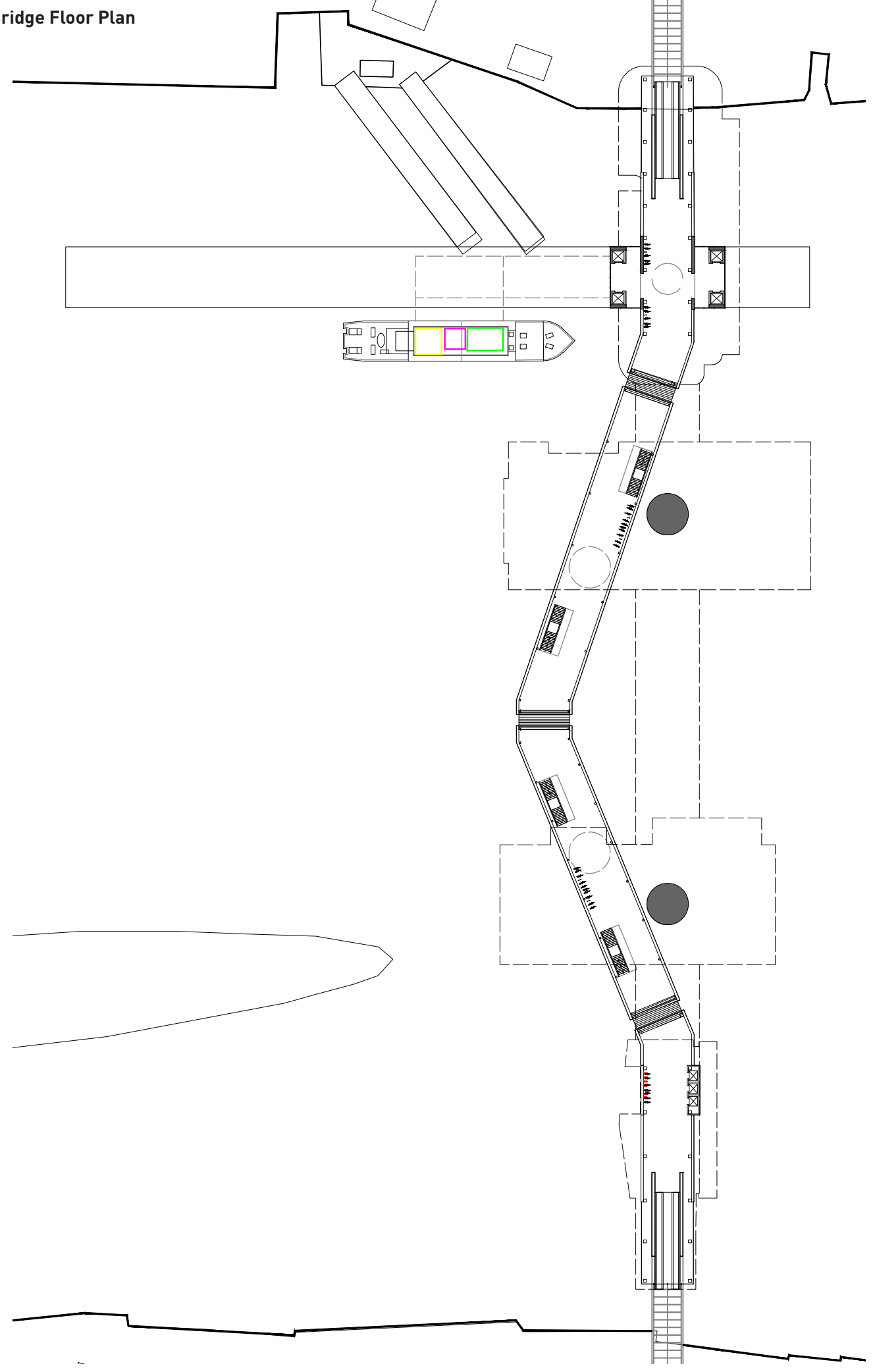

\begin{tabular}{l|l|l|l|l}
0 & 10 & 25 & 50 & 100
\end{tabular} 
Figure 58. Pedestrian Bridge Floor Plan

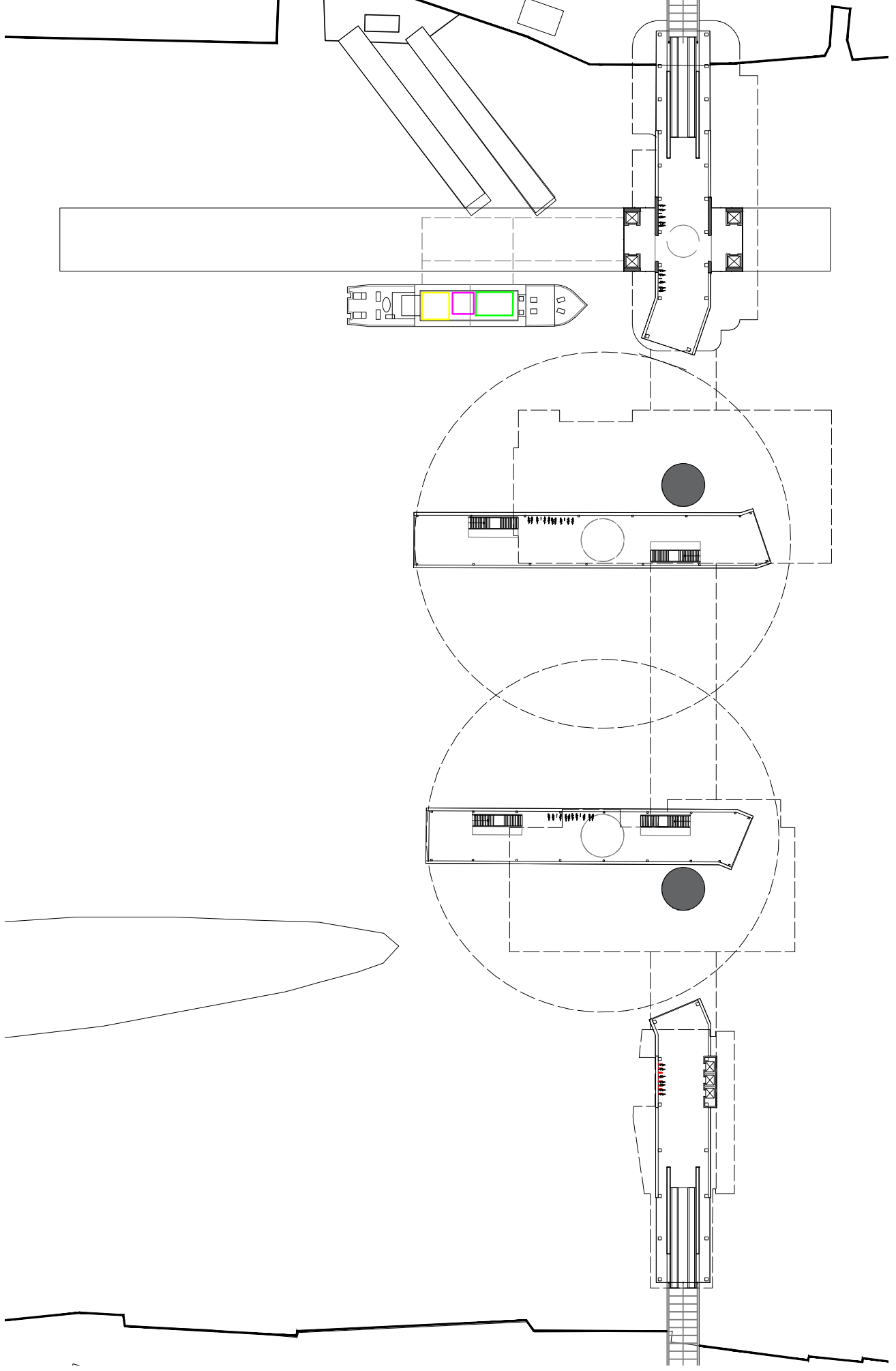


Figure 59. Sorting Pavilion Level One

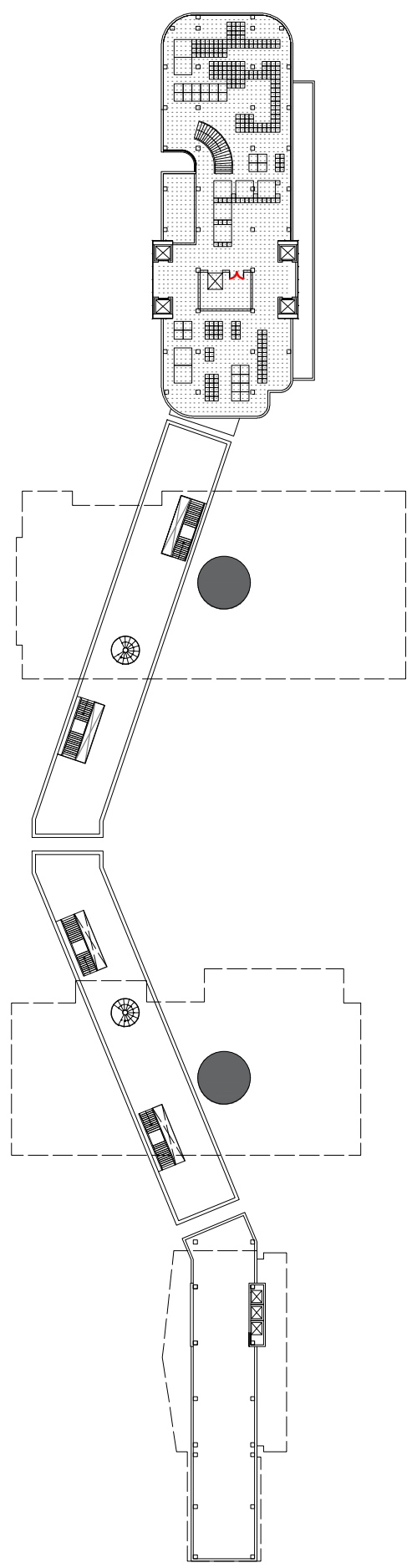

Figure 60. Exhibition Storage Level 1
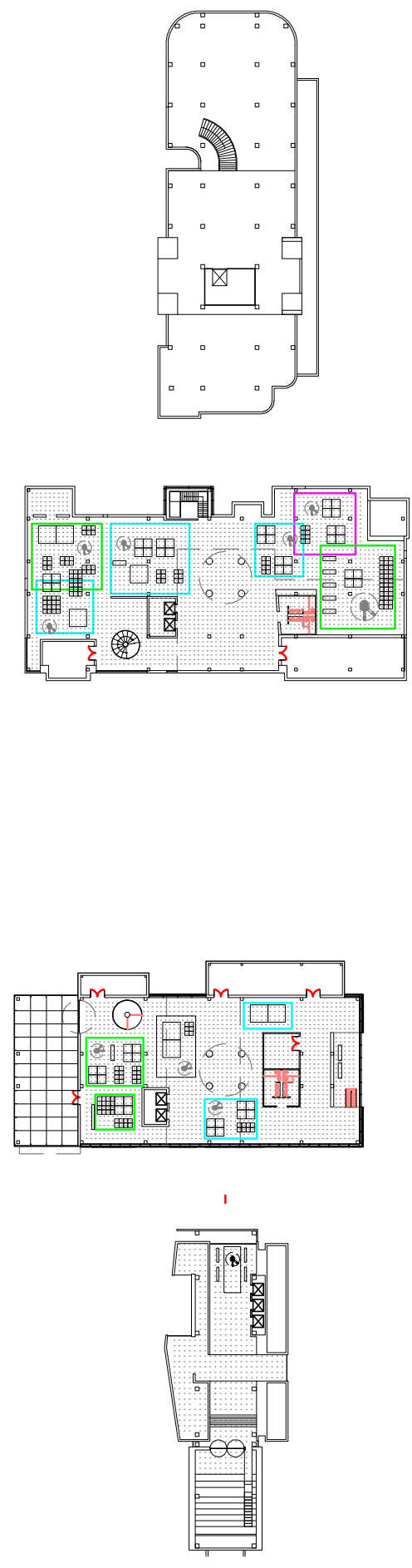
Figure 61. Sorting Pavilion Level One

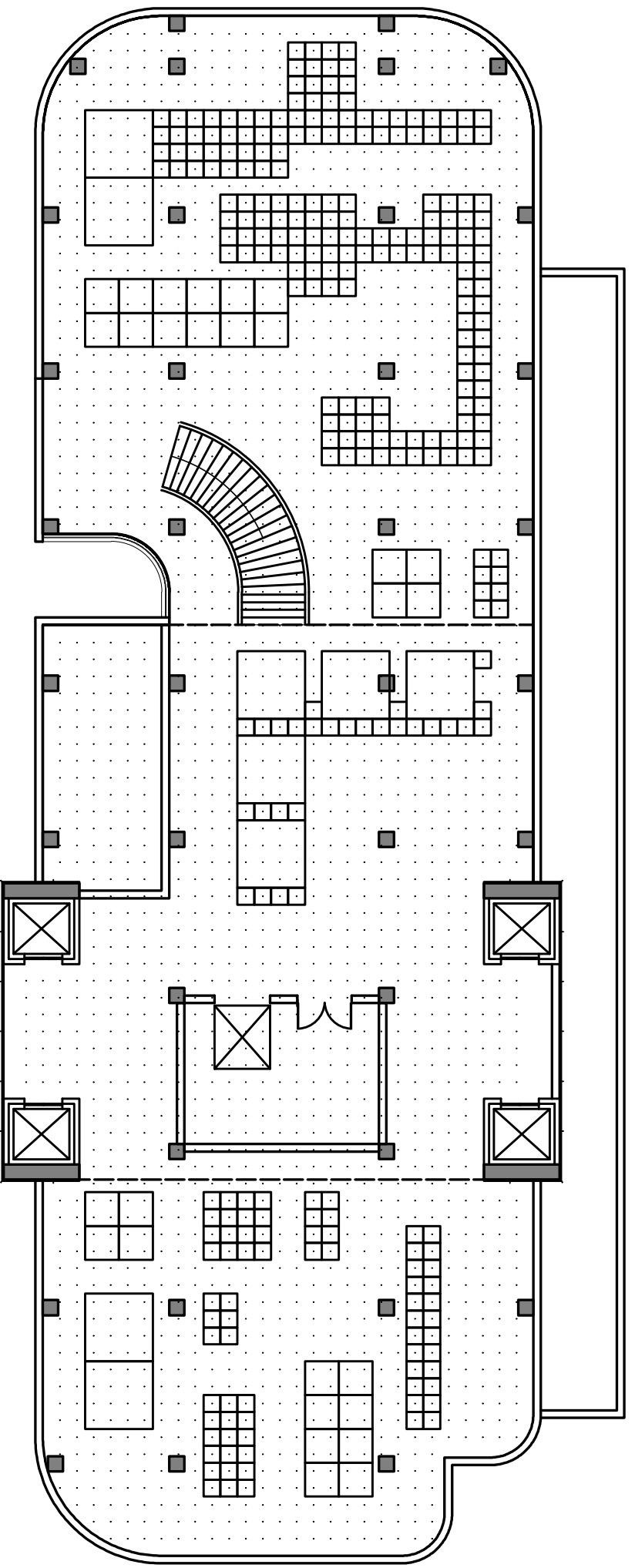




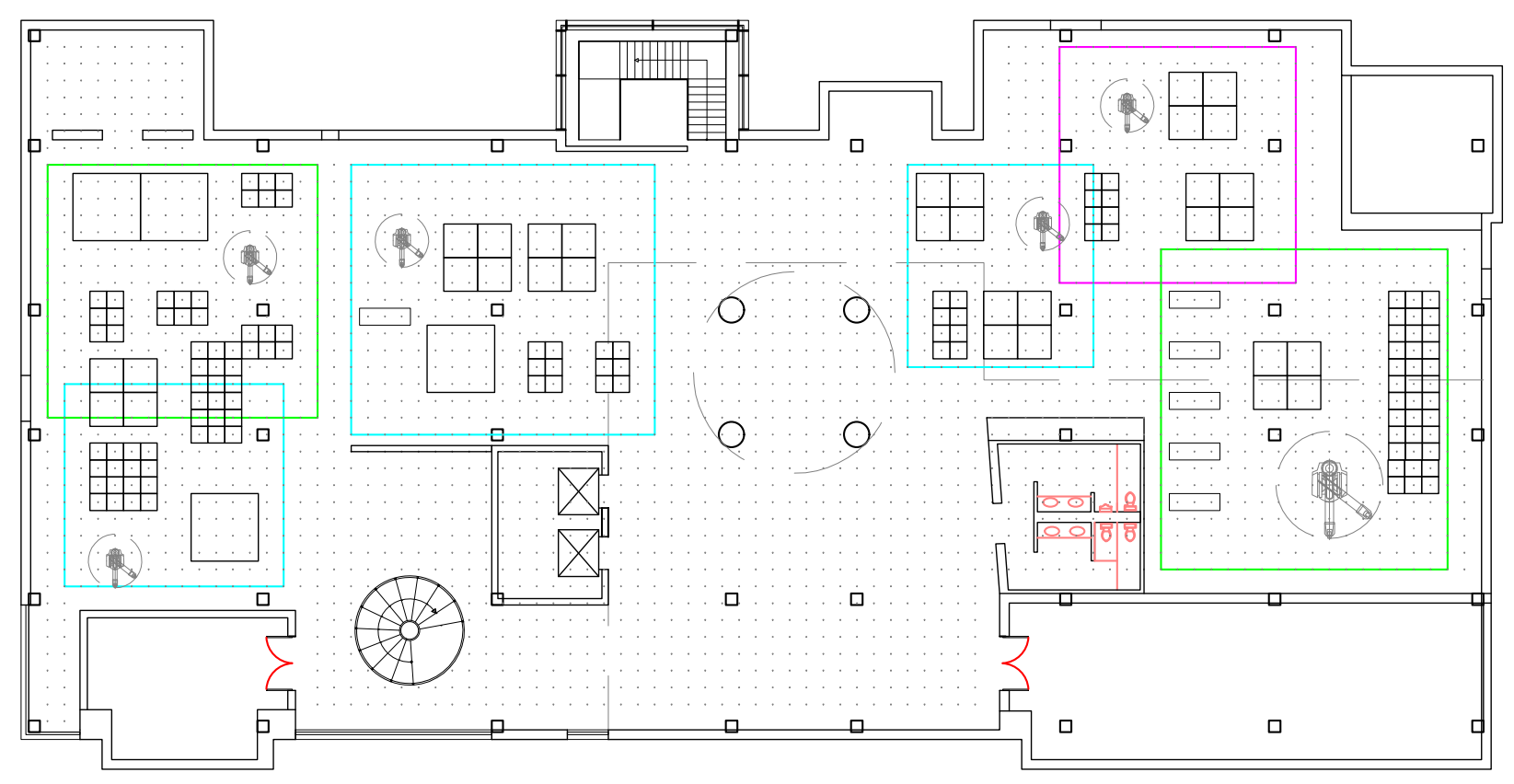

Figure 62. Exhibition Storage (1) Level One 
Figure 63. Exhibition Storage (2) Level One

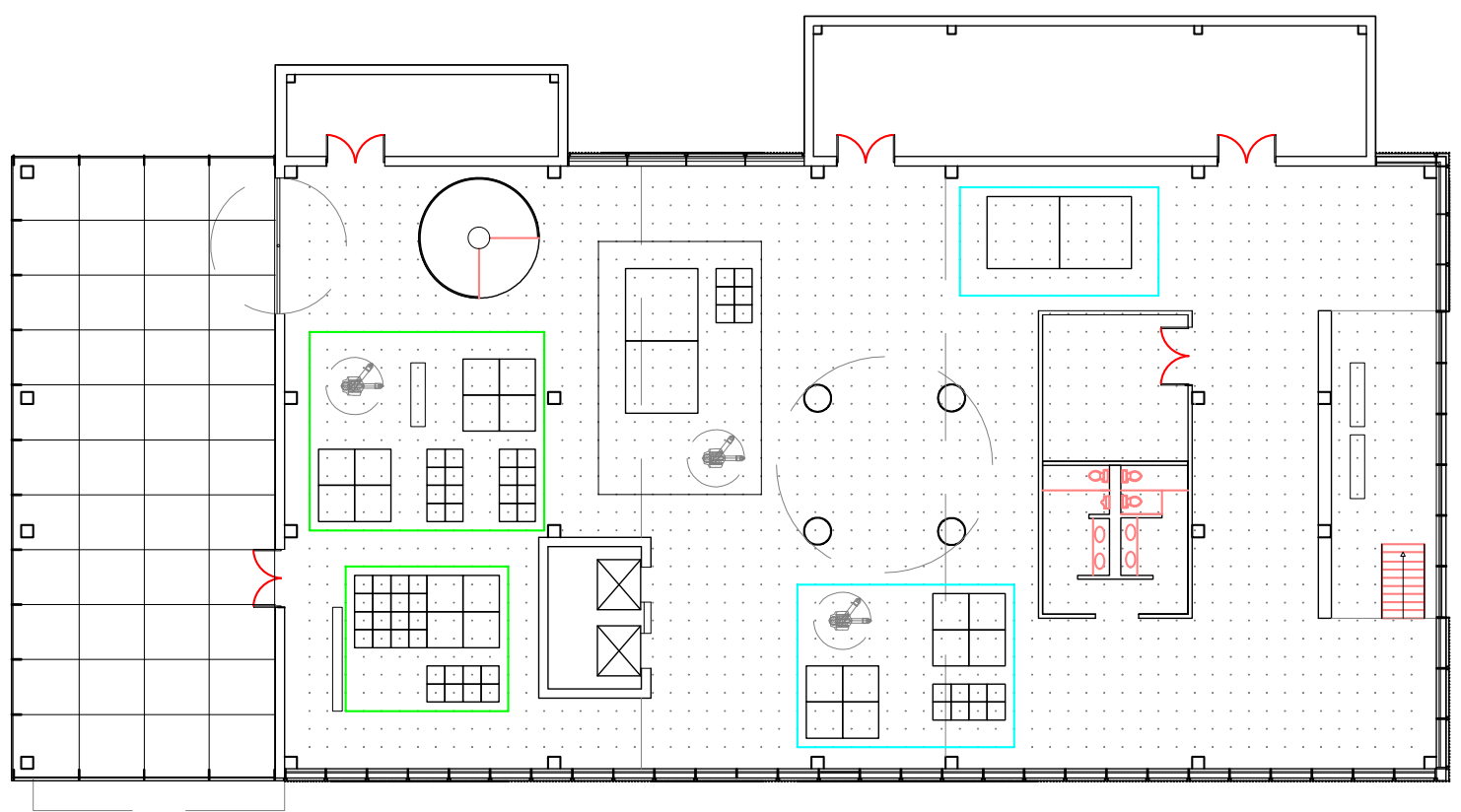


understanding museum artifact. By also treating artifacts as bites of information flowing through a system rather than static objects, artifacts also gain agency in interacting with artifacts across categorical boundaries. Artifact assemblages arise because of a system and architectural logic rather than traditional curatorial framework that was devoid of any context. In addition to the larger architectural prosthetics that make up the museum framework, human and non-human actors are required to ensure the constant flow of artifacts throughout the system at large. At the macro scale the bridge is serviced by large scale infrastructures such as barge transportation routes throughout the museum network while also repurposing the existing museums as nodes in service of this larger network. At the micro scale supply chain robotics produced by Amazon robotics are deployed within the museum to ensure the movement of artifacts throughout the system. Supply chain robotics utilize a ubiquitous sensor cloud and barcodes to navigate across the museum floors. They are positioned to bring artifacts to people, rather than the other way around, highlighted on figures 56,57, and 58. By utilizing a grid of two-dimensional sensors and bar-codes on the museum floor, the robotic system does not require that artifacts be fixed in space. ${ }^{40}$ With mechanisms like that of a car jack, they lift and carry artifacts to their required destination as dictated by museum guests or autonomous protocols throughout the system.
One of the fundamental technical requirements for museum typology is its ability to maintain the appropriate spatial conditions so that artifacts and users can co-exist. The architectural infrastructures utilized in the museum as bridge become critical prosthetics to support these constantly fluctuating storage systems. The mechanical logic for the museum infrastructure works at the individual component level. Each component must be serviced for several reasons to accommodate fluctuations at the local component scale while also accommodating a variety of artifacts circulating through the conduit. HVAC systems are celebrated on the facades of each component making up their formal representation. They are also oriented on the facades with the intent of designing a mechanical system that is flexible in servicing the movement of its component parts. This logic accommodates frequent storage changes with its ability for lateral movement rather than having to puncture floor plates and systems in the traditional top-down arrangement. 


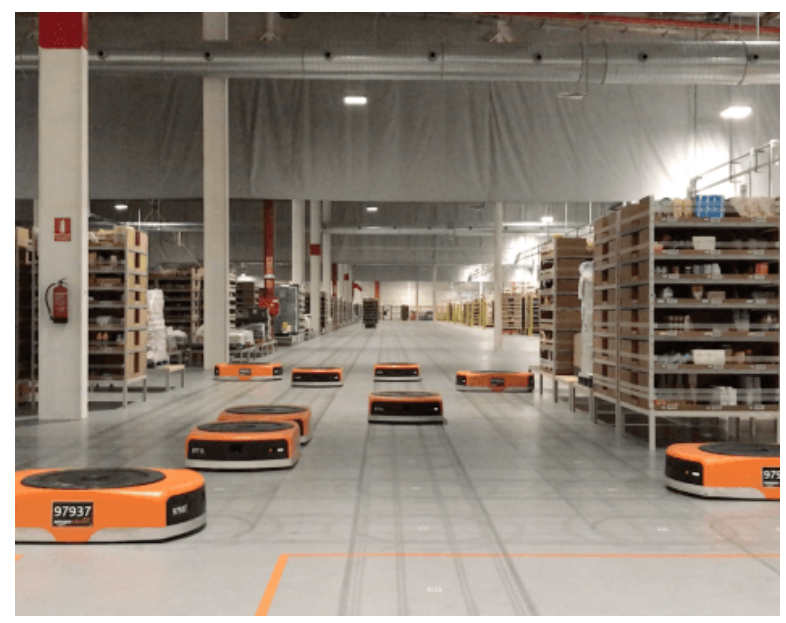

Figure 64. Amazon Fulfillment Centre 1

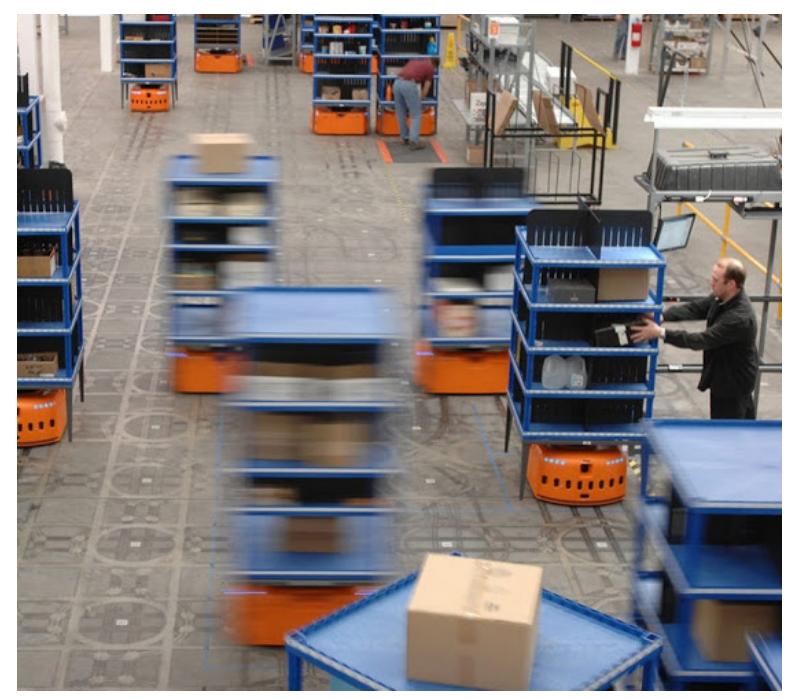

Figure 65. Amazon Fulfillment Centre 2

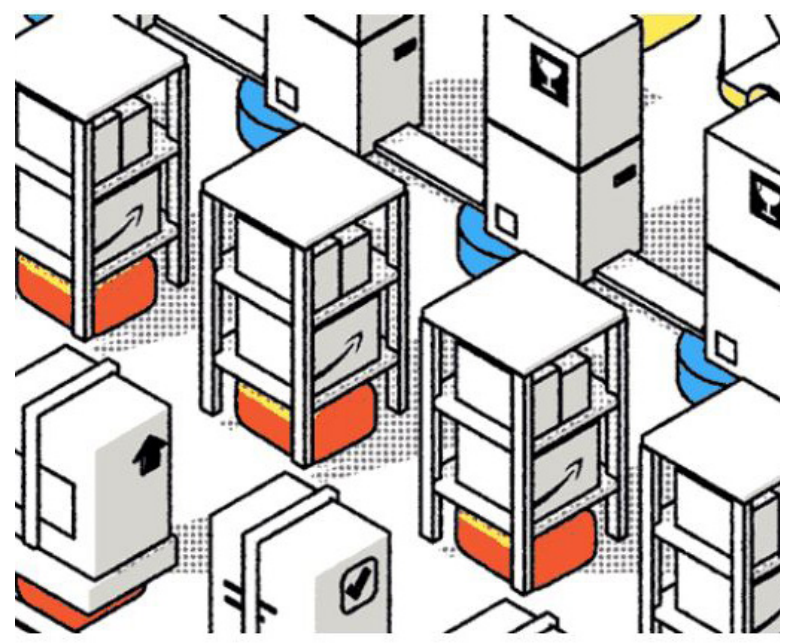

Figure 66. Amazon Warehousing Robotics 


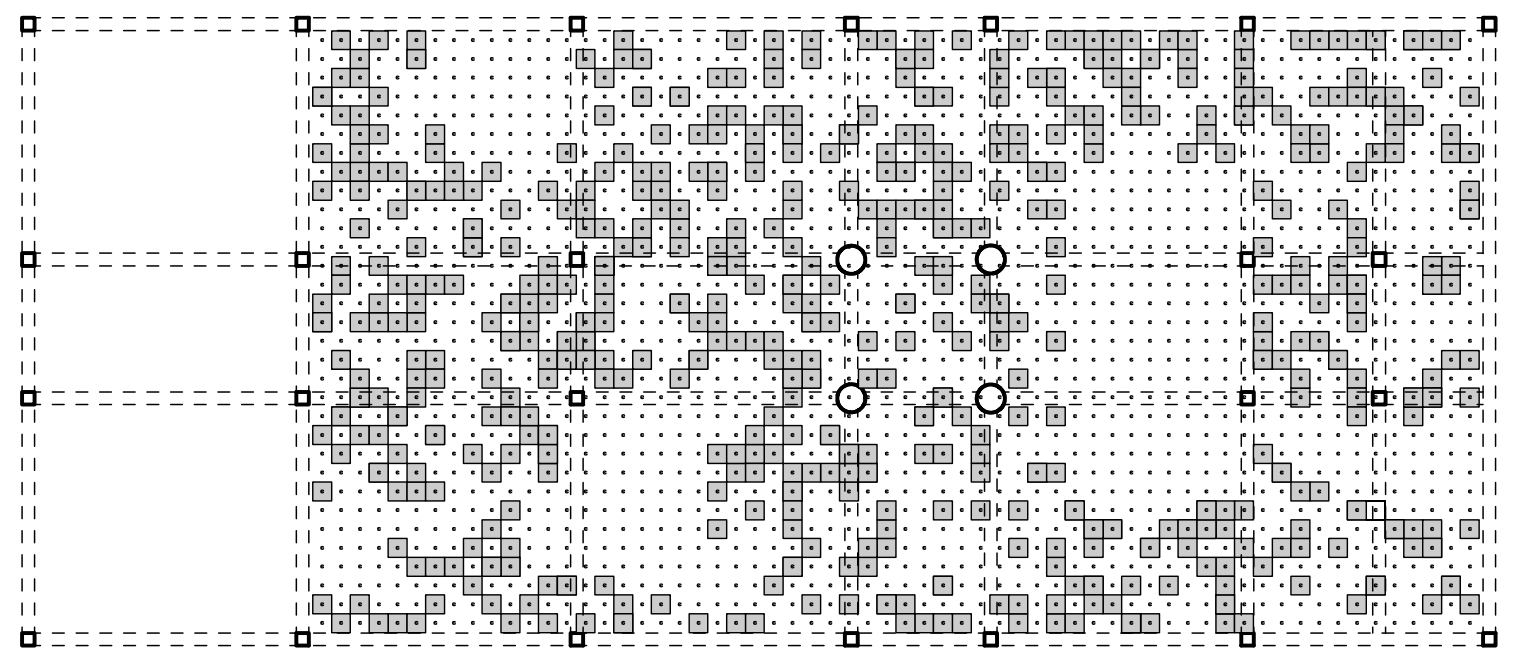

Figure 67. Assemblage Possibility 1

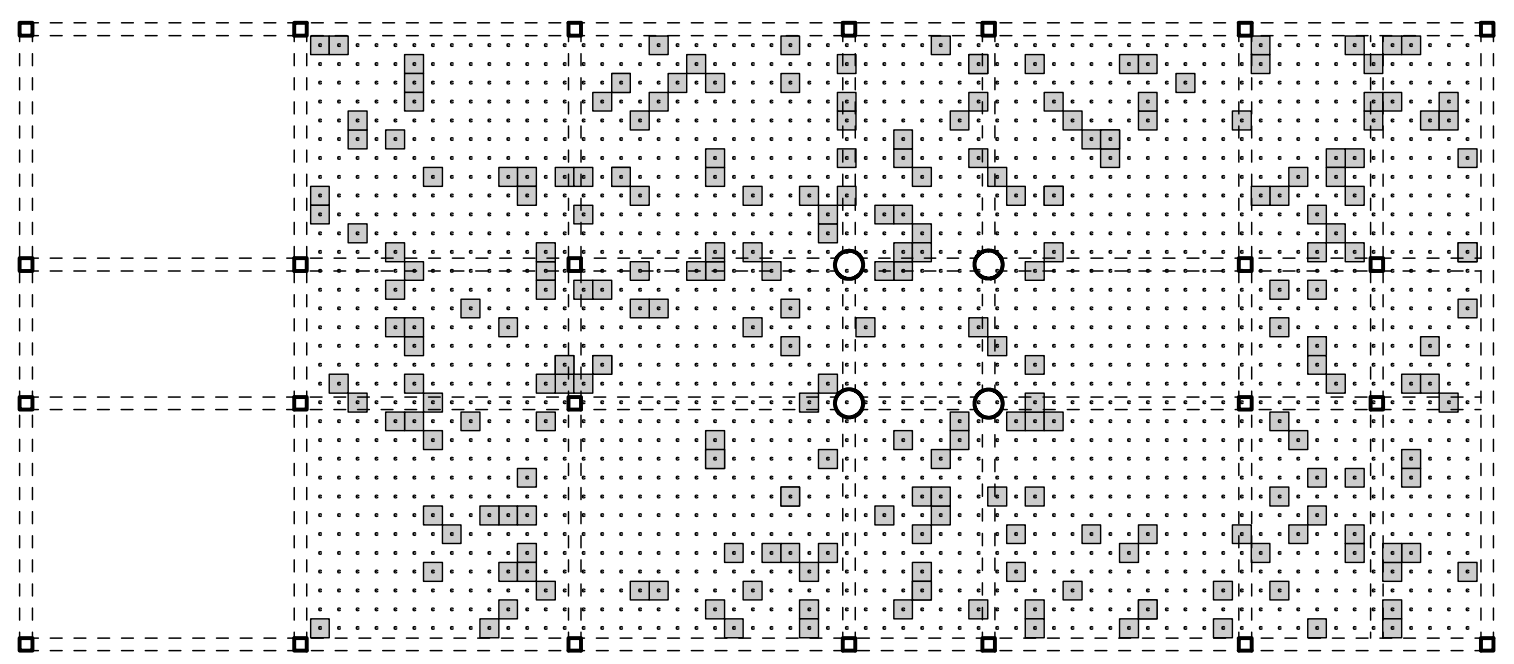

Figure 68. Assemblage Possibility 2 
Figure 69. Framing Storage structures

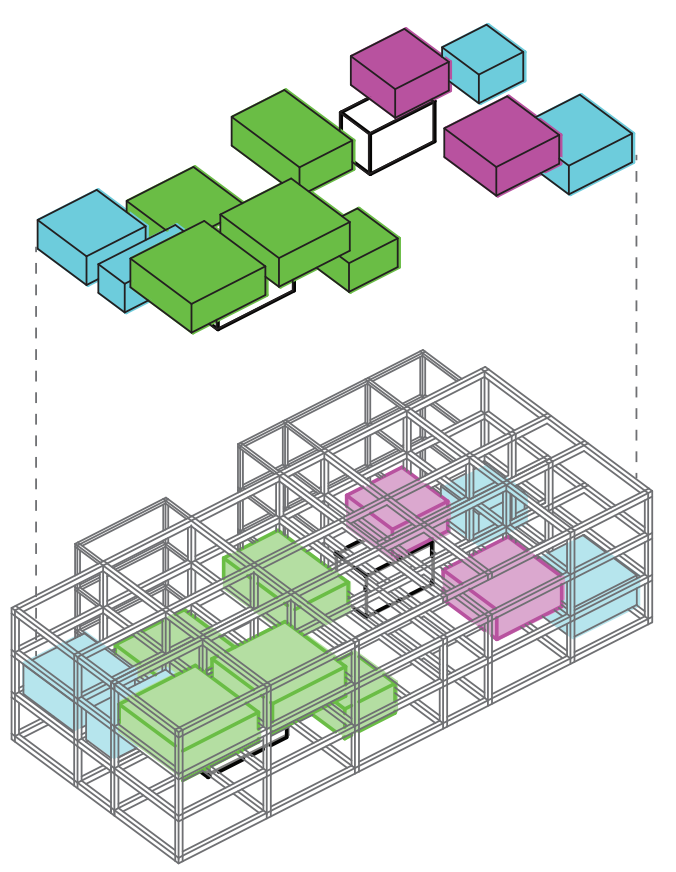

Figure 70. Enabling the Conduit
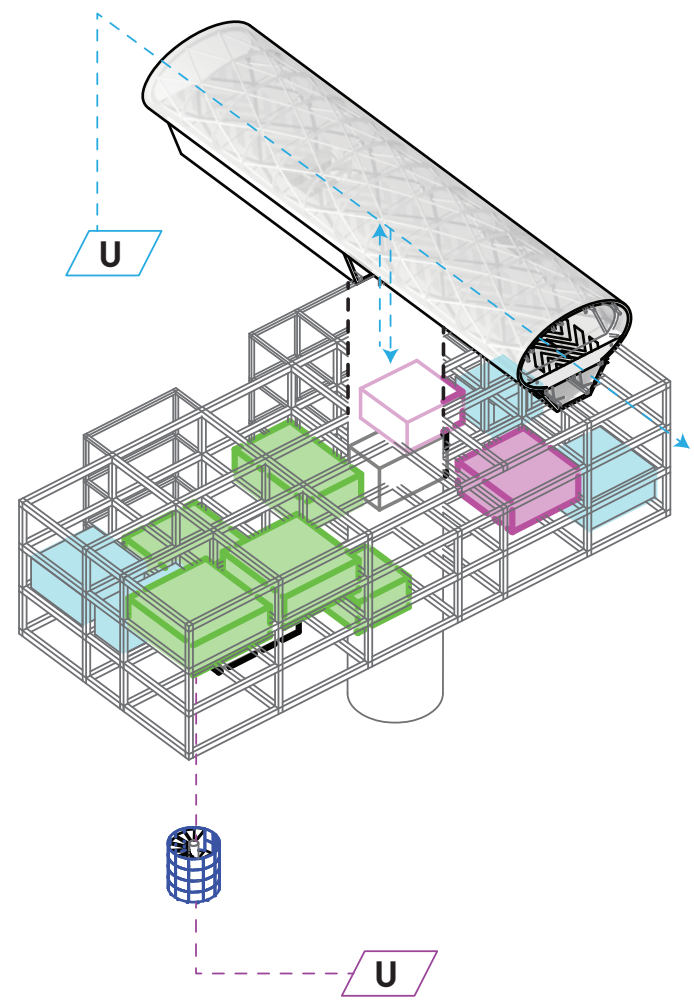


\subsection{ARTIFACT_USER}

Narrative continues to have a particularly significant place in the making and experiencing of both architecture and museums. The normative museum reinforces spatial relationship between user and artifact through static architectural boundaries. This becomes the platform for which narrative structures are developed through curatorial systems rather than organic user narratives. Utilizing infrastructural logic to deconstruct this model, the museum as bridge leverages architectural systems to allow users to develop their own museum experiences in concert with autonomous machines. The pedestrian bridge and artifact conveyor belt facilitate the movement of artifacts and users throughout the system. As a result, relationships between user and artifact shifts from spatial to temporal because the system dictates when they meet not where they meet. Temporal relationships are built and sustained by their continuous movement throughout the network. Ultimately, the architectural infrastructures and systems developed in the Museum as Bridge serve to reinforce this relationship between user and artifact because spatiality is continuously constructed and is part of the productivity inherent to the unfolding system. Primary movement of artifacts and users throughout the museum is first established by the development of the artifact conveyor belt and pedestrian bridge. These bridges become the threshold for traversing the River Thames. They also provide the inputs into the system throughout the entire length of the bridge in the form of vertical circulation into each component part. Movement of information throughout the system is also enabled by ubiquitous sensor grids that are overlaid throughout the museum to deconstruct both user and artifact into a common information stream that is coordinated and programmed throughout the system. Such a blurring of identity is produced by prosthetic tools, that reconstruct the body and convolute its borders. The body itself becomes an artifact within the system. The infrastructural system causes traditional categories such as body, prosthesis and architecture to slip into one another in service of the system. 
Figure 71. Fluctuating Program Blocks 01.Rhythm in museum blocks and overlays illustrates interior motion and the flowing of data throughout the circuit.

Figure 72. Facade Translation

02. Applying datums to proportion and create a variety of scales reflective of the interior museum structure and also in relation to the floor levels and overall proportion of the building.

Figure 73. Layered

03. Façade iteration, aggregating previous steps to develop a façade system representative of interior assemblages.

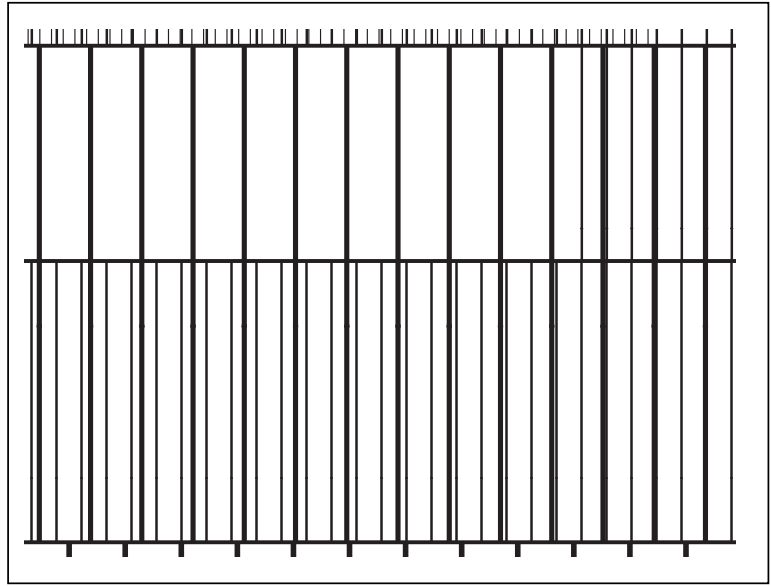




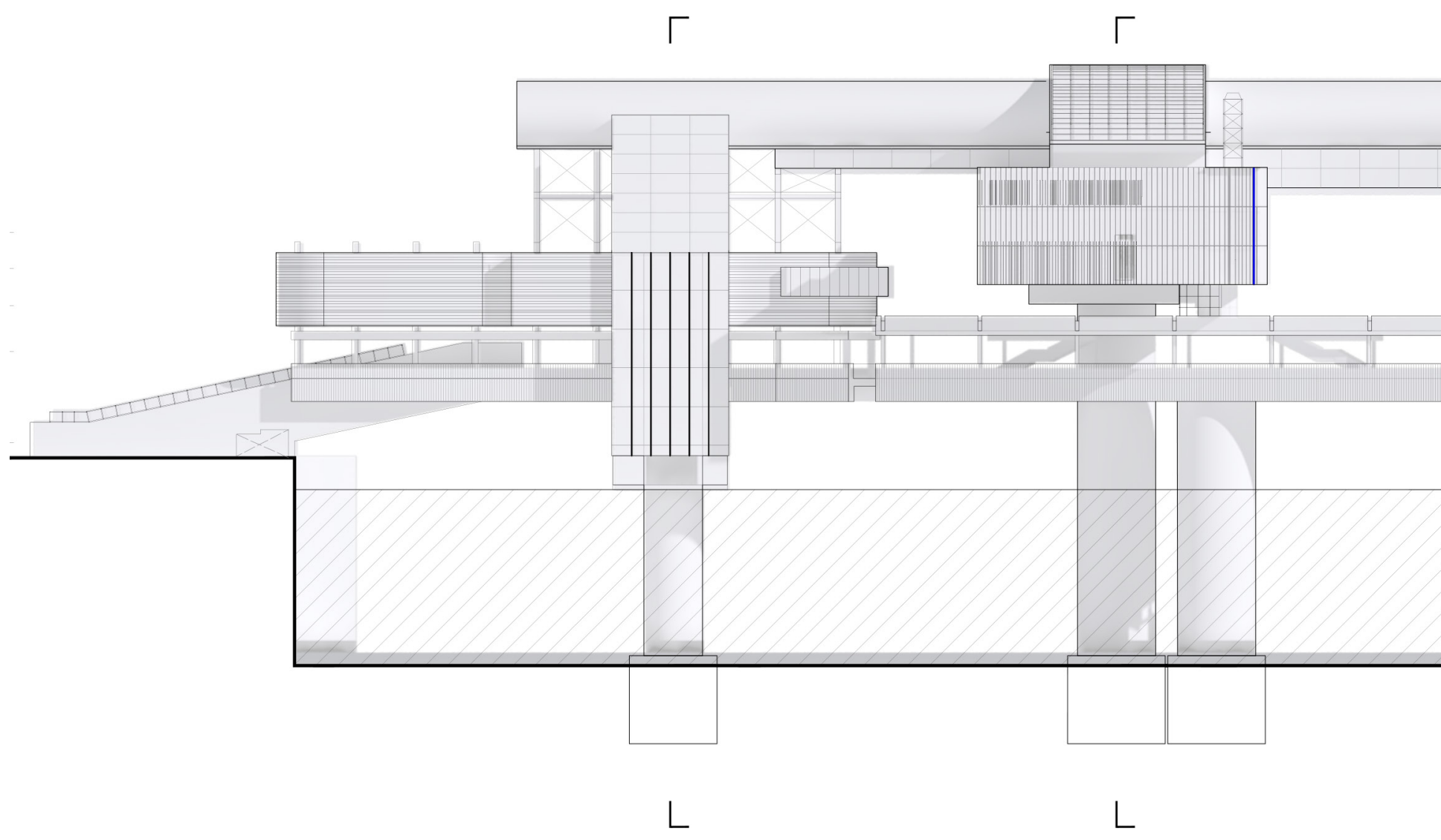


Figure 75. Render Looking East 


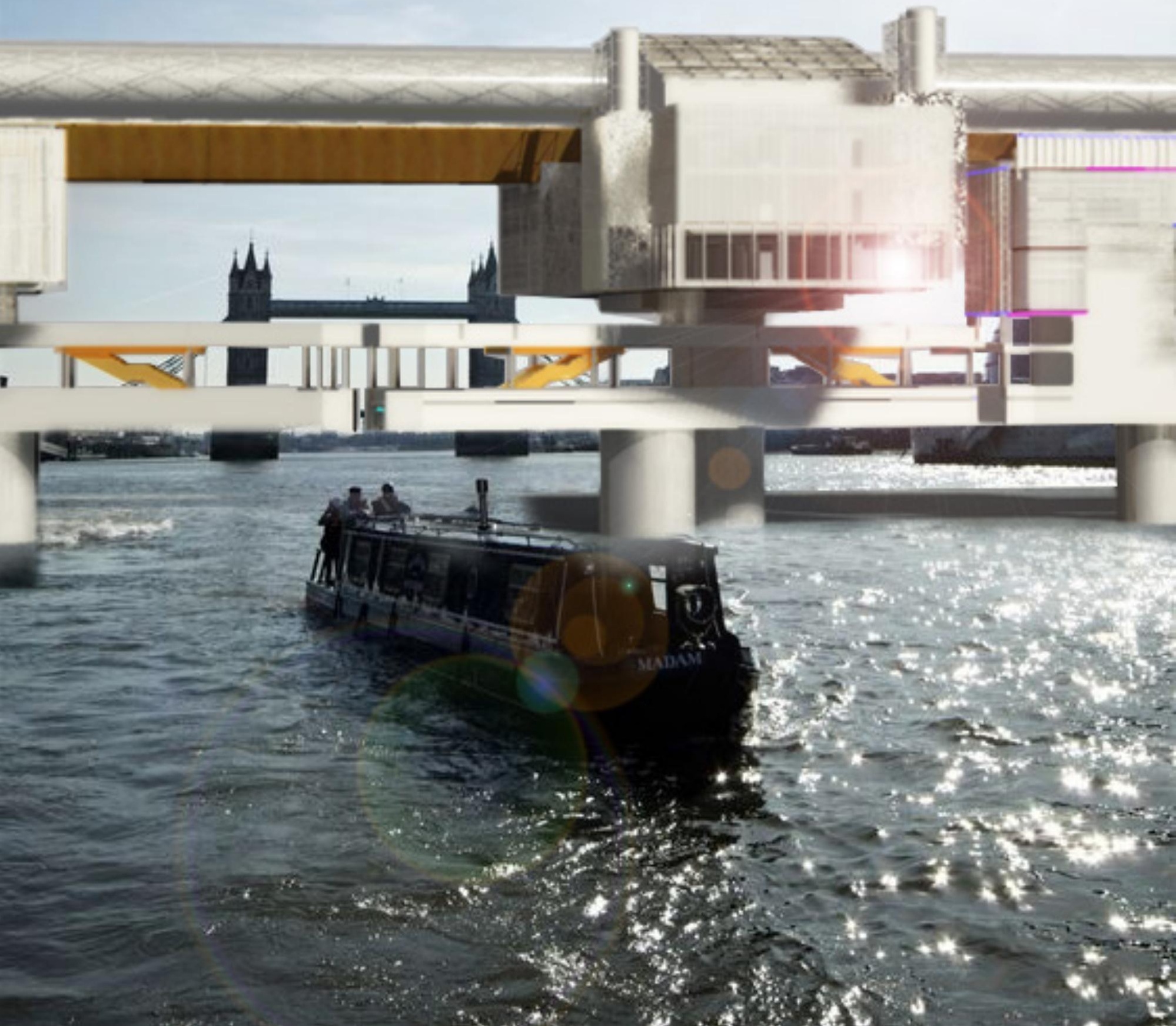




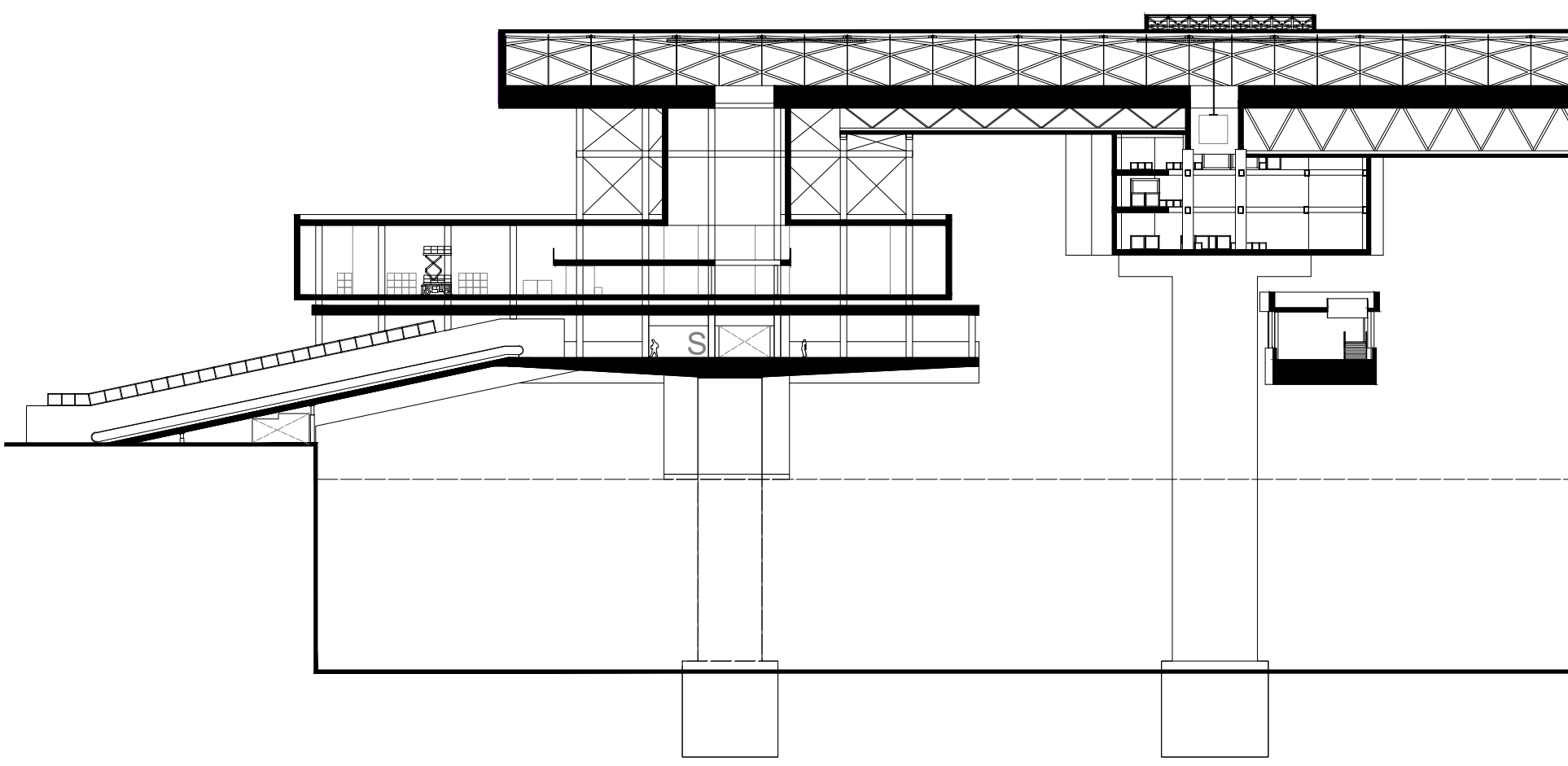




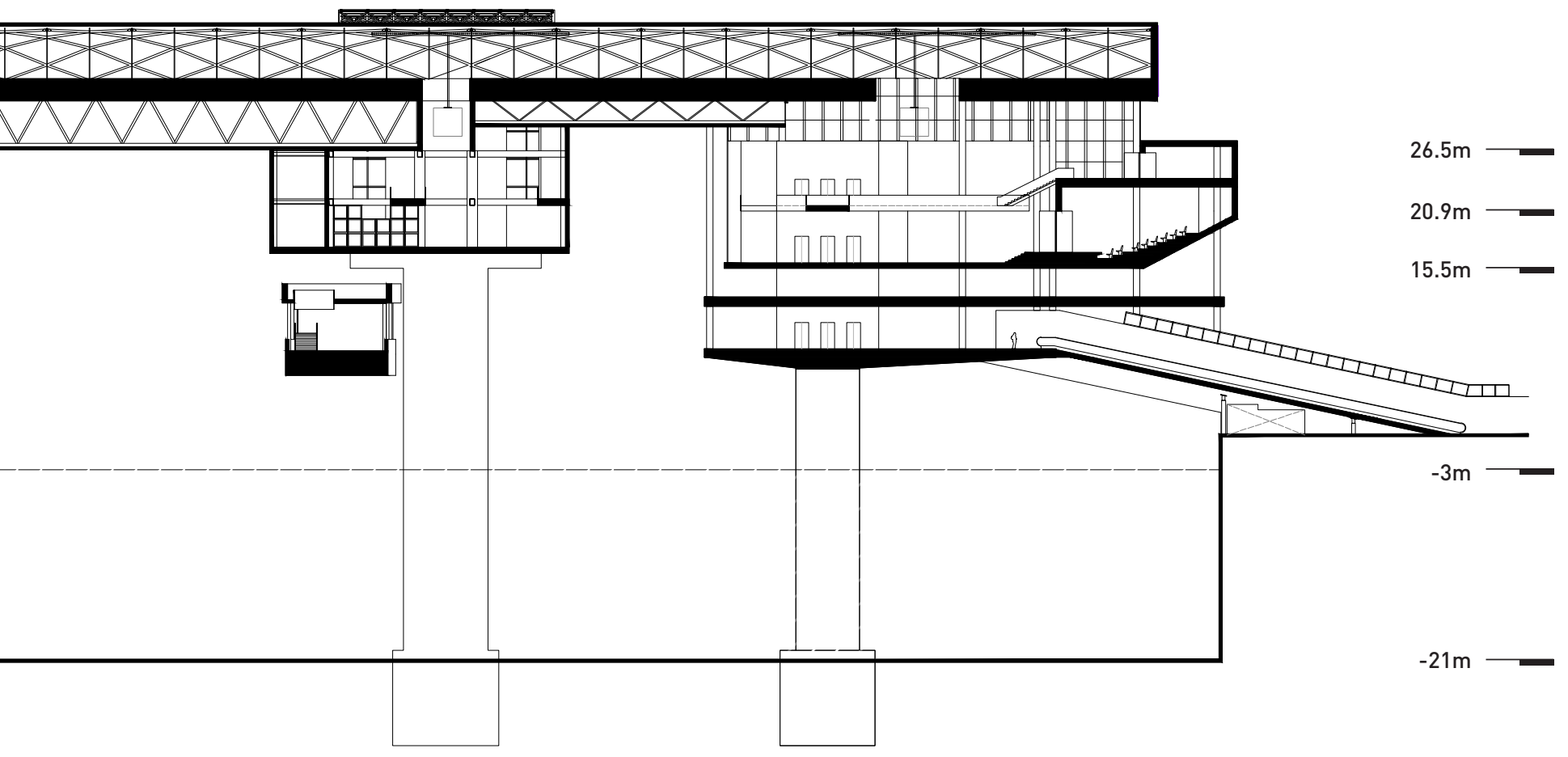




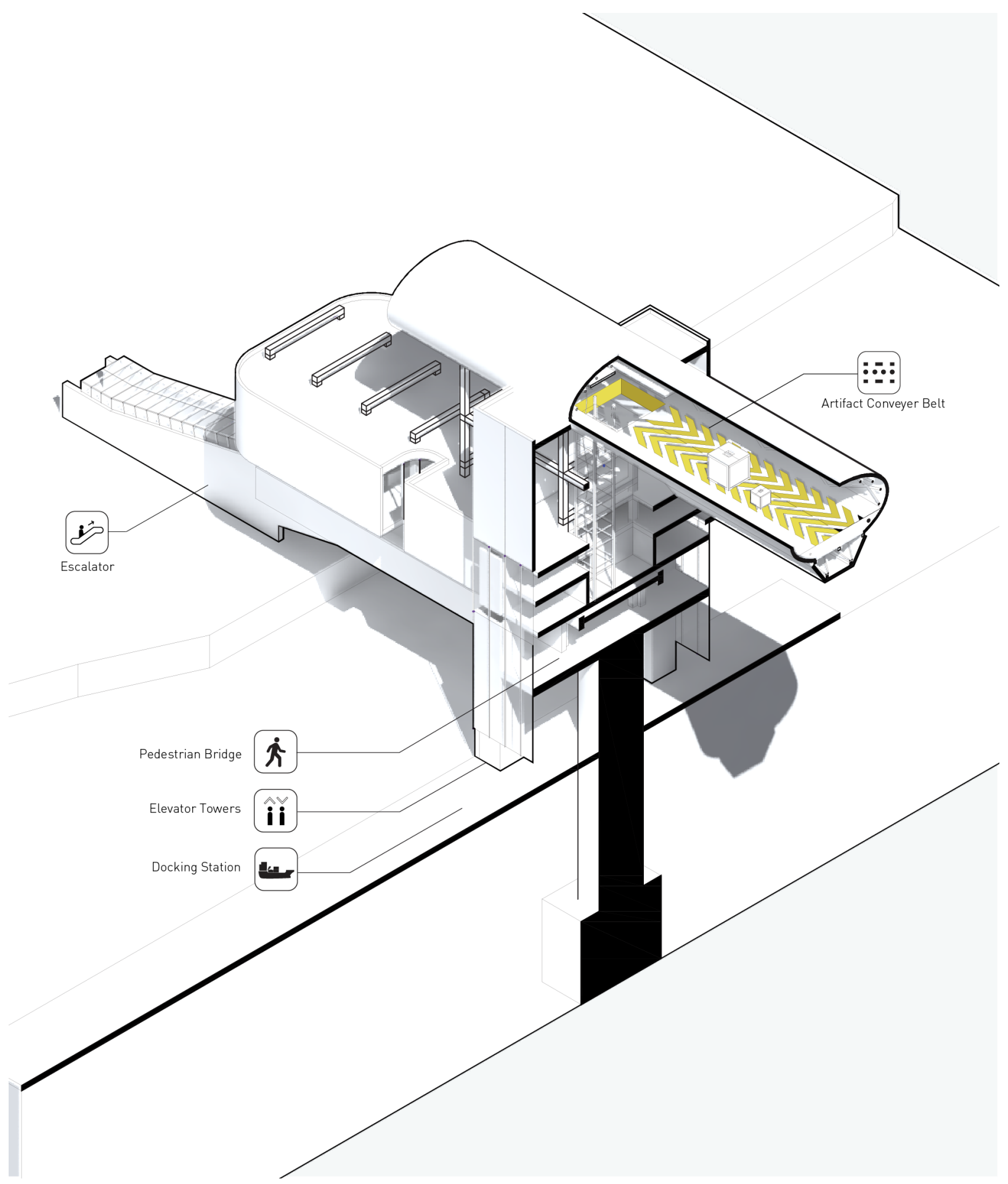

Figure 77. Sorting Pavilion 

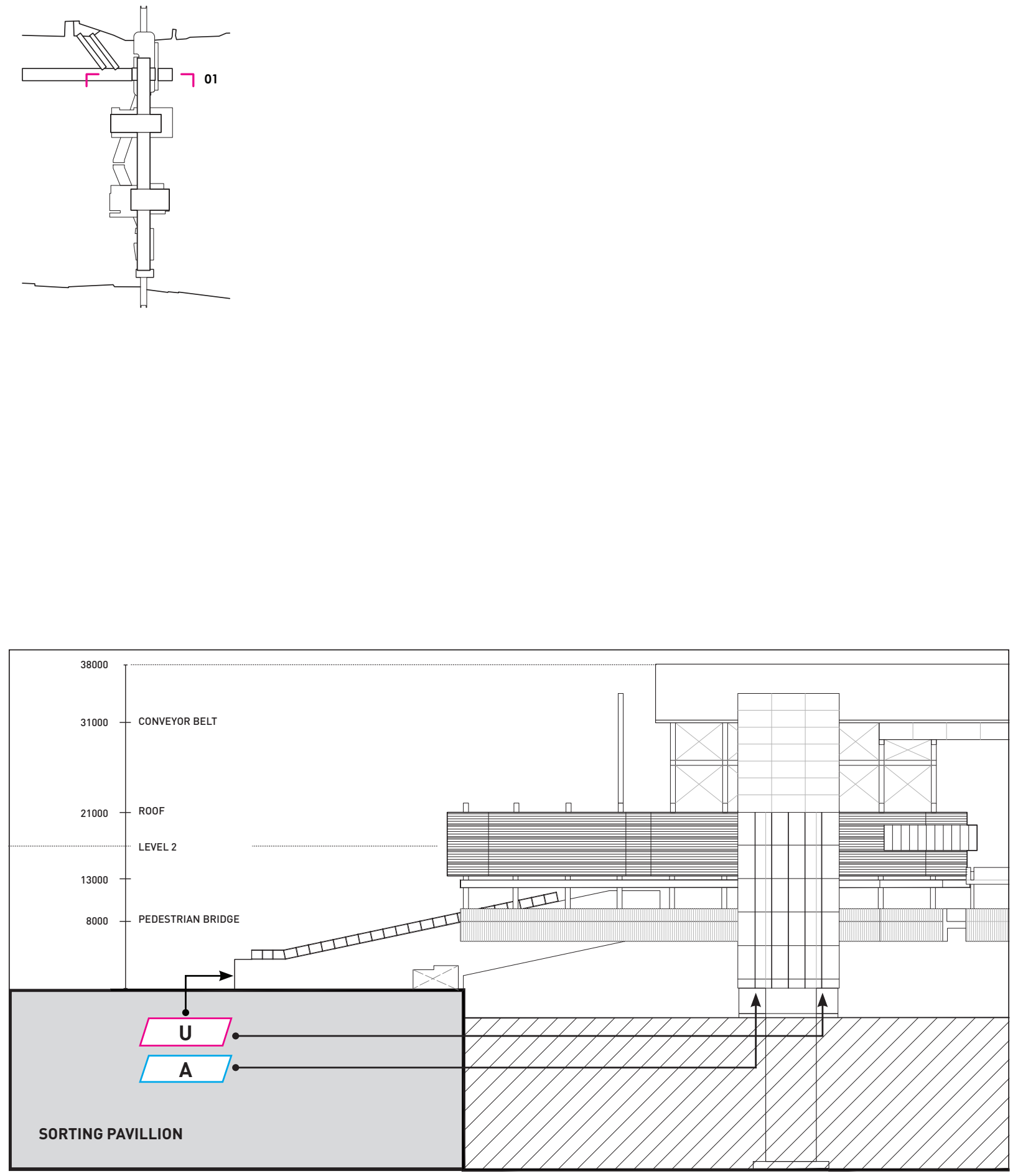

Figure 78. Sorting Pavilion Elevation 


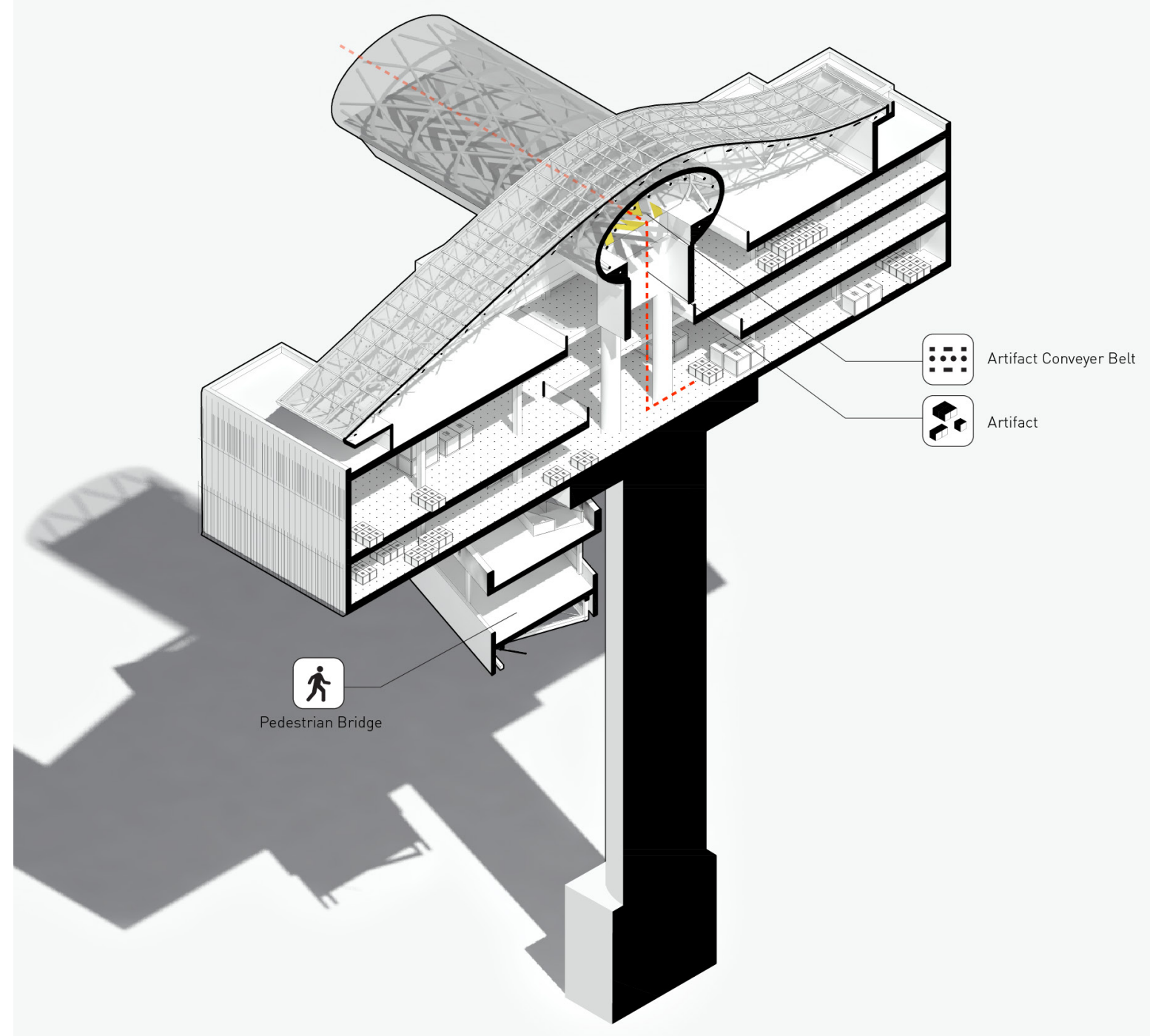

Figure 79. Exhibition Storage 1 

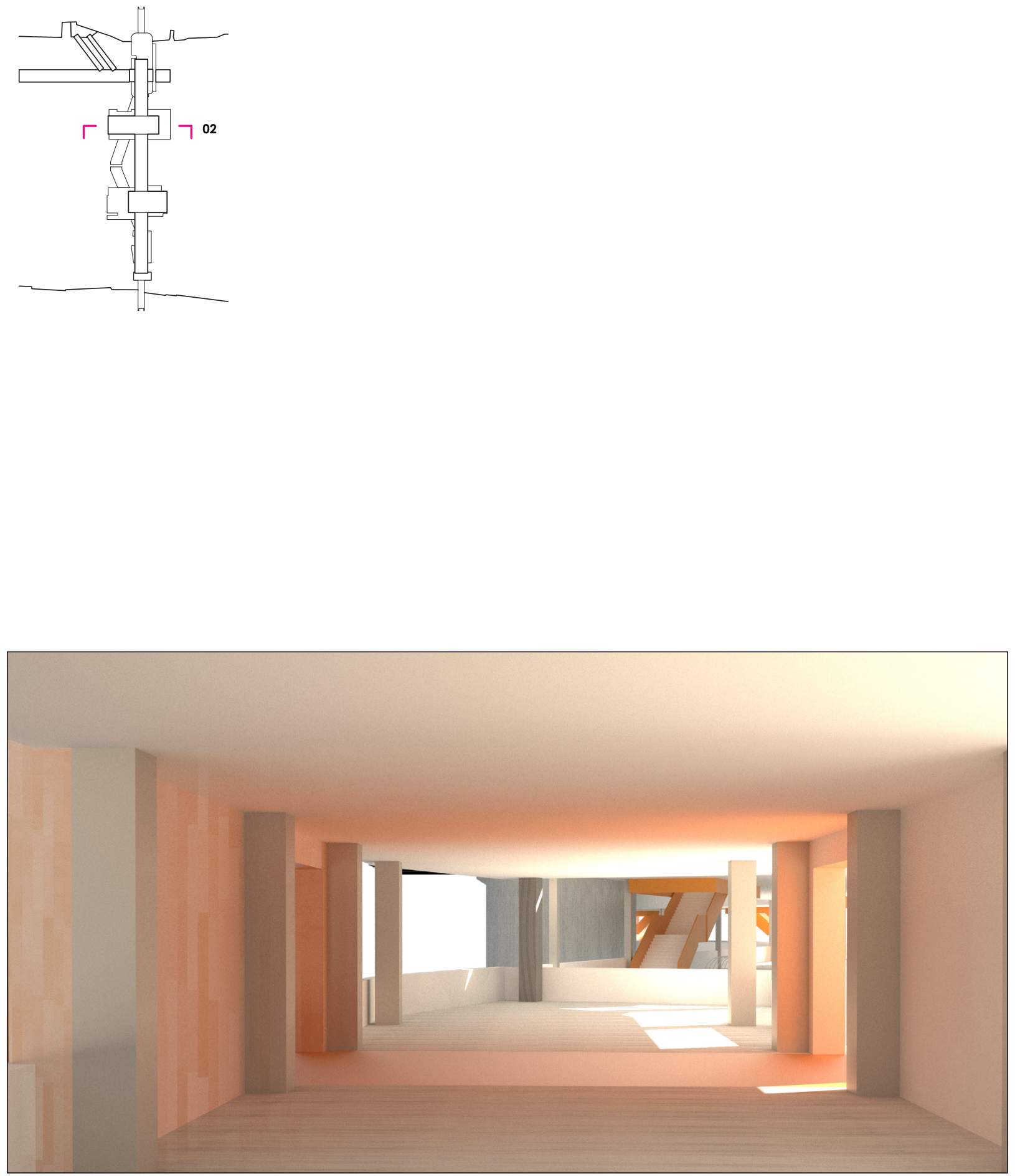

Figure 80. Pedestrian Walkway 


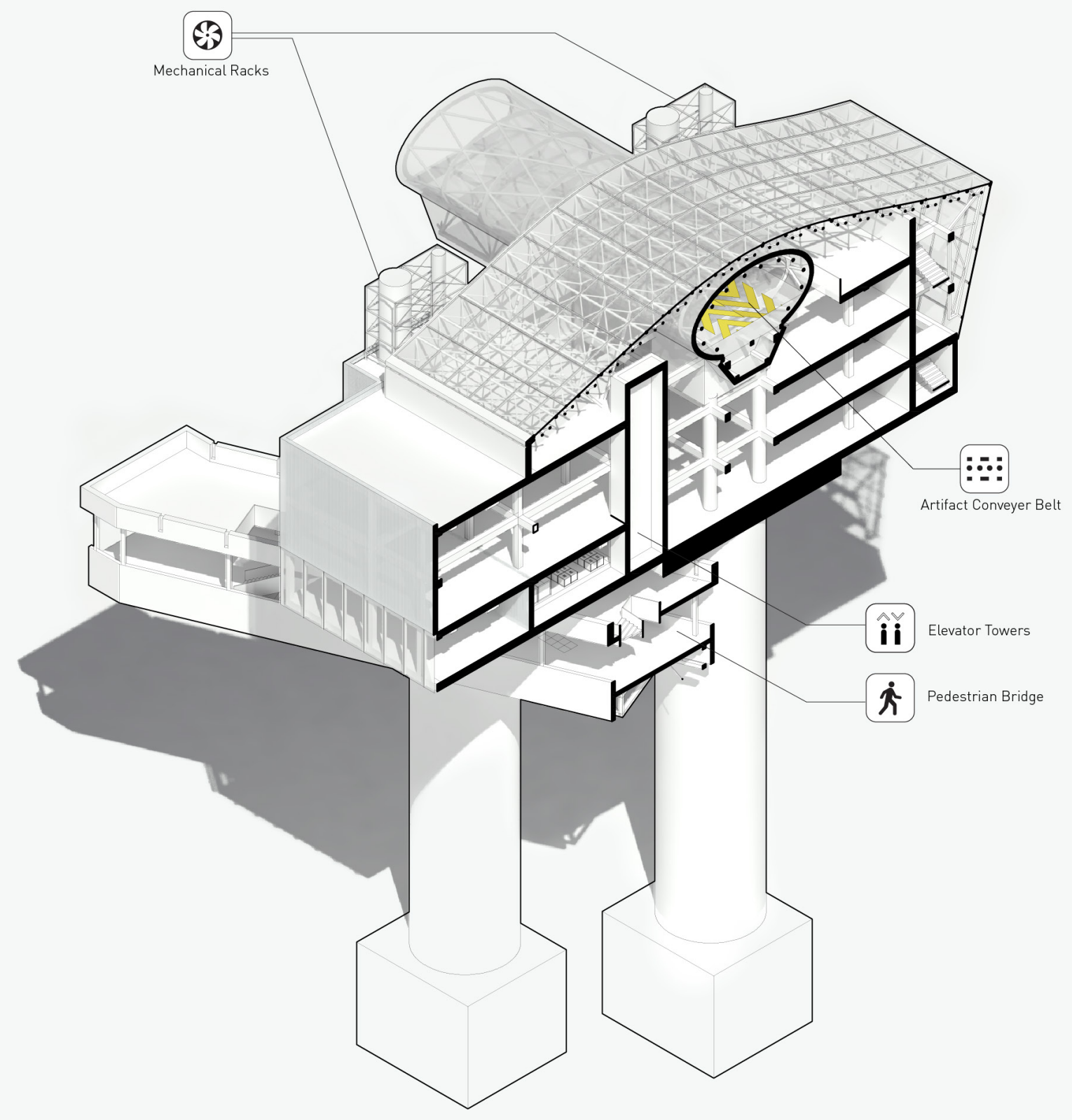

Figure 81. Exhibition Storage 2 

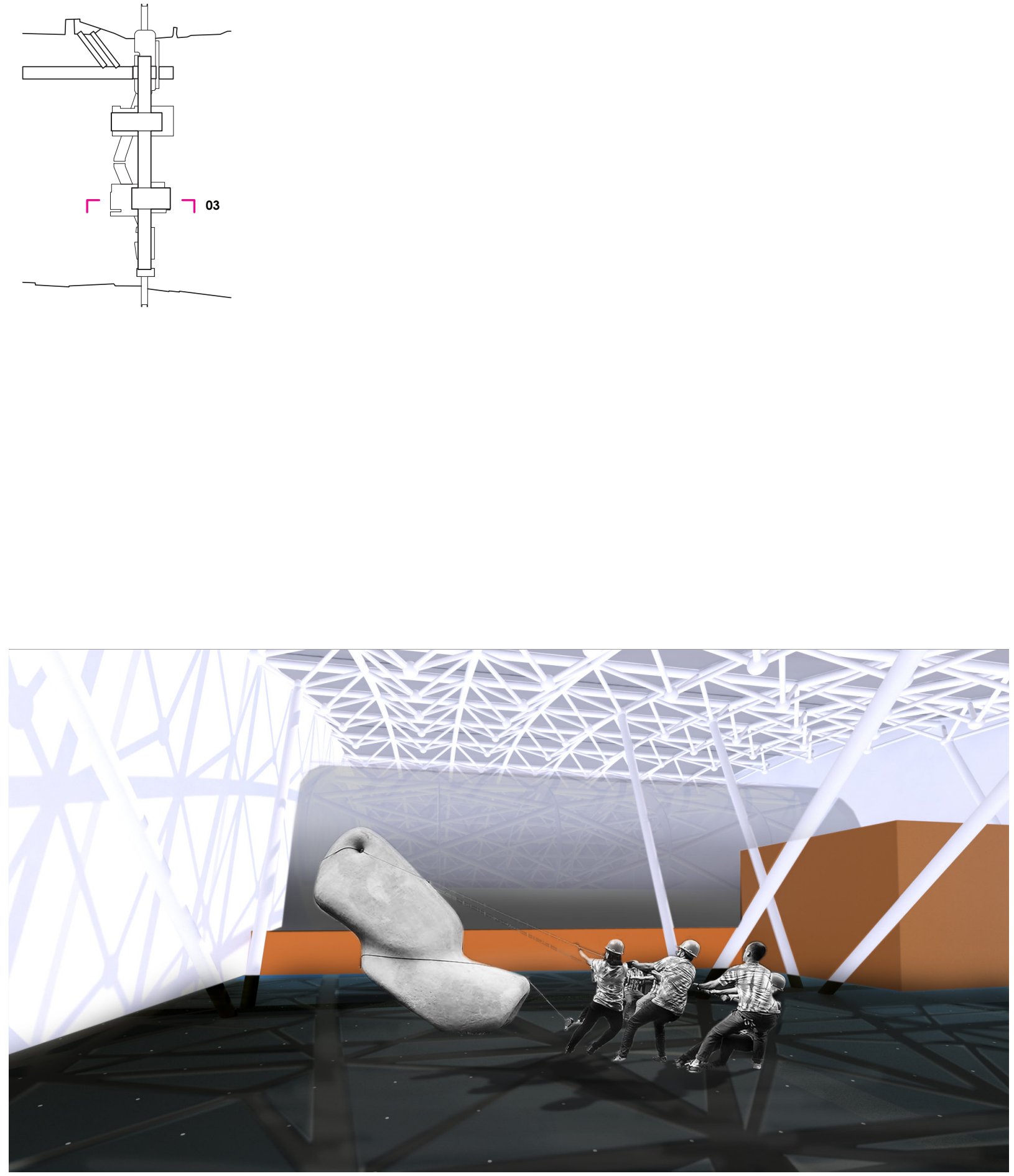

Figure 82. Sculpture Garden 


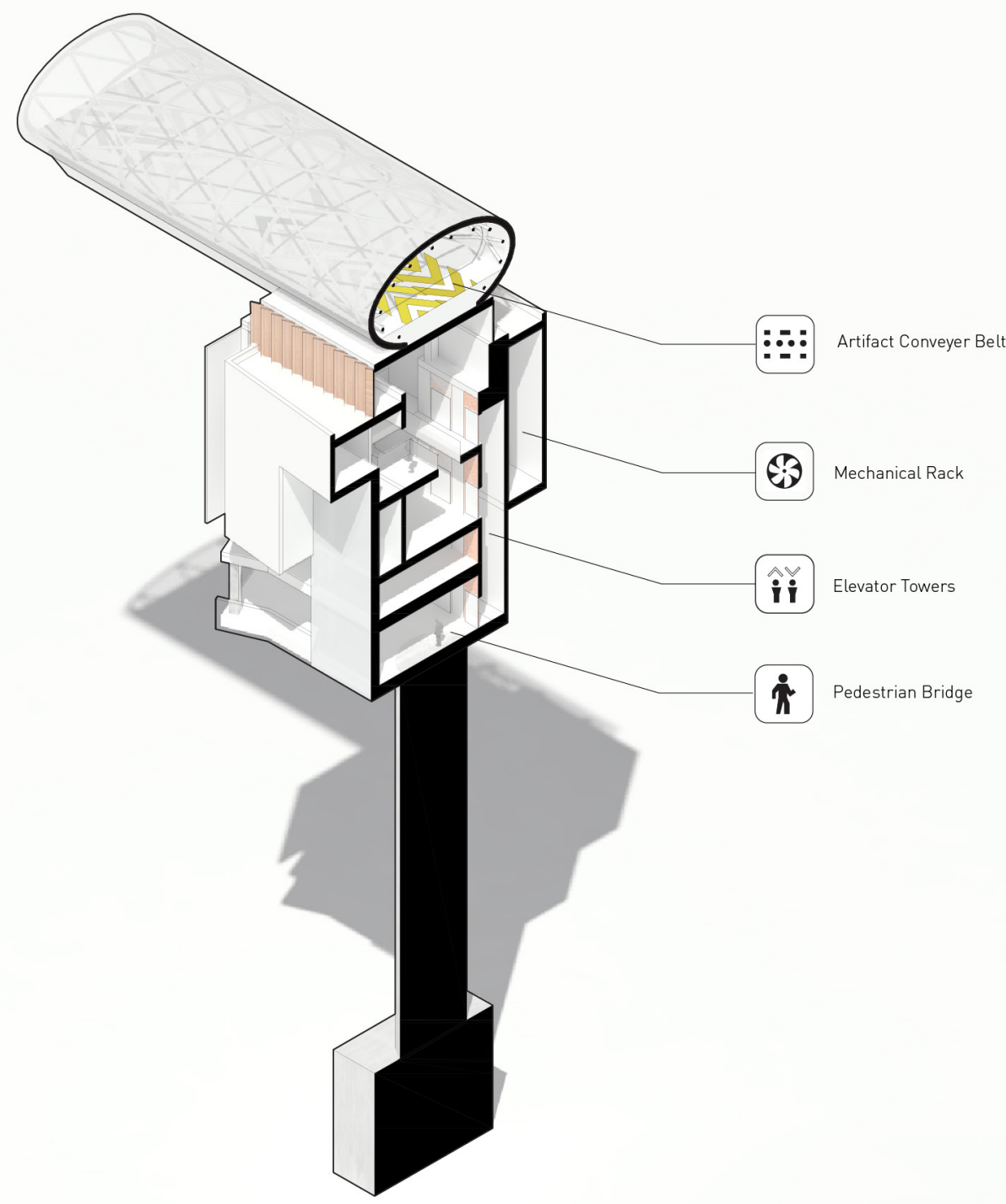



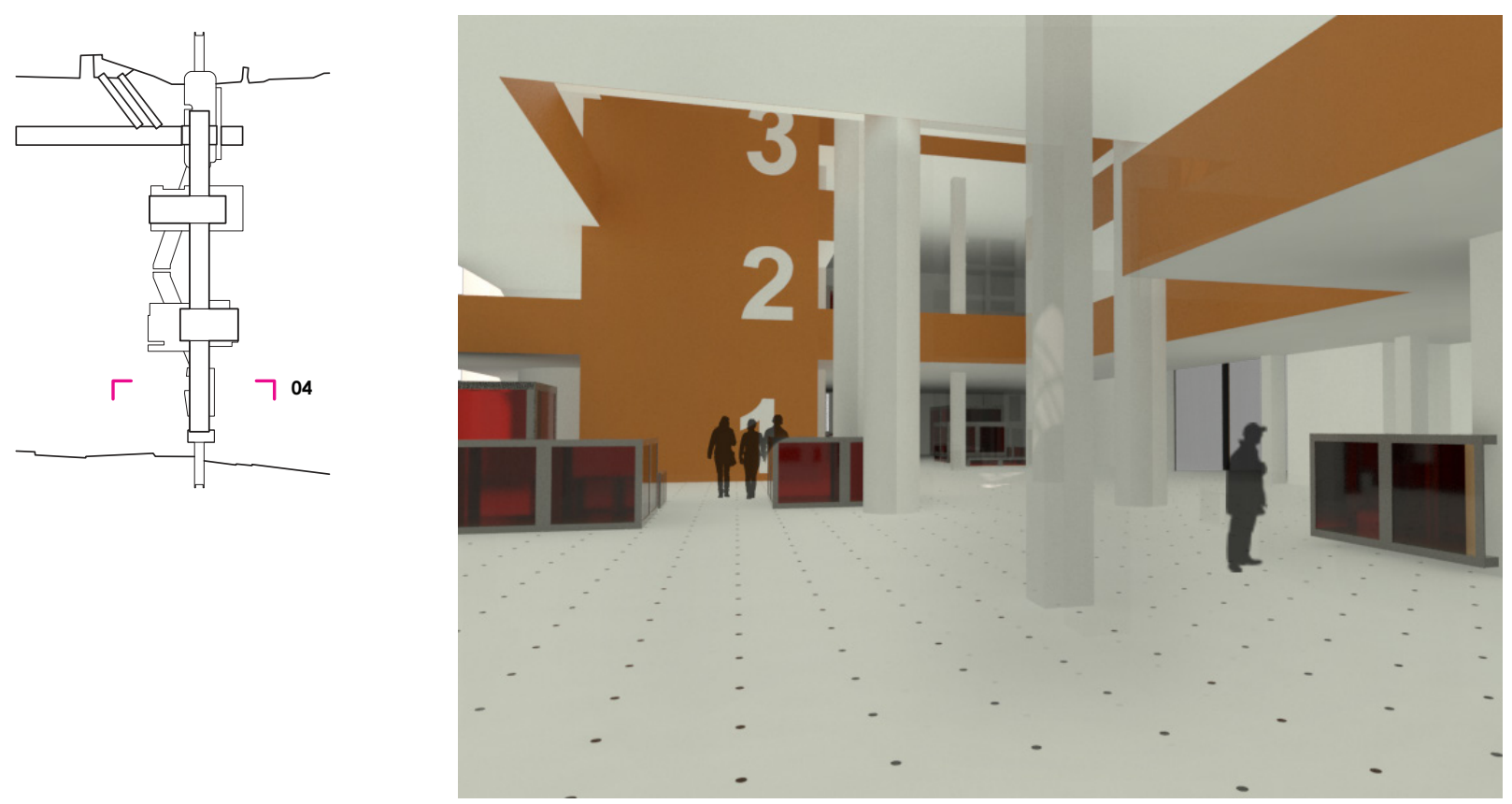

Figure 84. Interior Museum Render

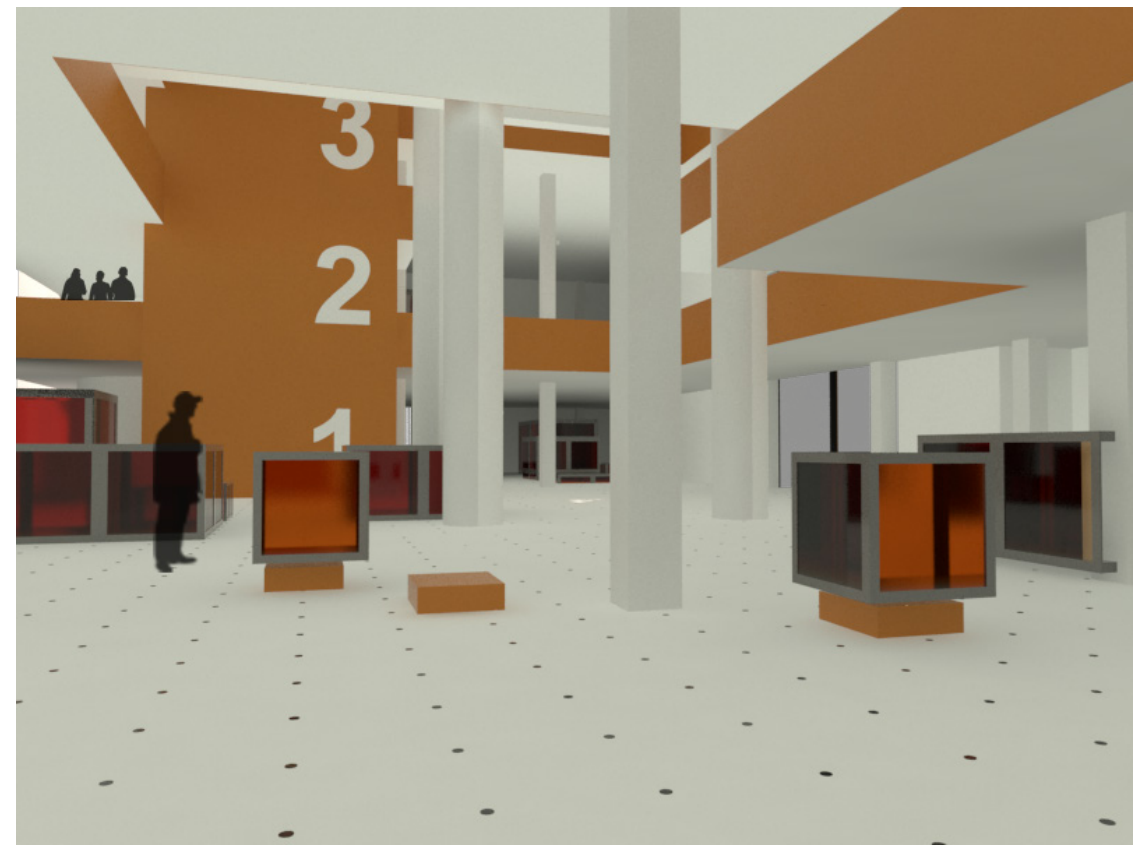

Figure 85. Interior Museum Render 


\section{NOTES}

38 Easterling, Keller. Extrastatescraft: The Power of Infrastructure Space. (London, Verso 2014) p.9

39 Koolhaas, Rem, and Bruce Mau. "Bigness or the problem of Large." In S,M,L,XL: Office for Metropolitan Architecture, 495-516. (New York, The Monacelli Press 1998) p. 495

40 Lecavalier, Jesse. The Rule of Logistics: Walmart and the Architecture of Fulfillment. (Minneapolis, University of Minnesota Press 2016) p. 219 


\section{6 \\ NEW TERRITORIES _}

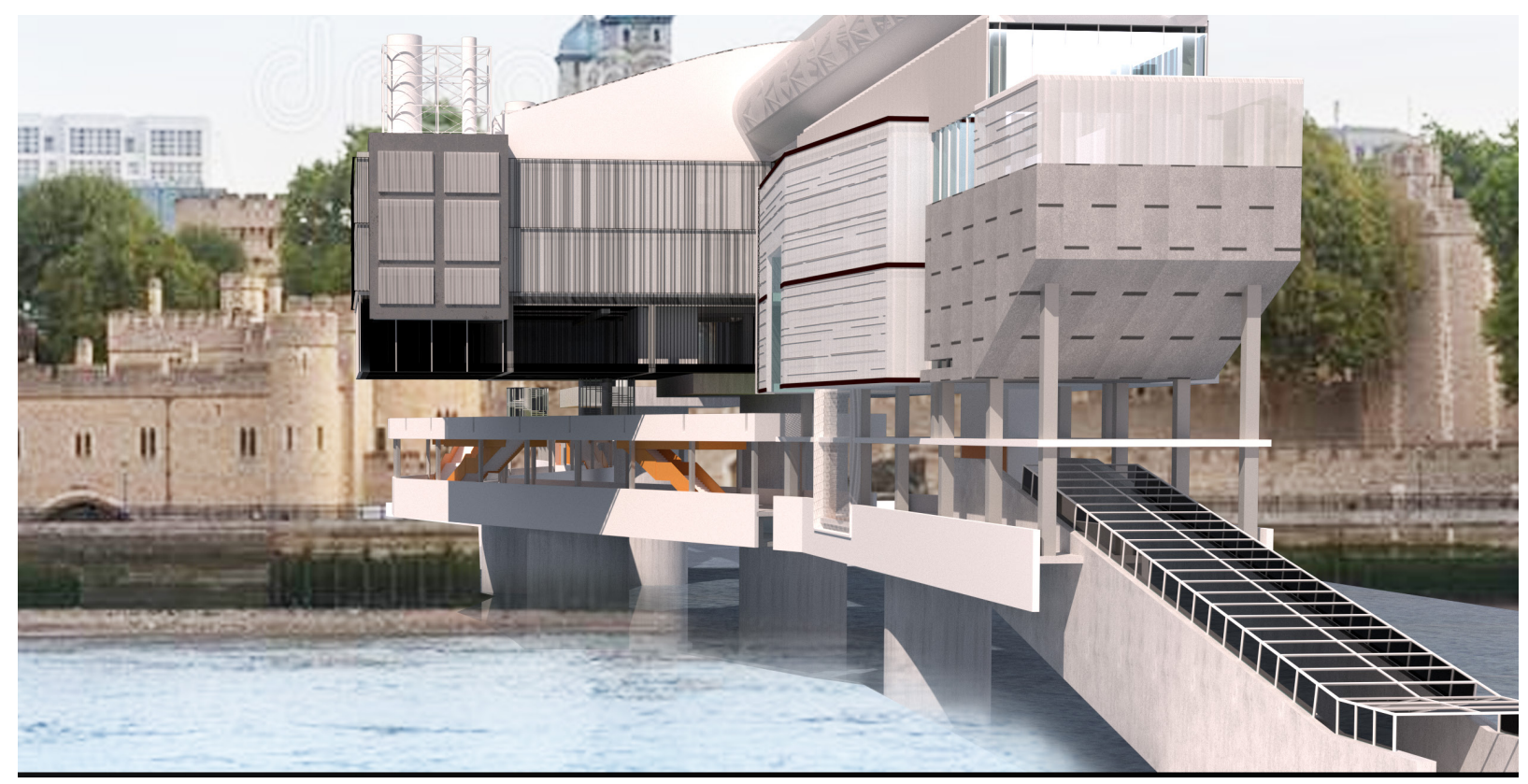

Figure 86. Render from South Side of Bridge

\section{A POSTHUMAN ARCHITECTURE}


This thesis has challenged the concept of the user in contemporary architecture, spurred by architectural practice's continued understanding of the user through primarily anthropocentric standards which have become contradictory within contemporary modes of operation. Since the development of cybernetics after the Second World War when technology began to encroach on the biological boundary, the concept of the Human has undergone wave after wave of theoretical and physical assault. Simultaneously, architecture was also fighting its own battle with the systematic deconstruction of the body of architecture which transitioned from Modernism to Post-Modernism to a presentday synthesis of contemporary architectural discourse. As a result, the proposal of The Museum as Bridge is an attempt to develop a working methodology for what an architecture could be when it emerges through the vehicle of a Posthuman user. The networks rendered legible by Posthuman architecture are critical in the representation of infrastructural systems that constitute Posthuman networks. Although the argument for a Posthuman architecture has been brewing since Le Corbusier's seminal work in Le Modulor and The Machine for Living, it has failed to reach the logical conclusion. What Posthuman networks have made evident is that the territory and scale of architecture has exponentially increased. Its failure to reach this logical conclusion is perfectly summed up by what Rem Koolhaas has identified as the "problem of the large" in $S, M, L, X L .{ }^{41}$ Posthuman architecture begins to address the points laid out in his theoretical approach to bigness. This thesis takes bigness one step further. Rather than defining bigness by the critical mass that a building occupies, Posthuman architecture expands the concept of bigness to the network and territory for which the building operates on. As Rem puts forth in his strategy for addressing bigness, "a web of umbilical chords to other disciplines are required whose performance is as critical as the architect's." 42 Posthuman architecture requires the leveraging of infrastructural and systems logic while reconstructing existing typologies through its modalities and conventions. As shown through the Museum as Infrastructure, this new mode of operation challenges existing spatial constructions and dissolves existing hierarchies. Technological systems, as extensions of architectural infrastructures, free architecture from the rigid structures and programmatic relationships to pursue a Posthuman architecture free from traditional ideologies and modes 
of operation. The project also showcases the potential of a Posthuman architectural modality in its ability to draw new object relationships within urban networks that have traditionally been under-represented in an architectural context. The drawing of new museum networks also allows us to analyze existing relationships between what were once traditionally isolated systems but are in fact interconnected networks.

As the preface to this thesis illustrated, infrastructural systems such as the Thames River and the development of imperial museums such as the British Museum were inextricably linked. The artifacts and prosthetics of the Posthuman user also revolve around local and global infrastructural systems. These artifacts constitute the technologies we use to extend the boundaries of our body threshold, fundamentally changing the scale of the user. Furthermore, how we understand the user's place in contemporary architecture defines, as evidenced by the widespread use of Le Modulor as a production tool, how we develop architectural environments. The Posthuman user is the starting point in this endeavor because human and machine intelligence have co-developed to the point where there is one globally networked subjectivity, and there is room for an ever more pervasive entanglement. As a result, architecture operates on a homogenous territory, devoid of any contextual significance. Infrastructure has become the single most pervasive prosthesis that mediates the lived experience. As with all prosthetics, architecture is a tool that augments a body's capacity. The Posthuman thesis posits that body, prosthetic, and space, highlighted as the three central parameters in this thesis, are networked in more complex and comprehensive ways. The framework for the development of a Posthuman architecture, and more specifically that of the Posthuman museum, rests upon this triad of parameters, and the fields between them.

Finally, we return to the title of the thesis:

Posthuman Contours_New Museum Infrastructures. The infrastructures and museum developed within this thesis are in search of rendering the contours of the Posthuman skin. What the Posthuman user makes evident is that architecture is now about the establishing of logistics and a set of protocols that begin to emerge as an infrastructural network. These logistics on one part are drawn out of Posthuman networks that emerge from the city and are drawn out of developing materials and building technologies. Not only have buildings as objects become open systems, but within the hypernetworked urban city they only exist because they are open. The system responds to the fluctuation of parameters from external networks and inevitably contributes to external networks through a common language of protocols. From the synthesis of critical dimensions of architectural and Posthuman theory, this thesis is positioned as a hybrid construct of a physical 
manifestation and theoretical interpretation of Posthumanism that evokes progressive thinking about the future of architecture and its operative parallels with infrastructural logic that goes beyond constructing space, but ultimately constructing the user. The most important achievement of this thesis was the development of an adaptive architectural assembly emerging from drawn out museum networks and reconstructing the museum typology through infrastructural logics. The dynamic properties of this multidisciplinary thinking engender a response to a Posthuman architectural future.

\section{NOTES}

41 Koolhaas, Rem, and Bruce Mau. "Bigness or the problem of Large." In S,M,L,XL: Office for Metropolitan Architecture (New York, The Monacelli Press 1998.) p. 495

42 Ibid. p.505 


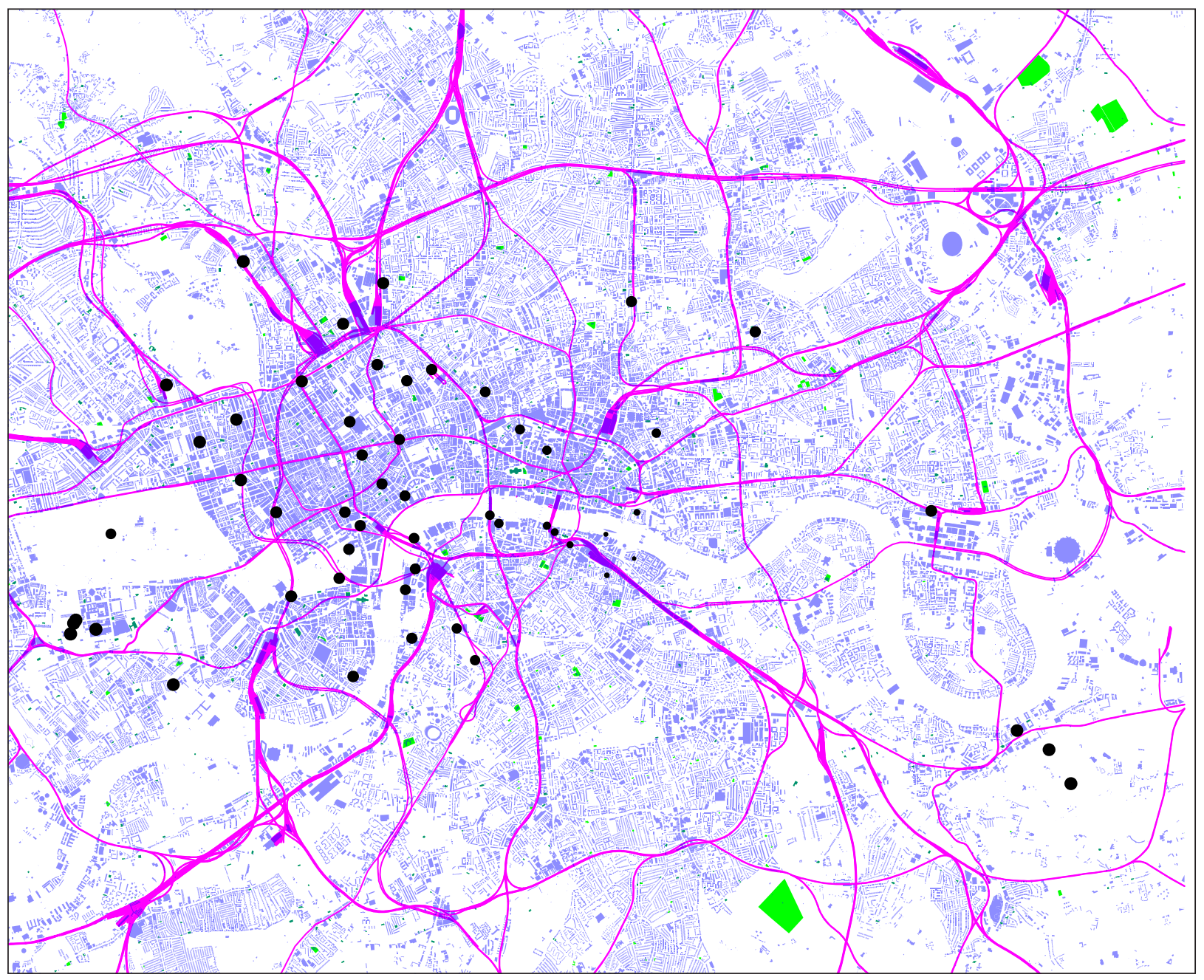

Figure 87. Museum Network

The first step to approaching the developing of a contextual relationship was to identify existing nodes within the museum framework in the city of London. The map plots out 54 major museum buildings in London for the purposes of quantifying their geographic proximity in relation to the identified site. The map also highlights the density of museum in close proximity to the River Thames and already existing relationships between museums and urban infrastructures such as the tube system.

\section{$M U S E U M \quad R E S E A R E$




\begin{tabular}{|c|c|c|c|c|}
\hline name & type & archives & structure & Classification \\
\hline geffrye museum & museum & homes & & history museum \\
\hline VA museum of childhood & museum & children & adaptive reuse & history museum \\
\hline museum of docklands & museum & river thames and docklands & & history museum \\
\hline tower bridge & attraction & tower bridge & twin towers & general museum \\
\hline fashion textile museum & museum & fashin and textile & converted warehouse & art museum \\
\hline raven row gallery & gallery & contemporary art & & art museum \\
\hline whitechapel gallery & gallery & contemporary art & & art museum \\
\hline hms belfast & attraction & naval museum & cruiser ship & history museum \\
\hline old operating theatre museum & museum & surgical history & operating theatre / hospital & history museum \\
\hline tate modern & museum & modern art & power station & art museum \\
\hline bankside gallery & gallery & public art & reuse & art museum \\
\hline hayward gallery & gallery & art & purpose built & art museum \\
\hline london dungeon & attraction & dungeon / TA & purpose built & general museum \\
\hline garden museum & museum & british gardens & & general museum \\
\hline imperial war museum london & museum & war \& infantry & reuse & history museum \\
\hline cinema museum & museum & cinema & lambath workhouse & art museum \\
\hline tate britain & museum & art & purpose built & art museum \\
\hline churchill war rooms & museum & imperial war & purpose built & history museum \\
\hline gaurds museum & museum & military & wellington barracks & history museum \\
\hline saatchi gallery & gallery & contemporary art & & art museum \\
\hline st.johns gate & attraction & TA & monastic gate & general museum \\
\hline florence nightingale museum & museum & florence nightingale & hospital & history museum \\
\hline guildhall art gallery & gallery & public art collection & purpose built & art museum \\
\hline museum of london & museum & city history & purpose built & history museum \\
\hline cutty sark & museum & naval museum & british clipper ship & history museum \\
\hline national maritime museum & museum & maritime & purpose built & history museum \\
\hline royal observatory & observatory & & purpose built & science and technology museum \\
\hline museum of branding & museum & consumer culture & purpose built & art museum \\
\hline design museum & museum & design & banana warehouse & art museum \\
\hline clock makers museum & museum & clocks & reuse & general museum \\
\hline natural history musueum & museum & natural history (dinosaurs) & purpose built & natural history museum \\
\hline victoria and albert museum & museum & decorative arts & purpose built & art museum \\
\hline serpentine gallery & gallery & contemporary art & tea pavillion & art museum \\
\hline science museum & museum & science stuff & purpose built & science and technology museum \\
\hline royal academy of the arts & museum & arts & purpose built & art museum \\
\hline national gallery & museum & art & purpose built & art museum \\
\hline household cavalry museum & museum & queens bodygaurds & reuse & history museum \\
\hline benjamin franklin house & museum & benjamin franklin & house & history museum \\
\hline somerset house & gallery & art & reuse & art museum \\
\hline courtauld gallery & museum & art & reuse & art museum \\
\hline london transport museum & museum & london transit vehicles & adaptive reuse & general museum \\
\hline national portrait gallery & gallery & portraits & purpose built & art museum \\
\hline sir john soane's museum & museum & houses & adaptive reuse & history museum \\
\hline the cartoon museum & museum & cartoons & reuse & art museum \\
\hline the british museum & museum & human history, art, culture & purpose built & general museum \\
\hline charles dickens museum & museum & charles dickens & house & history museum \\
\hline great museum of zoology & museum & natural histry & reuse & natural history museum \\
\hline bank of england museum & museum & bank history & reuse & history museum \\
\hline london canal museum & museum & regional history & victorian ice warehouse & history museum \\
\hline Jewish Museum & museum & jewish history & reuse-communs & history museum \\
\hline The Sherlock Holmes Museum & museum & sherlock holmes & house & general museum \\
\hline Freud Museum & museum & sigmund freud & house & history museum \\
\hline arsenal Museum & museum & arsenal footbal club & football stadium & general museum \\
\hline leighton house museum & museum & painting & house & art museum \\
\hline foundling museum & museum & handel memorabilia & hospital & general museum \\
\hline pollocks toy museum & museum & toy memorabilia & house & general museum \\
\hline
\end{tabular}

Figure 88. Museum Index 


\begin{tabular}{|c|c|c|c|c|c|c|c|c|}
\hline collection & $0 \%$ & $1-5 \%$ & $6-25 \%$ & $26-50 \%$ & $51-75 \%$ & $76-94 \%$ & $95-100 \%$ & AVG \\
\hline photographs & 1 & 6 & 12 & 8 & 2 & 9 & 59 & 14 \\
\hline social history & 2 & 5 & 8 & 17 & 15 & 21 & 21 & 13 \\
\hline archives & 2 & 26 & 56 & & & & & 28 \\
\hline costume + textiles & & 9 & 8 & 4 & 3 & 14 & 36 & 12 \\
\hline archaeology & 3 & 9 & 4 & 6 & 8 & 11 & 33 & 11 \\
\hline fine art & 4 & 10 & 9 & 5 & 10 & 14 & 19 & 10 \\
\hline coins & 4 & 5 & 2 & 5 & & 8 & 35 & 10 \\
\hline library & 2 & 11 & 10 & 1 & 1 & 3 & 30 & 8 \\
\hline art on paper & & 10 & 5 & 3 & & 9 & 28 & 11 \\
\hline decorative arts & 1 & 3 & 6 & 5 & 12 & 11 & 11 & 7 \\
\hline military & & 6 & 8 & 4 & 7 & 5 & 13 & 7 \\
\hline natural history & 2 & 3 & & 4 & 2 & 10 & 21 & 7 \\
\hline geology & 1 & 1 & 2 & 4 & 3 & 5 & 25 & 6 \\
\hline oral history & & 7 & & & & & 32 & 20 \\
\hline industrial & 4 & 1 & 7 & 4 & 6 & 4 & 13 & 6 \\
\hline sculpture & 4 & 6 & 3 & 3 & 4 & 4 & 11 & 5 \\
\hline personalia & & 5 & 1 & 5 & 2 & 8 & 12 & 6 \\
\hline agriculture & 1 & 7 & 3 & 5 & 2 & 5 & 9 & 5 \\
\hline ethnography & & 1 & 1 & 4 & 3 & 3 & 19 & 5 \\
\hline transport & 4 & 3 & 3 & 7 & 4 & 3 & 6 & 4 \\
\hline film & & 6 & 1 & & & & 20 & 9 \\
\hline hist. of science & 2 & 2 & 4 & 1 & 1 & 4 & 12 & 4 \\
\hline music & 1 & 2 & & 3 & 2 & 4 & 4 & 3 \\
\hline maritime & & 1 & & 4 & 2 & 2 & 4 & 3 \\
\hline
\end{tabular}

Figure 89. Mueum with percentage of artifacts in Storage

Figure 89 represents data extracted from the UCL study on artifact collections throughout the UK. The data gives a better understanding of how many artifact collections sit in storage spaces as a fraction of the museums overall collection. 


\begin{tabular}{|c|c|c|c|c|c|}
\hline & No. of museums with collection & \% with $95-100 \%$ in store & \#\# & $\%$ of individual collections stored offsite & \\
\hline oral history & 39 & $82 \%$ & 32 & $4 \%$ & history \\
\hline film & 27 & $74 \%$ & 20 & $9 \%$ & art \\
\hline ethnography & 31 & $61 \%$ & 19 & $33 \%$ & history \\
\hline geology & 41 & $61 \%$ & 25 & $19 \%$ & science \\
\hline photographs & 97 & $61 \%$ & 59 & $11 \%$ & art \\
\hline coins & 59 & $59 \%$ & 35 & $15 \%$ & general \\
\hline library & 58 & $52 \%$ & 30 & $13 \%$ & history \\
\hline art & 55 & $51 \%$ & 28 & $10 \%$ & art \\
\hline natural history & 42 & $50 \%$ & 21 & $18 \%$ & natural history \\
\hline costume + textile & 74 & $49 \%$ & 36 & $0 \%$ & art \\
\hline hist. of science & 26 & $46 \%$ & 12 & $15 \%$ & science \\
\hline archaeology & 74 & $45 \%$ & 33 & $24 \%$ & science \\
\hline personalia & 33 & $36 \%$ & 12 & $11 \%$ & general \\
\hline industrial & 39 & $33 \%$ & 13 & $29 \%$ & general \\
\hline sculpture & 35 & $31 \%$ & 11 & $13 \%$ & art \\
\hline maritime & 13 & $31 \%$ & 4 & $30 \%$ & history \\
\hline military & 43 & $30 \%$ & 13 & $9 \%$ & history \\
\hline agriculture & 32 & $28 \%$ & 9 & $35 \%$ & general \\
\hline fine art & 71 & $27 \%$ & 19 & $11 \%$ & art \\
\hline music & 16 & $25 \%$ & 4 & $21 \%$ & fart \\
\hline social history & 89 & $24 \%$ & 21 & $14 \%$ & history \\
\hline decorative arts & 49 & $22 \%$ & 11 & $12 \%$ & art \\
\hline transport & 30 & $20 \%$ & 6 & $22 \%$ & general \\
\hline archives & 84 & $0 \%$ & 0 & $9 \%$ & general \\
\hline
\end{tabular}

Figure 90. Off-site Storage

Figure 90 also expands on earlier storage research and classifies how much of artifact collections is being stored in off-site locations relative to the museum exhibition space.
In the process of setting up storage structures, museum classifications are broken down in the redistribution process. Using openended classification systems allows for more stimulating exhibition structures and allows for organic user narratives to emerge.

\begin{tabular}{|l|c|c|c|c|c|c|}
\hline history museum & 348 & $44 \%$ & 152 & & $26.11 \%$ & \\
\hline art & 424 & $44 \%$ & 188 & & $26.50 \%$ & \\
\hline general & 212 & $30 \%$ & 63 & & $17.64 \%$ & \\
\hline science & 141 & $50 \%$ & 70 & & $29.75 \%$ & \\
\hline & & & & & & \\
\hline
\end{tabular}

Figure 91. Averaging out collections in storage

The redistributed museum brings forward new possibilities for artifact collections that are traditionally kept separate. Figure 91 shows the numerical break down of average storage allocations within the Posthuman museum. 
Figure 92. Context Model. 1:2000

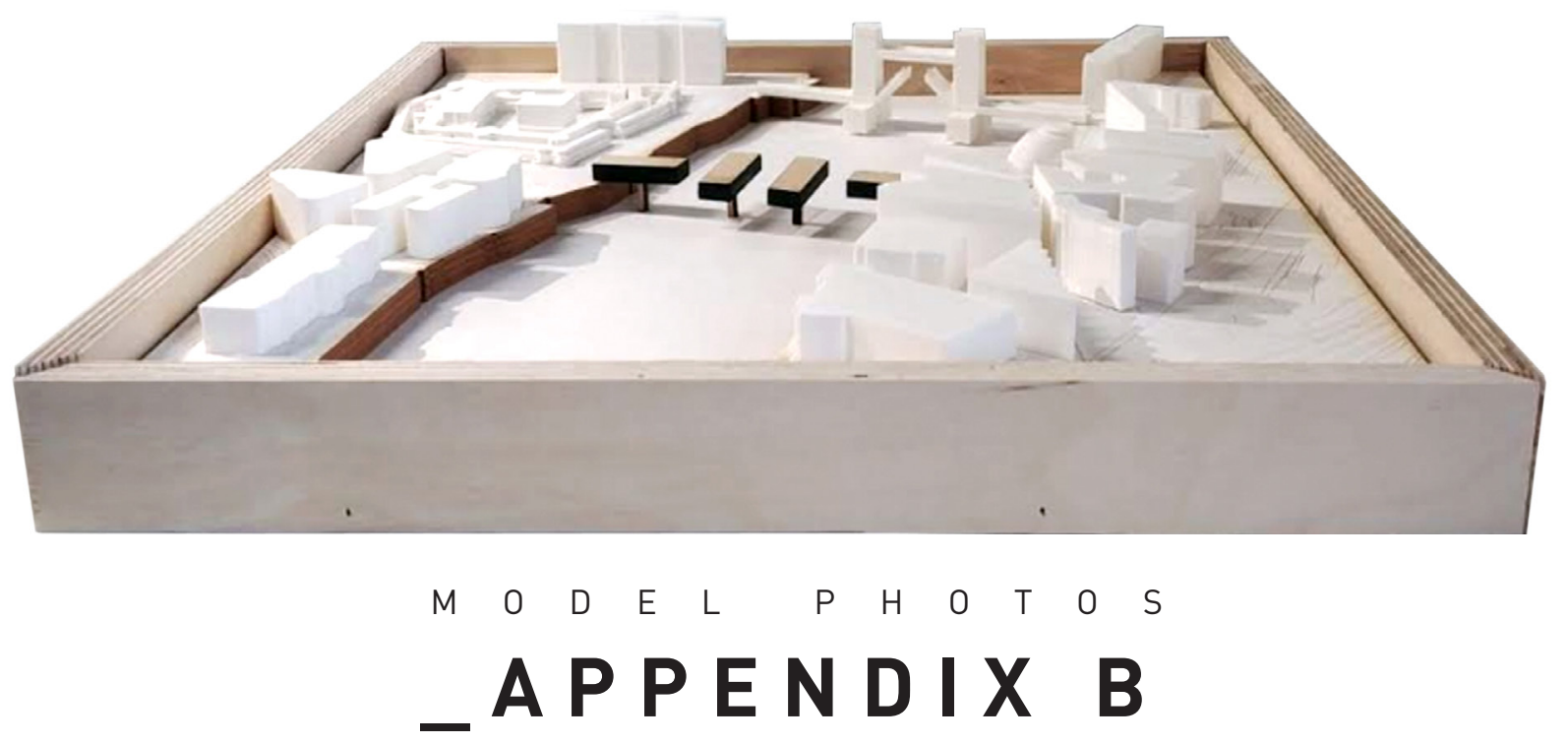




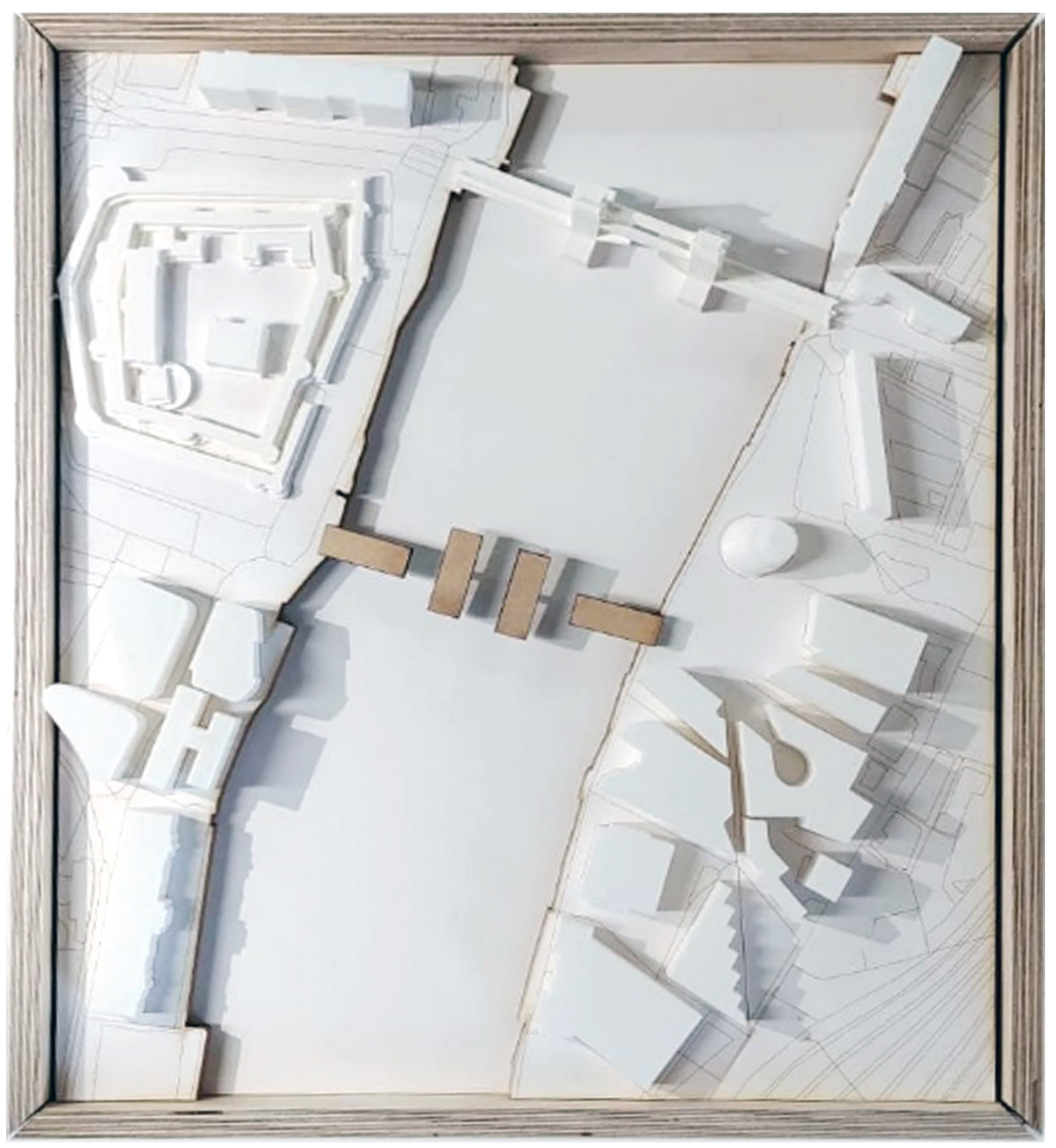

Figure 93. Context Model. 1:2000 


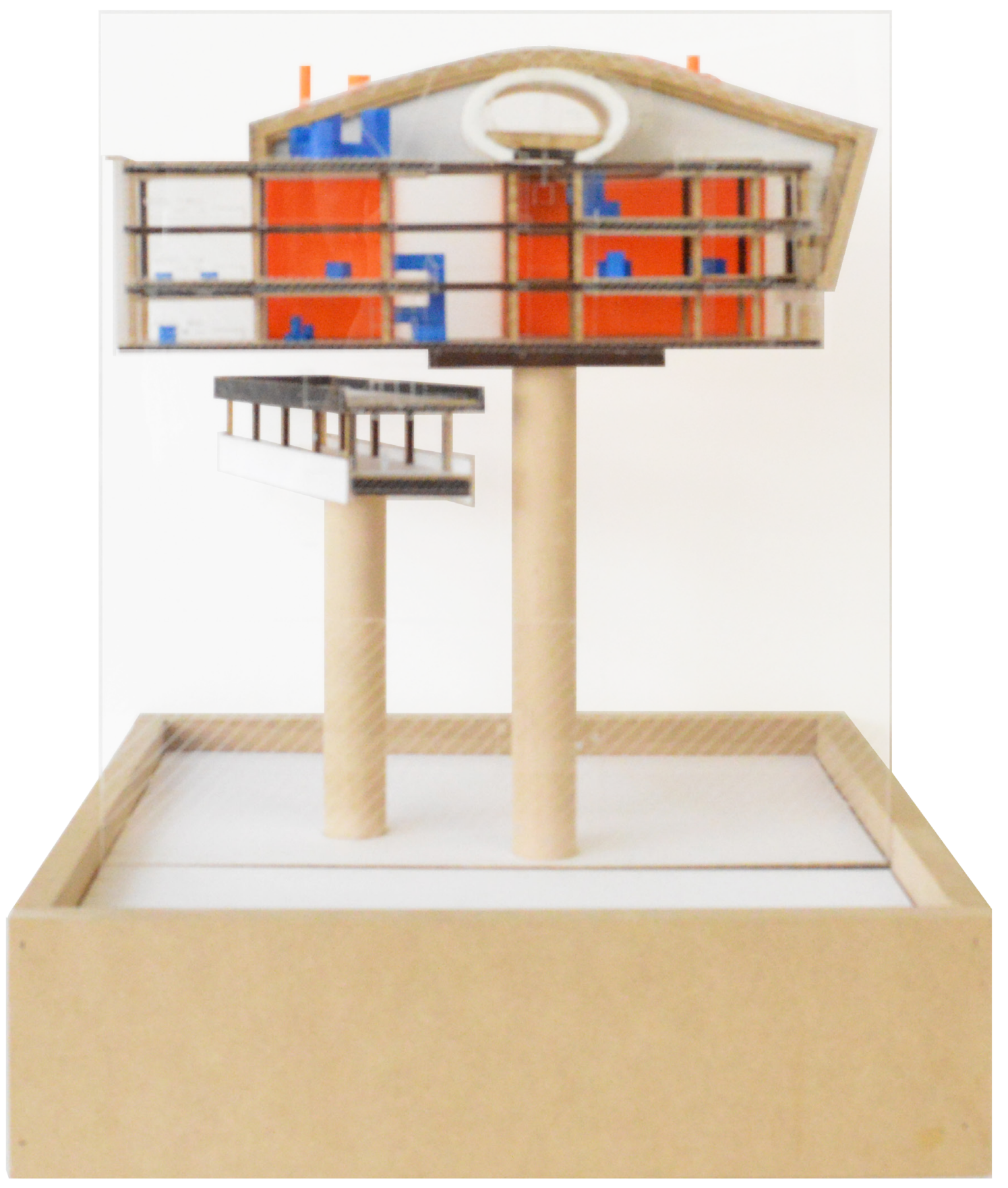

Figure 94. Sectional Model, 1:200 


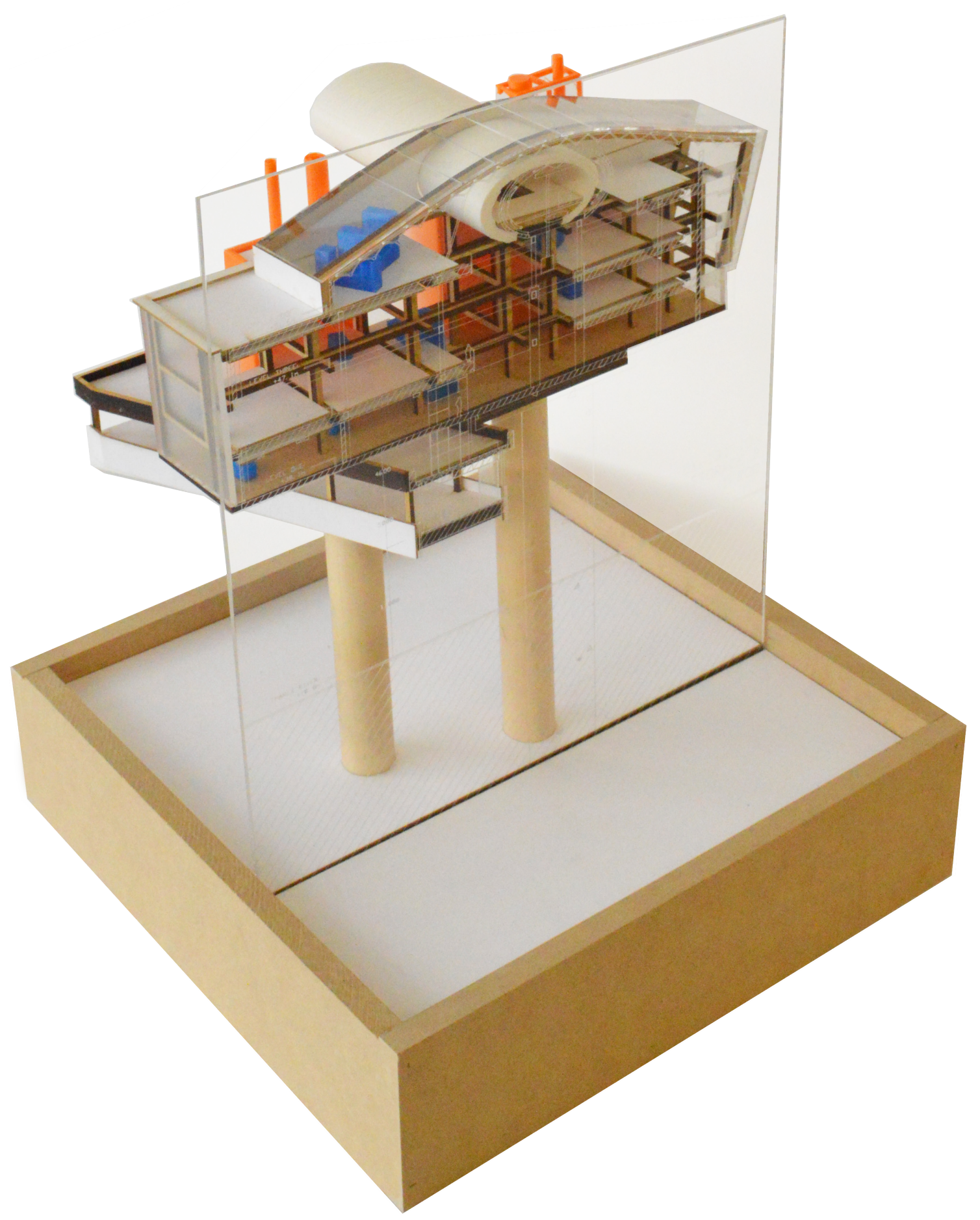

Figure 95. Sectional Model, 1:200 

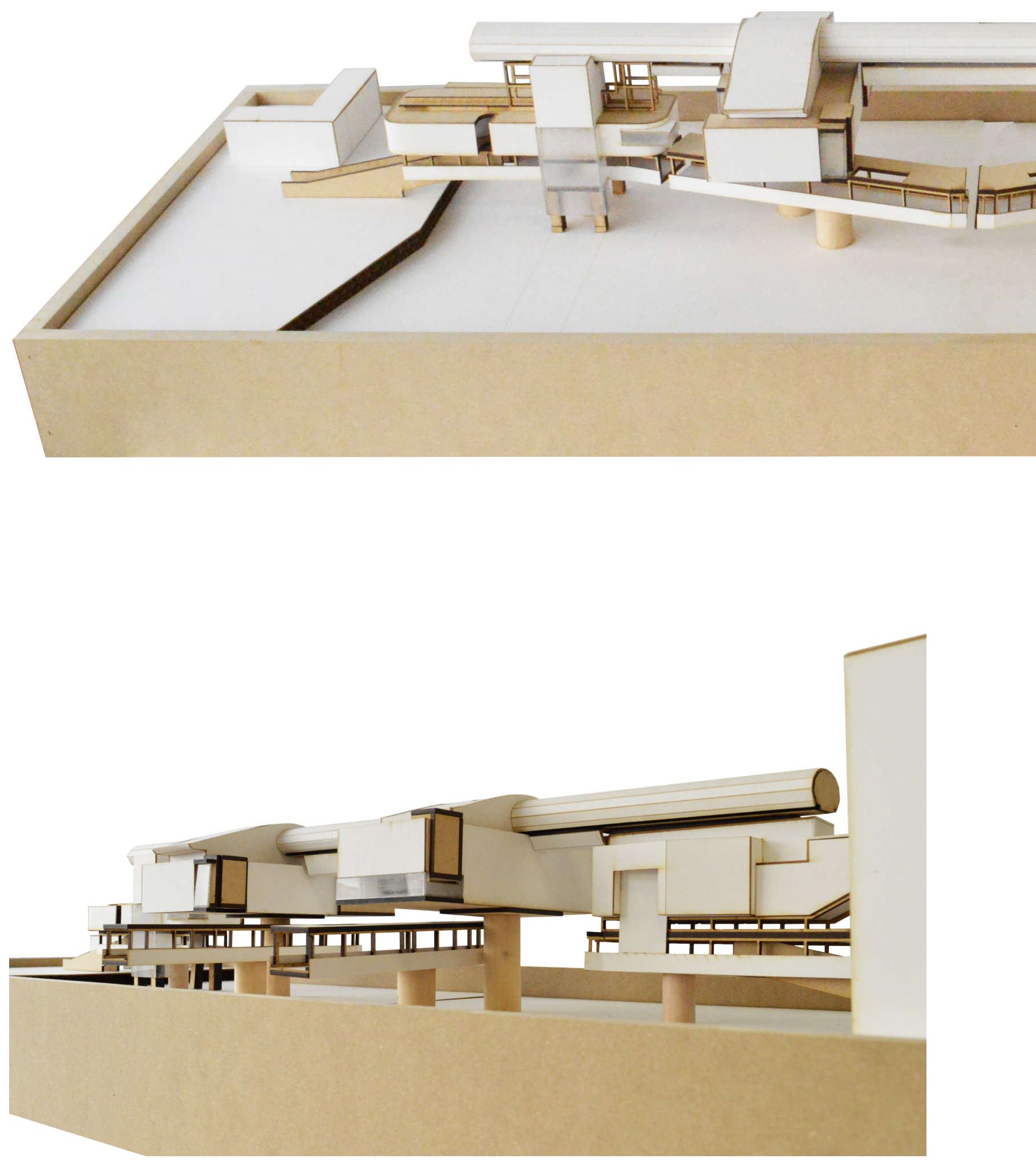
Figure 98. Building Model , 1:300

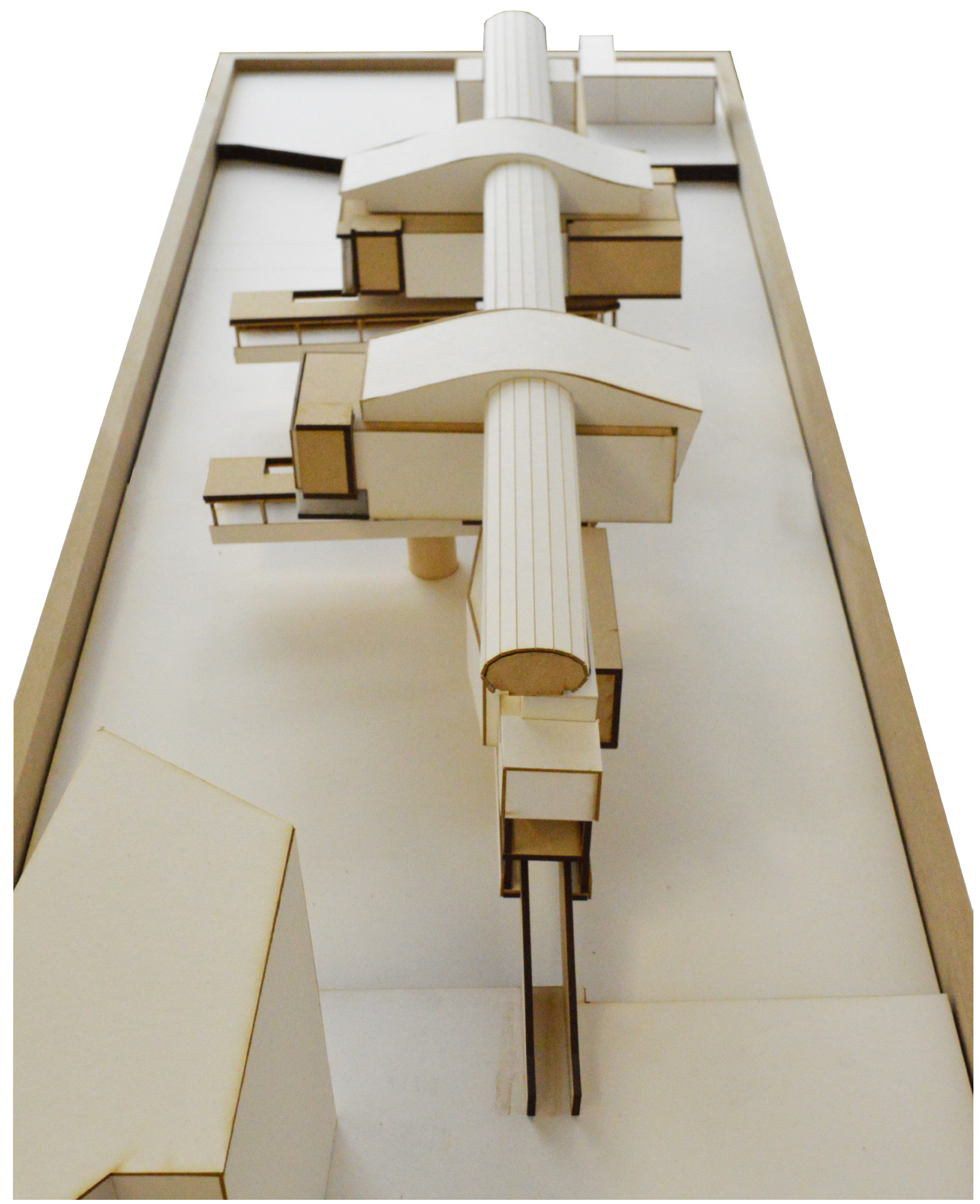




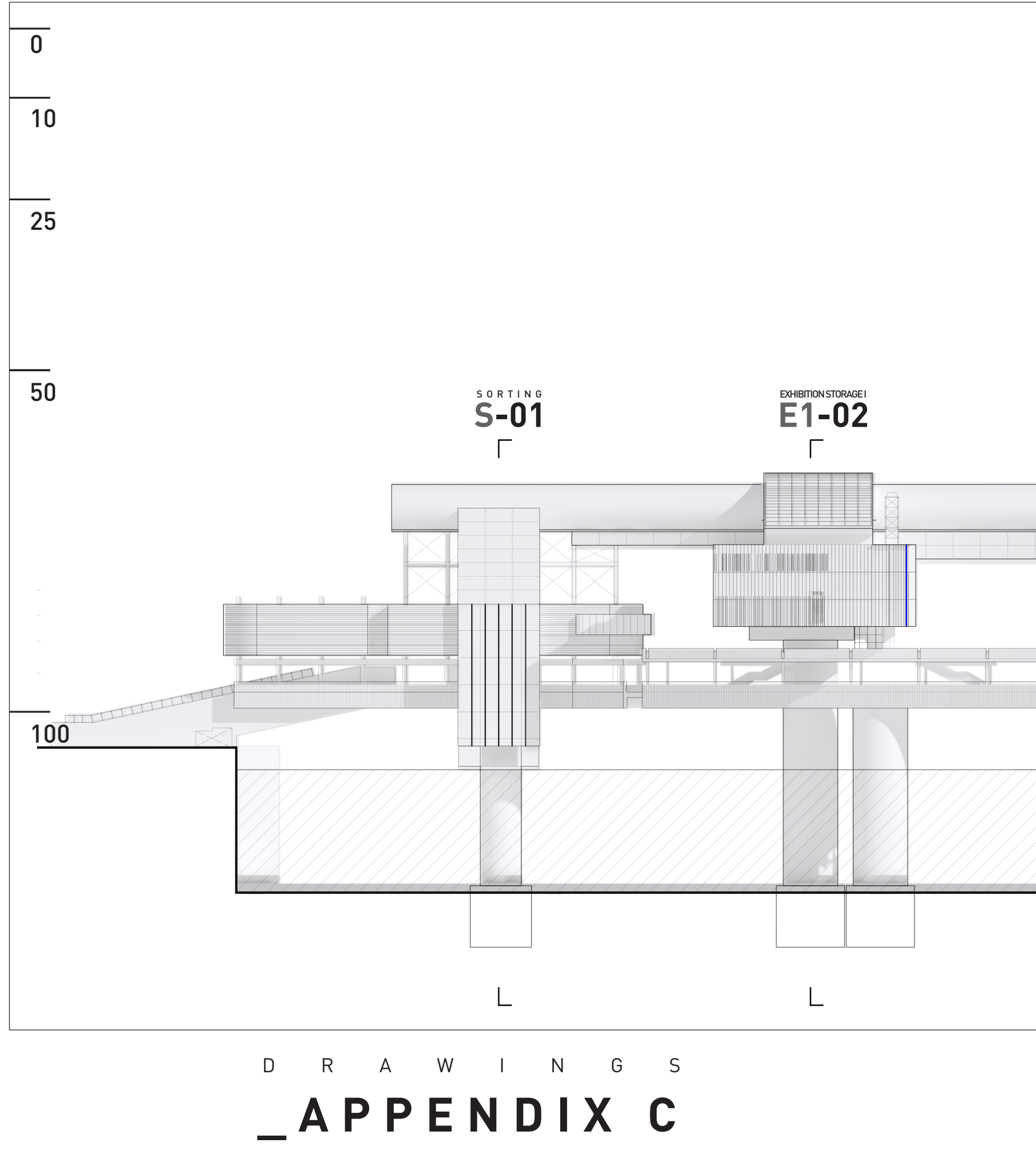




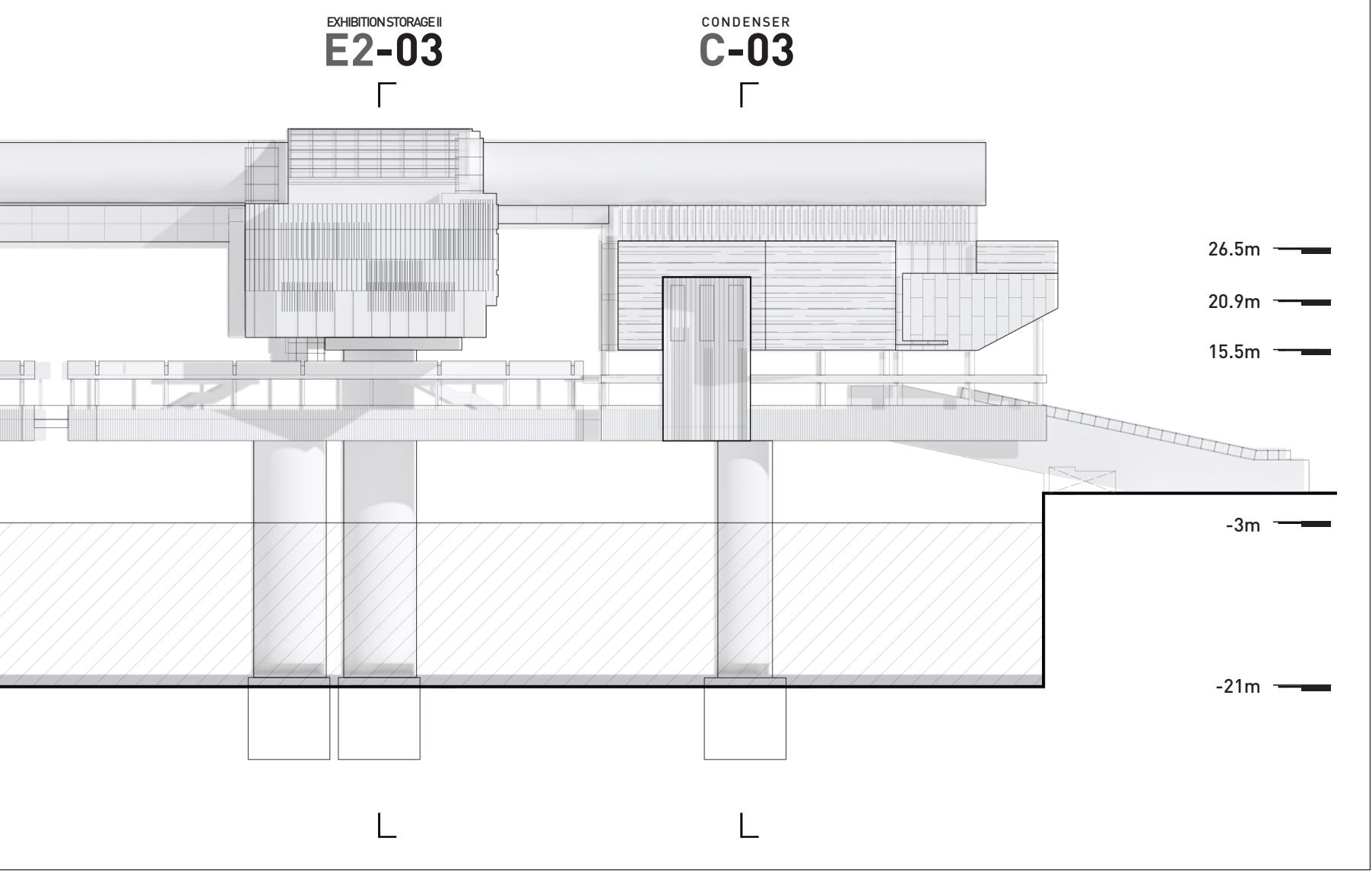

Figure 99. West Elevation 


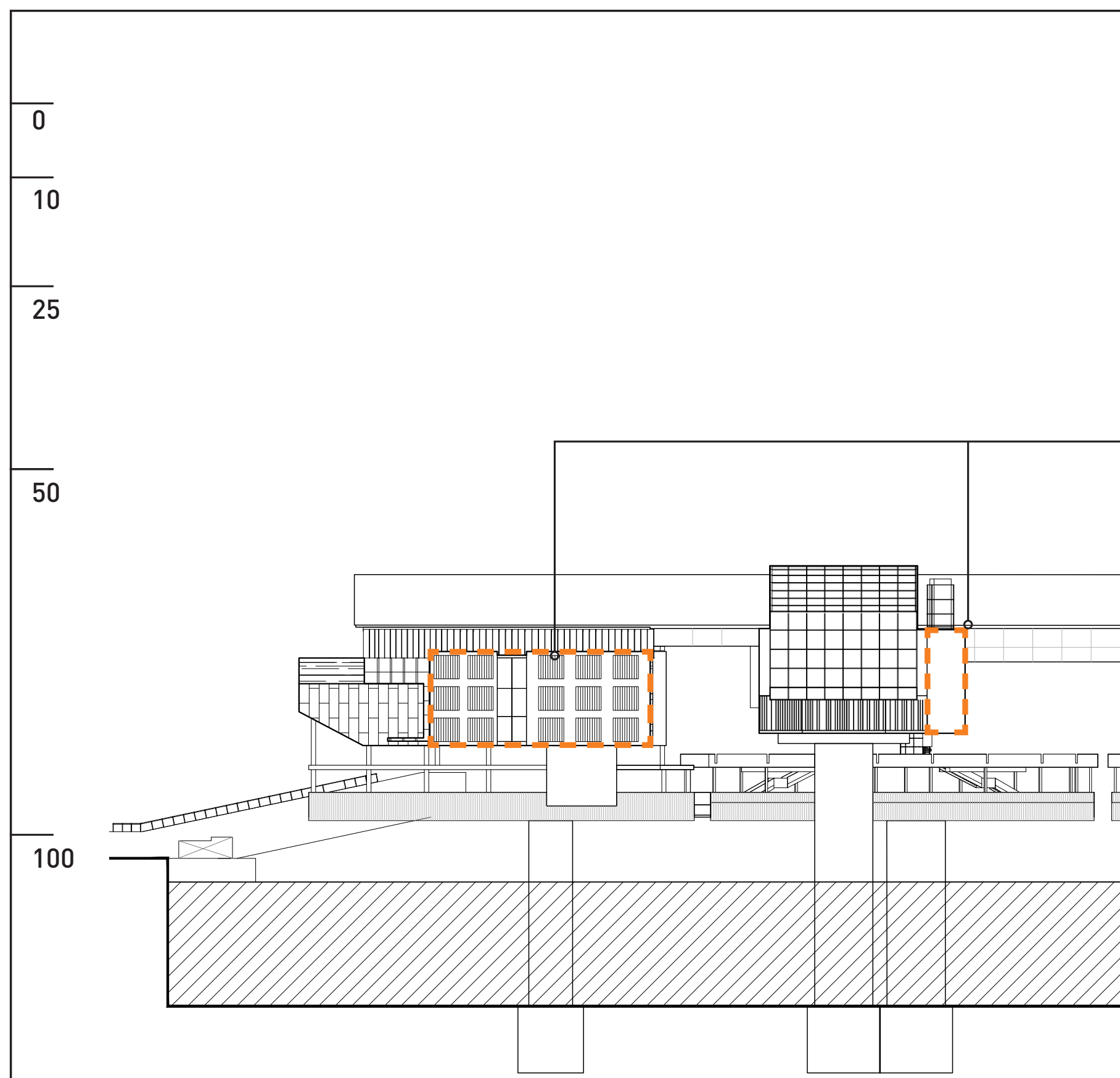


east elevation

\section{MECHANICAL RACKS}

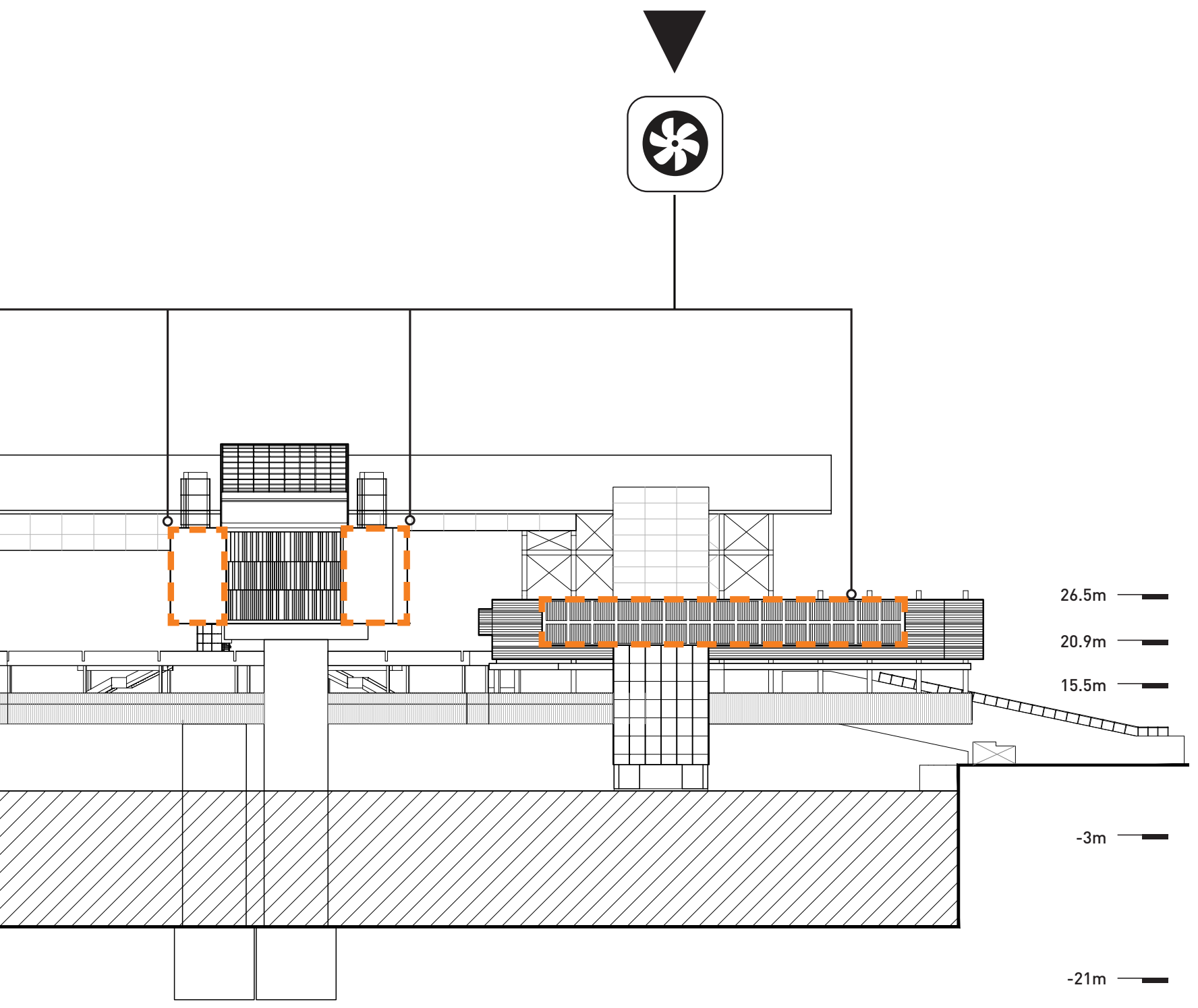




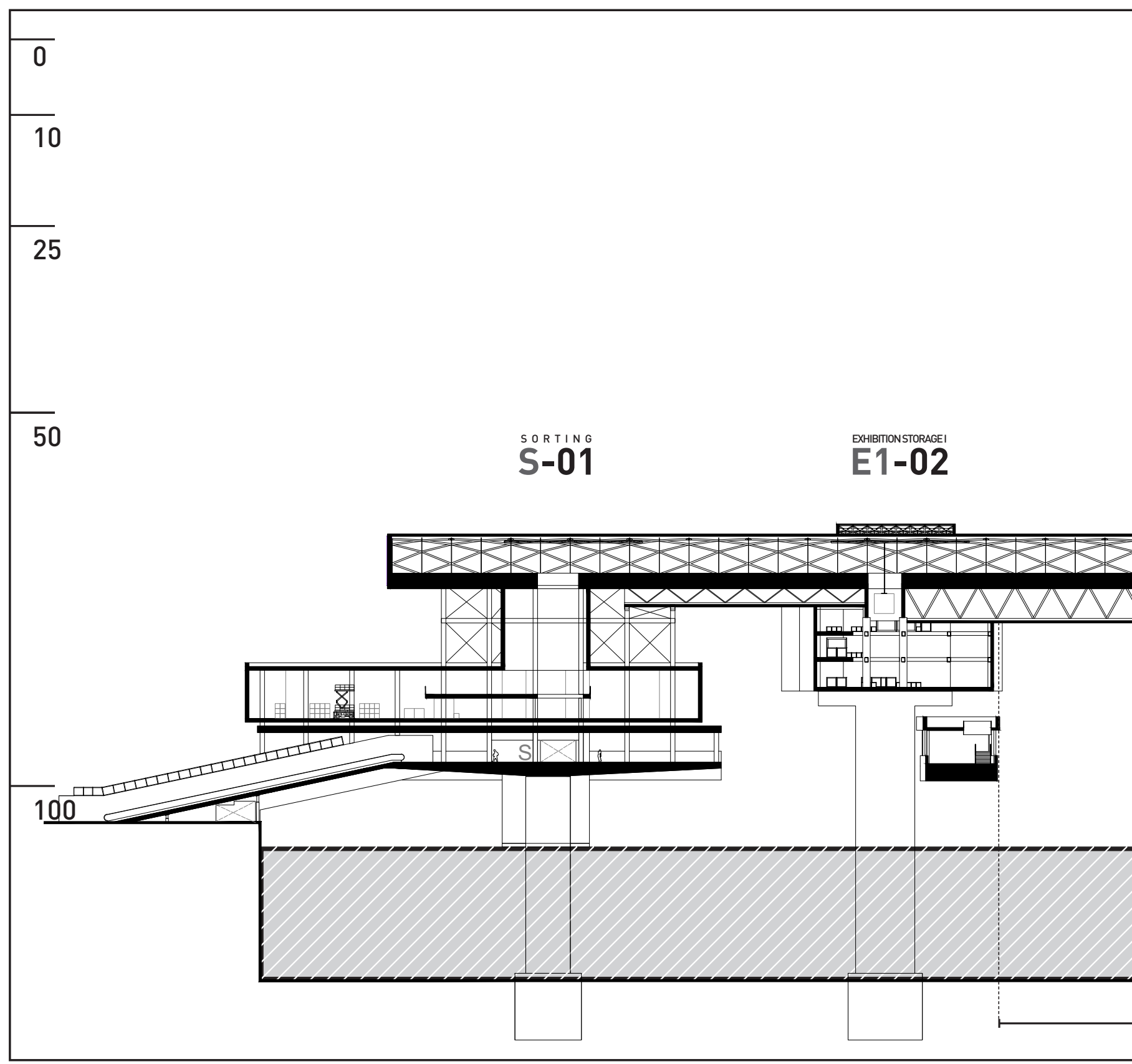




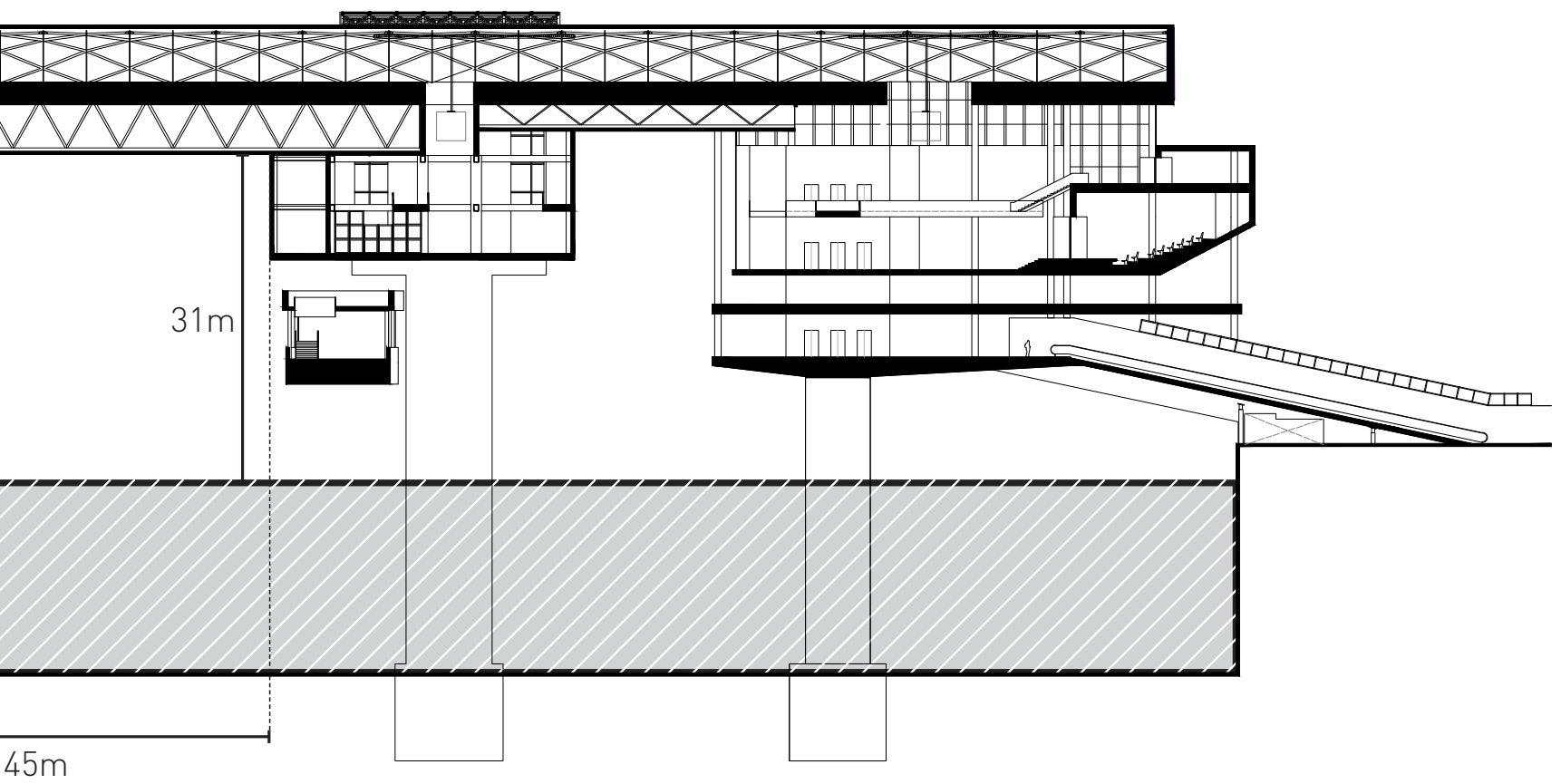

Figure 101. Longitudinal Section 


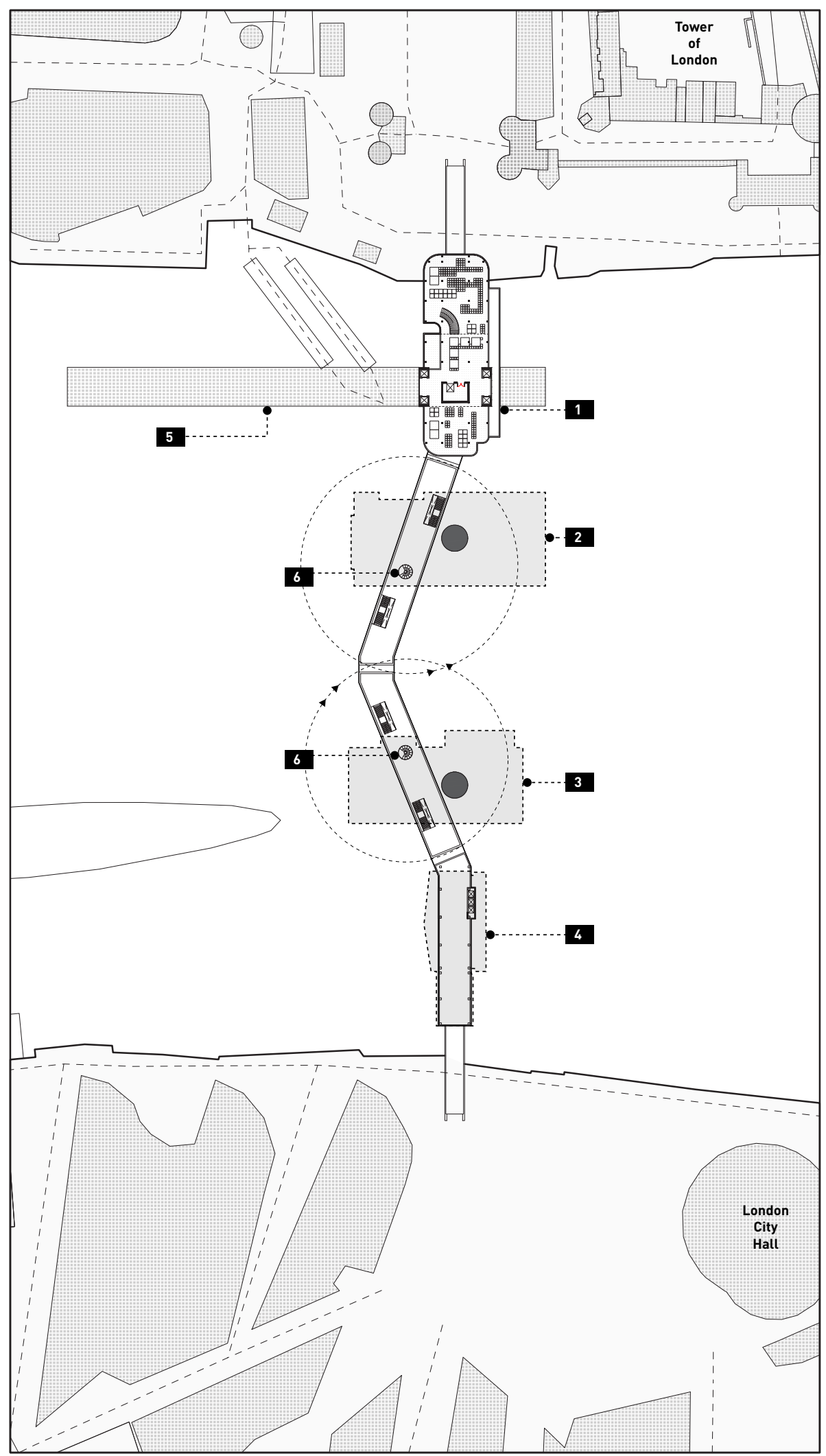

Figure 102. Level One 


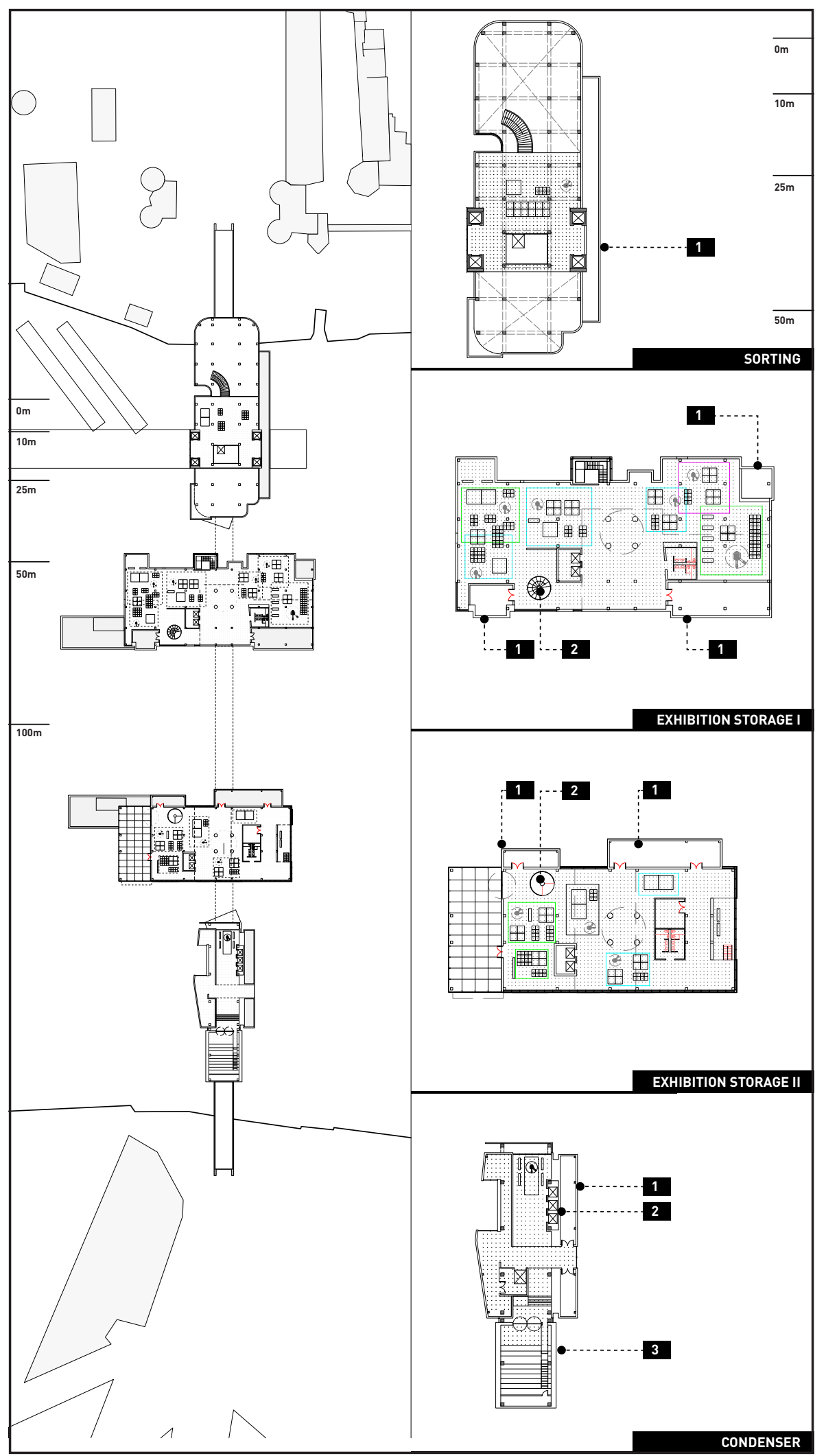

Figure 103. Level Two 


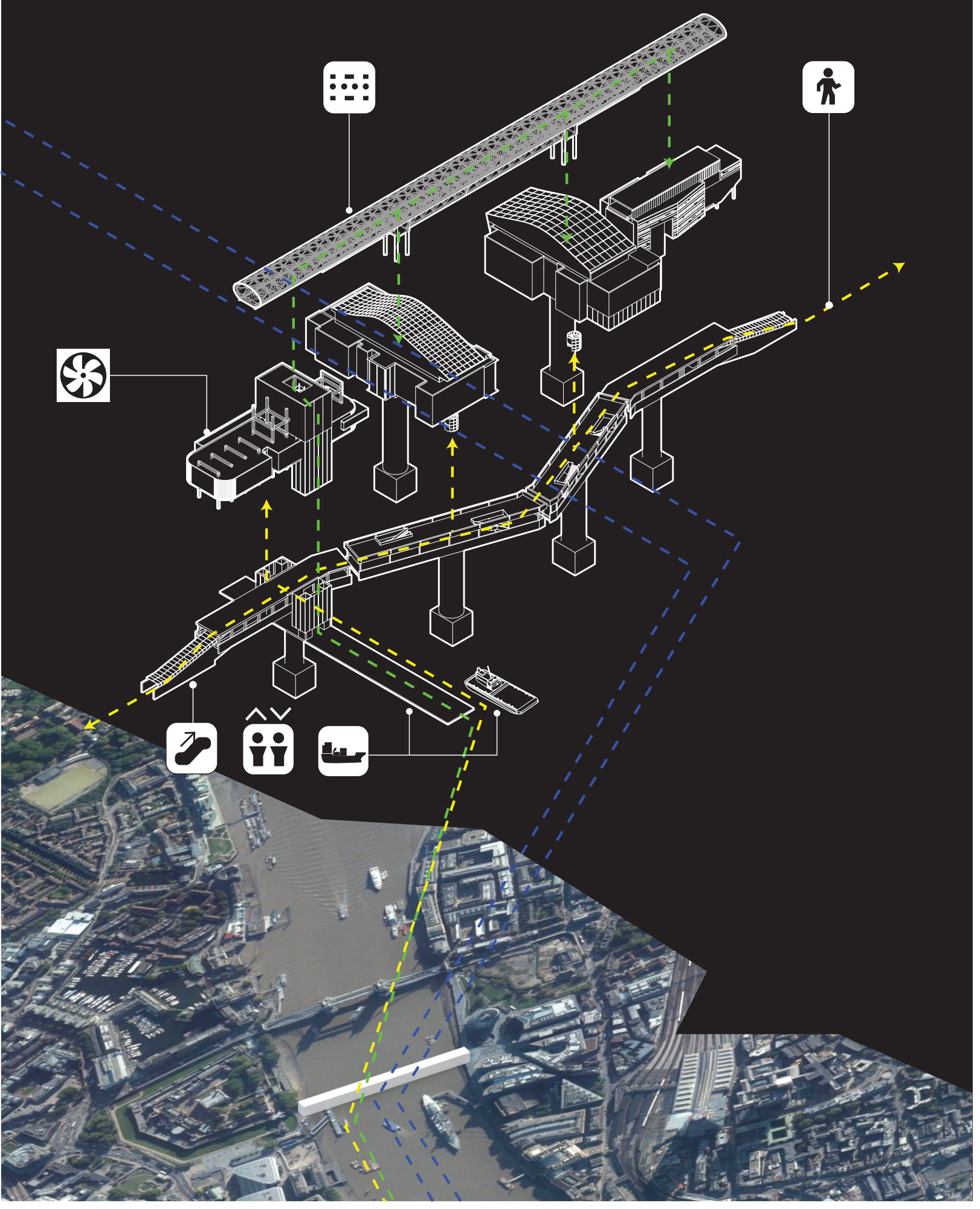


Figure 104. Large Axonometric 


\section{BIBLIOGRAPHY}

- denotes reference directly cited in the text.

- Barringer, T., \& Flynn, T. (Eds.). (1998). Colonialism and the Object: Empire, Material Culture and the Museum. London: Routledge.

- Bock, I. (2015). Six Canonical Projects by Rem Koolhaas: Essays on the History of Ideas . Berlin: Jovis .

Braham, W. W. (2007). Rethinking Technology: A Reader in Architectural Theory. London: Routledge, Taylor \& Francis Group.

Carpo, M. (2013). The Digital Turn in Architecture. Chichester: John Wiley \& Sons.

Castells, M. (1996). The Rise of the Network Society. Malden : Blackwell Publishers .

Chen, M. (2012). Signal Space: New York's Soft Frequency Terrains. Bracket: Goes Soft, 57-62.

- Corbusier, L. (1961). Modulor: A Harmonious Measure to the Human Scale and Universally Applicable to Architecture and Mechanics. London: Faber and Faber.

Corner, J. (1999). The Agency of Mapping: Speculation, Critique, and Invention. In Mappings (pp. 213-253). London: Reaktion Books Ltd. .

Deleuze, G., \& Guattari, F. (1988). A Thousan Plateaus: Capitalism and Schizophrenia. Minneapolis: University of Minnesota Press.

Duncan, T., \& McCauley, N. (2012). A Narrative Journey: creating storytelling environment with architecture and digitla media. In S. MacLeod, Museum Making: Narratives, Architectures, Exhibitions (pp. 288297). New York: Routledge .

- Duthie, E. (2011). The British Museum: An Imperial Museum in a Post-Imperial World. Public History Review, 18, pp. 12-25.

- Easterling, K. (2014). Extrastatescraft: The Power of Infrastructure Space . London: Verso .

Graham, M. (2015). Information Geographies and Geographies of Information. In New Geographies 07: Geographies of Infromation (pp. 159-167). Cambridge: Harvard University Press .

- Harrison, A. (2013). Charting Posthuman Territory. In Architectural Theories of the Environment: Posthuman Territory (pp. 3-33). New York: Routledge .

Hayles, K. N. (1999). How We Became Posthuman: Virtual Bodies in Cybernetics, Literature, and Informatics . Chicago: University of Chicago Press. 
- Ito, T. (1992). Architecture in a Simulated City. Oz, 14, 23-35.

- Keene, S. (Ed.). (2008). Collections for people: Museums'stored collections as a public resource. London: UCL Institute of Archaeology .

- Koolhaas, R., \& Mau, B. (1998). Strategy of the Void . In S,M,L,XL: Office for Metropolitan Architecture (pp. 602-654). New York: The Monacelli Press.

- Koolhaas, R., \& Mau, B. (1998). Bigness or the problem of Large. In S,M,L,XL: Office for Metropolitan Architecture (pp. 495-516). New York: The Monacelli Press.

- Kwinter, S. (n.d.). The Computational Fallacy. (A. Menges, Ed.) Computational Design Thinking, 211-215.

- Latour, B. (2004). How to Talk about the Body? The Normative Dimension of Science Studies. Body and Society, 10, pp. 205-229.

- Leach, N. (2002). Introduction . In Designing for a Digital World (pp. 6-13). Chichester: John Wiley \& Sons .

- Leach, N. (2005). Martin Heidegger. In N. Leach, Rethinking Architecture: A reader in cultural theory (pp. 94-119). New York: Taylor \& Francis e-Library.

- Lecavalier, J. (2016). The Rule of Logistics: Walmart and the Architecture of Fulfillment. Minneapolis: University of Minnesota Press.

- Mathews, S. (2007). From Agit-Prop to Free Space: The Architecture of Cedric Price. London: Black Dog Publishing .

- Mathews, S. (2009). The Fun Palace as Virtual Architecture: Cedric Price and the Practices of indeterminacy. Journal of Architectural Education, 593), 39-48. Retrieved March 23, 2018

Mazlish, B. (1993). The Fourth Discontinuity: The Co-Evolutions of Humans and Machines . New Haven.

- McLuhan, M. (1964). Understanding Media: The Extensions fo Man . New York: McGraw Hill .

McTavish, D., Ripley, C., \& Velikov, K. (2015). Infra Eco Logi Urbanism: A Project for the Great Lakes Megaregion. Zurich: Park Books.

- Mltchell, W. J. (2013). Against Program. In A. L. Harrison, Architectural Theories of the Environment: Posthuman Territory (pp. 154-162). New York: Routledge .

- Naredi-Rainer, P. v. (2004). A Design Manual: Museum Buildings. Basel: Birkhauser.

Negroponte, N. (1995). Being Digital. New York: Alfred A. Knopf. 


\section{BIBLIOGRAPHY}

- denotes reference directly cited in the text.

- Parry, R., \& Sawyer, A. (2005). Space and the machine: Adaptive museums, pervasive technology and the new gallery environment. In S. MacLeod, Reshaping Museum Space: Architecture, Design, Exhibitions (pp. 34-52). New York: Routledge.

Propen, A. D. (2014). Design, Mediation, and the Posthuman. Maryland: Lexington Books .

Shepard, M. (2011). Sentient City: Ubiquitous Computing, Architecture, and the Future of Urban Space. New York: Architectural League of New York.

- Silberman, N. A. (1989). Nationalism and Archaeology. New York: H. Holt.

- Simpson, M. G. (2001). Making Representations in the Post-Colonial Era. . Psychology Press.

- Skolnick, L. H. (2005). Towards a new museum architecture: Narrative and Representation . In S. MacLeod, Reshaping Museum Space: Architecture, Design, Exhibitions (pp. 118-130). New York: Routledge .

Teyssot, G. (2005). Hybrid Architecture: An Environment for the Prosthetic Body . Sage Journals , 72-84.

Varnelis , K., \& Friedberg, A. (2008). Place" The Networking of Public Space. Networked Publics(18).

- Velikov, K. (2016). Posthuman Frontiers: Data, Designers, and Cognitive Machines . Acadia 2016: Posthuman Frontiers: Data, Designers, and Cognitive Machines; Proceedings of the 36th Annual Conference of the Association for Computer Aided Design. Maine: Acadia Publishing Company .

Weizman, E. (2017). Beyond the Threshold of the Human. In New Geographies 09: Posthuman (pp. 81-90). Cambridge: Harvard University Press .

- Wigley, M. (1991). Prosthetic Theory: The Disciplining of Architecture . Assemblage No. 15, 6-29.

Wiszniewski, D. (2012). City as museum, museum as city: mediating the everyday and special narratives of life." . In Museum Making: Narratives, Architectures, Exhibitions (pp. 119-131). New York: Routledge .

Wolfe, C. (2009). What is Posthumanism? Minneapolis: University of Minnesota Press .

Zaera-Polo, A. (2017). The Posthuman City: Urban Questions for the Near Future. In New Geographies 09: Posthuman (pp. 70-81). Cambridge: Harvard University Press . 
